\title{
IV. Tatsachenfeststellung im Verhältnis zwischen nationalen Gerichten und EGMR
}

\section{Inhaltsverzeichnis}

A. Subsidiaritätsrechtlicher Zusammenhang zwischen der Qualität des nationalen Verfahrens und der Tatsachenfeststellungsfunktion des EGMR

B. Prozedurale Anforderungen der EMRK an die Tatsachenfeststellung der nationalen

Gerichte

1. Art. 13 EMRK und Art. 3 EMRK als dogmatische Grundlagen........

a. Funktion und Verhältnis von Art. 13 EMRK und Art. 3 EMRK.

b. Anknüpfungspunkte der prozeduralen Vorgaben aus Art. 13 und 3 EMRK.

c. Allgemeine Leitsätze zur Wirksamkeit des Rechtsbehelfs.

2. Systematisierung der Rechtsprechung des EGMR zu den prozeduralen Anforderungen an die innerstaatliche Tatsachenfeststellung.

a. Rechtsprechung zu Refoulement-Fällen......................................................................... 96

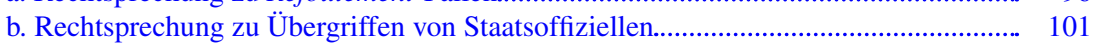

c. Allgemeine Leitsätze.................................................................................................. 110

C. Variabler Kontrollmaßstab des EGMR bezüglich der innerstaatlichen

Tatsachenfeststellung...

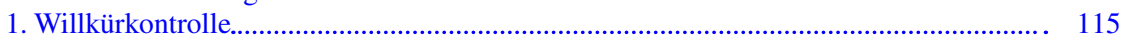

2. De-novo-Prüfung der innerstaatlich festgestellten Tatsachen.............................................. 117

a. Anwendungsbereich der de-novo-Prüfung.............................................................. 117

b. Darstellung des Wirkungsmechanismus am Beispiel zweier Fälle................................ 118

3. Beweisrecht als Instrument eines effektiven Schutzes der Konventionsrechte................. 122

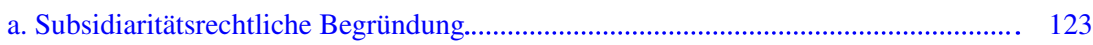

b. Der Fall El-Masri v. Mazedonien............................................................................ 124

D. Subsidiaritätsrechtliche Würdigung der herrschenden Praxis des EGMR ............................. 127

1. Problematische Einzelfälle........................................................................................ 128

a. Beweis ,au-delà de tout doute raisonnable“. Der Fall Ioan Pop v. Rumänien............... 128

b. Grenzen des prozeduralen Kriteriums bei der Bemessung des Kontrollmaßstabs in Tatsachenfragen. Der Fall Dembele v. Schweiz........................................................... 130

c. Beweislastumkehr in Grauzonenfällen. Der Fall Sadkov v. Ukraine................................. 134

2. Stimmiges Gesamtbild............................................................................................... 136 
Im vorliegenden Kapitel soll untersucht werden, wie sich das Verhältnis von nationalstaatlichen Gerichten und EGMR im Hinblick auf die Tatsachenfeststellung konkret gestaltet. Im Vordergrund steht dabei die Frage, ob und unter welchen Umständen der EGMR von der innerstaatlichen Tatsachenfeststellung abweichen soll. Solche in der Praxis durchaus vorkommende Abweichungen beruhen teilweise auf einer von den innerstaatlichen Instanzen differierenden beweisrechtlichen Herangehensweise des EGMR. Unterschiede können sich aber wie eben erläutert ${ }^{1}$ auch daraus ergeben, dass der EGMR mit Tatsachenbehauptungen und Beweisen konfrontiert wird, die den innerstaatlichen Gerichten nicht vorlagen; diese (auch) temporale ,novenrechtliche“ Dimension bleibt vorläufig indes zugunsten einer materiellen Betrachtungsweise ausgeklammert und ist erst im nächsten Teil dieser Arbeit zu beleuchten. ${ }^{2}$

Im Hinblick auf die in diesem Kapitel einschlägige Fragestellung soll zunächst der subsidiaritätsrechtliche Zusammenhang zwischen der Qualität des innerstaatlichen Verfahrens und der beweisrechtlichen Herangehensweise des EGMR etwas ausführlicher skizziert werden. ${ }^{3}$ Wie sich zeigen wird, hängt die Kontrolldichte des EGMR in Tatsachenfragen maßgeblich von der Qualität des innerstaatlichen Verfahrens ab. Diese Qualität bemisst sich im Verfahren vor dem EGMR namentlich nach den prozeduralen Vorgaben, die sich aus der EMRK selbst ergeben. Vor diesem Hintergrund sind zunächst die Vorgaben aufzugreifen, welche der EGMR in seiner Rechtsprechung zu Art. 13 EMRK und Art. 3 EMRK für die innerstaatliche Tatsachenfeststellung in Fällen zu Art. 3 EMRK entwickelt hat; fokussiert wird dabei auf Refoulement-Fälle sowie auf Fälle zu behaupteten Übergriffen von Staatsoffiziellen. ${ }^{4}$ Auf diesen Betrachtungen aufbauend ist aufzuzeigen, dass der Kontrollmaßstab des EGMR in Tatsachenfragen in Anknüpfung an die herausgearbeiteten prozeduralen Qualitätsmerkmale tatsächlich zwischen einer reinen Plausibilitätsprüfung und einer umfassenden de-novo-Prüfung oszilliert. ${ }^{5}$ In diesem Zusammenhang ist auch darauf einzugehen, wie der EGMR mit Beweisproblemen umgeht, die sich insbesondere dann ergeben, wenn innerstaatlich in kompletter Negation der verfahrensrechtlichen Verpflichtungen aus der EMRK überhaupt keine Untersuchung behaupteter Konventionsverletzungen stattgefunden hat.

Wie in einer abschließenden Würdigung zu zeigen sein wird, konvergiert die Praxis des EGMR in dieser wie in den übrigen Konstellationen im Grundsatz mit den Vorgaben, die sich aus dem Subsidiaritätsgrundsatz ergeben. ${ }^{6}$ Die Kritik, die an vereinzelten Urteilen geäußert worden ist, mag zwar im Einzelfall ihre Berechtigung haben; sie ist aber nicht geeignet, dem EGMR generell den Vorwurf zu machen, bei der Tatsachenfeststellung den Subsidiaritätsgrundsatz außer Acht zu lassen.

\footnotetext{
${ }^{1}$ Vgl. oben, III. B. 4. b.

${ }^{2} \mathrm{Vgl}$. nachfolgend, V.

${ }^{3} \mathrm{Vgl}$. nachfolgend, IV. A.

${ }^{4} \mathrm{Vgl}$. nachfolgend, IV. B.

${ }^{5} \mathrm{Vgl}$. nachfolgend, IV. C.

${ }^{6} \mathrm{Vgl}$. nachfolgend, IV. D.
} 


\section{A. Subsidiaritätsrechtlicher Zusammenhang zwischen der Qualität des nationalen Verfahrens und der Tatsachenfeststellungsfunktion des EGMR}

Wie im letzten Kapitel ausgearbeitet worden ist, statuiert der Subsidiaritätsgrundsatz für den Vorgang der Tatsachenfeststellung einen Handlungsvorrang innerstaatlicher Behörden und Gerichte. ${ }^{7}$ Die Institutionen der Konventionsstaaten müssen der ihnen vorrangig überantworteten Aufgabe einer methodisch nachvollziehbaren Tatsachenfeststellung aufgrund des Subsidiaritätsgrundsatzes aber auch tatsächlich nachkommen. Kommen sie der Aufgabe nicht in vollem Umfang nach, ist der EGMR nicht nur berechtigt, sondern sogar gehalten, das entstandene Vakuum auszufüllen.

Der EGMR selbst hat in diesem Sinne verschiedentlich deutlich gemacht, dass er sich mit einer Korrektur der innerstaatlichen Tatsachenfeststellungen nur dann zurückhält, wenn das innerstaatliche Verfahren den von ihm definierten qualitativen Vorgaben gerecht geworden ist. ${ }^{8}$ Andeutungen dieses subsidiaritätsrechtlichen $\mathrm{Zu}$ sammenhangs finden sich im Urteil Denisenko und Bogdanchikov v. Russland aus dem Jahr 2009: ${ }^{9}$
,[...] [T] he [circumstances of] the first applicant's alleged ill-treatment were rather com- plex. He claimed to have been beaten up after being involved in a scuffle and after an arrest which, according to some police officers, had been accompanied by the use of force against him [...]. The Court has found that the investigation into the alleged ill-treatment was beset by critical flaws and proved to be incapable of shedding light on the cause of his injuries and the circumstances accompanying their infliction. In this connection the Court reiterates that it is sensitive to the subsidiary nature of its role and recognises that it must be cautious in taking on the role of a first-instance tribunal of fact, where this is not rendered unavoida- ble by the circumstances of a particular case [...]. Nonetheless, where allegations are made under Article 3 of the Convention the Court must apply a particularly thorough scrutiny [...] even if certain domestic proceedings and investigations have already taken place [...]. "10

Während in früheren Urteilen allgemein von einer besonders aufmerksamen Kontrolle der innerstaatlichen Tatsachenfeststellung die Rede war, ${ }^{11}$ stellte der EGMR der Erwägung in Denisenko und Bogdanchikov v. Russland also den Hinweis voran, dass die innerstaatliche Tatsachenfeststellung ungenügend gewesen sei. Damit war die Basis dafür gelegt, die Kontrollintensität bezüglich innerstaatlicher Tatsachenfeststellung direkt von der Qualität des innerstaatlichen Verfahrens abhängig zu machen. Erstmals ausdrücklich erwähnt hat der EGMR diesen Zusammenhang soweit ersichtlich im Urteil El-Masri v. Mazedonien:

\footnotetext{
${ }^{7}$ Vgl. dazu und zum Folgenden oben, III. B. 4. a.

${ }^{8}$ Vgl. mit Bezug auf das Non-Refoulement-Gebot auch De Weck, S. $270 \mathrm{ff}$.

${ }^{9}$ Vgl. zuvor aber schon EGMR, Urteil vom 4. Dezember 1995, Ribitsch v. Österreich, Joint Dissenting Opinion Ryssdal, Matscher und Jambrek, § 1: ,,[...] Our conclusion: The respondent Government ordered of their own motion an inquiry which led to close scrutiny of the case by independent courts at three different levels of jurisdiction. It is not the Court's task to substitute its own assessment of the facts for that conducted by the national courts, unless these have proceeded improperly, which was not the position in the instant case."

${ }^{10}$ EGMR, Urteil vom 12. Februar 2009, Denisenko und Bogdanchikov v. Russland, § 83.

${ }^{11}$ Vgl. beispielsweise EGMR, Urteil vom 26. Juli 2007, Cozaru v. Rumänien, § 65.
} 
„[...] [L]a Cour, sensible à la nature subsidiaire de sa mission, reconnaît qu'elle ne peut sans de bonnes raisons assumer le rôle de juge du fait de première instance lorsque cela n'est pas rendu inévitable par les circonstances de l'affaire dont elle se trouve saisie [...]. Toutefois, lorsque des allégations sont formulées sur le terrain de l'article 3 de la Convention, elle doit se livrer à un "examen particulièrement attentif » [...], quand bien même certaines procédures et investigations auraient déjà été menées au plan interne [...]. En d'autres termes, la Cour est disposée, dans un tel contexte, à examiner d'un œil plus critique les conclusions des juridictions nationales. Pour ce faire, elle peut prendre en compte la qualité de la procédure interne et toute déficience propre à vicier le processus décisionnel $[\ldots]$. "12

In Fällen zu Art. 3 EMRK muss der EGMR demnach besonders kritischen Auges überprüfen, ob die innerstaatlichen Tatsachenfeststellungen zutreffend sind. Einzubeziehen sind bei dieser Prüfung insbesondere auch die Qualität des innerstaatlichen Verfahrens und allfällige Versäumnisse, die geeignet sein könnten, den Prozess der Tatsachenfeststellung zu beeinträchtigen. ${ }^{13}$ Der Maßstab zur Beurteilung der Qualität des innerstaatlichen Verfahrens kann dabei nur in der EMRK und nicht in den nationalen Verfahrensordnungen begründet liegen, denn der EGMR muss im Einflussbereich der Europaratsstaaten einen einheitlichen Menschenrechtsschutz gewährleisten. ${ }^{14}$

Anknüpfend an diese Logik prüft der EGMR im Rahmen seiner Urteile zu Art. 3 EMRK heute oftmals, ob die innerstaatlichen Behörden in ihren Verfahren die prozeduralen Anforderungen eingehalten haben, die sich namentlich aus Art. 3 oder Art. 13 EMRK ergeben. ${ }^{15}$ Ist die Antwort negativ, fliesst aus dem Subsidiaritätsgrundsatz für den EGMR die Pflicht, kompensatorisch tätig zu werden und die Tatsachen eigenständig festzustellen. Beispielsweise in Orlov und andere v. Russland hat der EGMR in diesem Sinne herausgestrichen, dass er sich mit einer eigenen Würdigung der Beweise stärker zurückgehalten hätte, wenn die russischen Gerichte die vorliegenden Beweise im Hinblick auf die von den Beschwerdeführern behauptete Involvierung von Staatsoffiziellen in ihre Entführung überhaupt gewürdigt hätten. ${ }^{16}$

\footnotetext{
${ }^{12}$ Vgl. EGMR (Große Kammer), Urteil vom 13. Dezember 2012, El-Masri v. Mazedonien, § 155. Bestätigt im heutigen diesbezüglichen Leiturteil EGMR (Große Kammer), Urteil vom 28. September 2015, Bouyid v. Belgien, § 85.

${ }^{13}$ Bestätigt beispielsweise in EGMR, Urteil vom 26. April 2016, Amarandei v. Rumänien, § 141.

${ }^{14}$ Vgl. dazu schon oben, I. A. bei Fn. 13.

${ }^{15}$ EGMR, Urteil vom 6. Juli 2017, Sadkov v. Ukraine, § 90, mit zahlreichen Hinweisen auf die Rechtsprechung. Vgl. auch EGMR, Urteil vom 28. Juni 2016, Kulyk v. Ukraine, § 75.

${ }^{16}$ Vgl. EGMR, Urteil vom 14. März 2017, Orlov und andere v. Russland, § 94: „In the present case no assessment of evidence was carried out by the domestic courts. It is therefore for the Court to assess the facts of the case as presented by the parties. [...]." Ähnliche Überlegungen finden sich in weiteren Urteilen; vgl. EGMR, Urteil vom 9. Juni 2016, Popovi v. Bulgarien, § 62. Vgl. für eine ähnliche Erwägung im Kontext eines Falls zur medizinischen Versorgung eines Häftlings EGMR, Urteil vom 22. März 2016, Litvinov v. Russland, § 85: „In the absence of an effective remedy to air complaints of inadequate medical services afforded to inmates, the Court may find itself obliged to perform a first-hand evaluation of evidence before it to determine whether the guarantees of Articles 2 or 3 of the Convention have been respected."
} 
Zieht man diese Herangehensweise im konkreten Einzelfall auf eine abstrakte Ebene, lässt sich die subsidiaritätsrechtliche Leitlinie für die Tatsachenfeststellung des EGMR im Verhältnis zu den nationalstaatlichen Gerichten wie folgt formulieren: Grundsätzlich stellt der EGMR auf die Tatsachenfeststellung der nationalen Gerichte ab und korrigiert diese nur im Falle von Willkür. Dies gilt jedoch nur insoweit, als die nationalen Gerichte der ihnen primär zugewiesenen Aufgabe einer methodisch nachvollziehbaren Tatsachenfeststellung nachgekommen sind. Ist solches zu verneinen, liegen jene ,zwingenden Gründe“ vor, die es nach der Rechtsprechung gebieten, dass der EGMR in die innerstaatliche Tatsachenfeststellung eingreift und eigene Feststellungen trifft. Nachfolgend ist in Anbetracht dieser Zusammenhänge zu erläutern, welche Kriterien sich aus der Rechtsprechung des EGMR zur Beurteilung der Qualität innerstaatlicher Tatsachenfeststellung herauskristallisieren lassen und worauf sich diese Kriterien dogmatisch stützen.

\section{B. Prozedurale Anforderungen der EMRK an die Tatsachenfeststellung der nationalen Gerichte}

\section{Art. 13 EMRK und Art. 3 EMRK als dogmatische Grundlagen}

In Fällen zu Art. 3 EMRK fließen die prozeduralen Verpflichtungen insbesondere aus Art. 13 EMRK und Art. 3 EMRK selbst. In enforced-disappearance-Fällen leiten sich zusätzliche Untersuchungspflichten aus Art. 5 EMRK ab. ${ }^{17}$ Allerdings unterscheiden sich die Untersuchungspflichten aus dieser Bestimmung nicht kategorisch von den verfahrensrechtlichen Verpflichtungen, die sich auch aus Art. 13 EMRK und Art. 3 EMRK ergeben, weshalb die nachfolgenden Ausführungen auch aufgrund der Eingrenzung des Forschungsgegenstands der vorliegenden Arbeit $^{18}$ - auf letztere Bestimmungen fokussieren.

\section{a. Funktion und Verhältnis von Art. 13 EMRK und Art. 3 EMRK}

Wie bereits mehrfach ausgeführt, sollen die Konventionsgarantien nach der Konzeption der EMRK in erster Linie auf der Ebene der Mitgliedstaaten gewährleistet werden. ${ }^{19}$ Die Beschwerde an den EGMR ist den Verfahren in den Mitgliedstaaten nachgelagert und kommt nur subsidiär zur Anwendung. ${ }^{20}$ Prozessualer Ausdruck dieser Grundkonzeption sind Art. 13 EMRK und Art. 35 Ziff. 1 EMRK. ${ }^{21}$ Nach

\footnotetext{
${ }^{17} \mathrm{Vgl}$. dazu und zum Folgenden van der Wilt/Lyngdorf, S. 50.

${ }^{18} \mathrm{Vgl}$. dazu oben, I. D.

${ }^{19} \mathrm{Vgl}$. oben, I. A., III. B. 1.

${ }^{20}$ EGMR (Große Kammer), 26.10.2000, Kudla v. Polen, § 152.

${ }^{21}$ Breuer, in: Kommentar EMRK, Rn. 1 zu Art. 13 EMRK.
} 
Art. 13 EMRK hat jede Person, die ,in ihren in dieser Konvention anerkannten Rechten oder Freiheiten verletzt worden ist, (...) das Recht, bei einer innerstaatlichen Instanz eine wirksame Beschwerde zu erheben [...]“. Art. 13 EMRK als ,Verfahrensgrundrecht ${ }^{\text {“22 }}$ stellt mithin sicher, dass die Konventionsgarantien schon auf mitgliedstaatlicher Ebene effektiv implementiert werden. ${ }^{23}$ Ein effektiver Schutz umfasst dabei einerseits die inhaltliche Prüfung einer behaupteten Konventionsverletzung und anderseits Wiedergutmachung, wenn eine Konventionsverletzung zu bejahen ist. ${ }^{24}$ Soweit ein solcher effektiver Rechtsschutz besteht, sind Rechtssuchende dazu verpflichtet, den innerstaatlichen Instanzenzug auszuschöpfen (Art. 35 Ziff. 1 EMRK) ${ }^{25}$ Zwischen Art. 13 und Art. 35 Ziff. 1 EMRK besteht insoweit ein enger Konnex. ${ }^{26}$

Neben Art. 13 EMRK statuieren auch die materiellen Konventionsgarantien bestimmte Untersuchungspflichten; diese verfahrensrechtlichen Gehalte leitet der EGMR aus einer Zusammenschau von Art. 1 EMRK mit dem jeweiligen materiellen Konventionsrecht ab. ${ }^{27}$ Dogmatisch tragende Begründung ist dabei - auch im Zusammenhang von Art. 3 EMRK - der Effektivitätsgrundsatz:

\section{„[...] pour que l'interdiction [...] de la torture et des peines et traitements inhumains ou dégradants [...] s'avère efficace en pratique, il faut qu'existe une procédure permettant [...] d'enquêter sur [...] les allégations de mauvais traitements infligés à une personne se trouvant entre [les] mains [d'agents publics]. " 28}

Art. 13 EMRK und die prozeduralen Gehalte von Art. 3 EMRK schließen sich dabei nicht etwa gegenseitig aus, sondern ergänzen sich im Hinblick auf die Sicherstellung eines effektiven verfahrensrechtlichen Schutzes der Konventionsgarantien schon auf innerstaatlicher Ebene. ${ }^{29}$ Art. 13 EMRK ist dabei insofern umfassender, als er nicht nur die Fälle zu Art. 3 EMRK abdeckt, sondern auf alle Konventionsrechte anwendbar ist. Zudem verlangt er über eine effektive Untersuchung hinausgehend auch eine angemessene Wiedergutmachung. ${ }^{30}$ In Bezug auf die hier interessierenden prozeduralen Vorgaben zur Untersuchung des maßgeblichen

\footnotetext{
${ }^{22}$ Frowein/Peukert, Rn. 1 zu Art. 13 EMRK.

${ }^{23}$ Peters/Altwicker, S. 173; Christoffersen, S. 374, spricht von Art. 13 EMRK als „,central provision concerning the implementation of the ECHR".

${ }^{24} \mathrm{Vgl}$. Leach, Rn. 6553. Siehe auch EGMR, 30.10.1991, Vilvarajah und andere v. Vereinigtes Königreich, $\S 122$.

${ }^{25}$ EGMR, Urteil vom 7. Juli 2015, V.M. und andere v. Belgien, §§ 178-179.

${ }^{26}$ Breuer, in: Kommentar EMRK, Rn. 1 zu Art. 13 EMRK; Lanter, S. 30 ff.

${ }^{27}$ Vgl. EGMR (Große Kammer), Urteil vom 17. September 2014, Mocanu und andere v. Rumänien, $\S 317$.

${ }^{28}$ Vgl. EGMR (Große Kammer), Urteil vom 17. September 2014, Mocanu und andere v. Rumänien, § 316 (Hervorhebung durch den Verfasser).

${ }^{29}$ Vgl. Altermann, S. 90 ff.; De Weck, S. 276, m.w.H.

${ }^{30} \mathrm{Vgl}$. EGMR, Urteil vom 18. Juni 2002, Orhan v. Türkei, § 384. Angedeutet wird dies auch in EGMR, Urteil vom 1. Juli 2014, Saba v. Italien, Partly Dissenting Opinion Lemmens: ,[...] il importe de faire une nette distinction entre le volet procédural de l'article 3, qui concerne l'efficacité des mesures préventives, et l'article 13, qui concerne le redressement de la violation commise.“
} 
Sachverhalts bleibt Art. 3 EMRK (prozedural) jedoch im Verhältnis zu Art. 13 EMRK eine lex specialis, ${ }^{31}$ die denselben Anwendungsbereich und dieselbe dogmatische Tragweite aufweist. ${ }^{32}$ Es rechtfertigt sich vor diesem Hintergrund, die Bestimmungen nachfolgend in einem zu betrachten. ${ }^{33}$

Bei der Umsetzung der prozeduralen Vorgaben aus Art. 13 EMRK und Art. 3 EMRK genießen die Konventionsstaaten ein großes Ermessen: ${ }^{34}$ „Art. 13 does not go so far as to require any particular form of remedy, contracting states being afforded a margin of discretion in conforming to their obligations under this provision. ${ }^{\text {" } 35}$ Die Bestimmung schreibt den Konventionsstaaten also nicht die Mittel vor, sondern verpflichtet sie lediglich dazu, im Ergebnis wirksame innerstaatliche Rechtsbehelfe zur Verfügung zu stellen. ${ }^{36}$ Selbiges ließe sich aufgrund der Rechtsprechung auch für den prozeduralen Gehalt von Art. 3 EMRK sagen. ${ }^{37}$ Das Gegenstück zur Freiheit in der Ausgestaltung der nationalen Verfahrensordnungen bildet jedoch die Verpflichtung der Staaten, im Sinne einer organizational duty innerstaatliche Verfahren zur Verfügung zu stellen, die den Anforderungen von Art. 13 EMRK und dem prozeduralen Gehalt von Art. 3 EMRK gerecht werden. ${ }^{38}$ Soweit derartige Verfahren fehlen, sind die Vertragsstaaten gehalten, sie zu schaffen. ${ }^{39}$

\section{b. Anknüpfungspunkte der prozeduralen Vorgaben aus Art. 13 und 3 EMRK}

Die Anwendung von Art. 13 EMRK ist beschränkt auf Fälle, in denen die Verletzung materieller Konventionsgarantien in Frage steht. Ein Recht auf wirksame innerstaatliche Beschwerde besteht mit anderen Worten nur, soweit die Verletzung der Konventionsgarantien aus Abschn. I der EMRK beziehungsweise aus einem Zusatzprotokoll gerügt wird. ${ }^{40}$ Art. 13 EMRK ist akzessorisch zu den materiellen Konventionsrechten und hat keine „unabhängige Existenz““. ${ }^{41}$ Dies gilt selbstredend auch für die prozeduralen Gehalte von Art. 3 EMRK, die zum vornherein nur zum

\footnotetext{
${ }^{31}$ Vgl. EGMR, Urteil vom 12. Mai 2015, Identoba v. Georgien, § 106.

${ }^{32}$ In diesem Sinne auch van der Wilt/Lyngdorf, S. 49.

${ }^{33}$ Dies umso mehr, als auch der EGMR nicht immer klar zu unterscheiden scheint, warum er in einem Fall Art. 3 EMRK (prozedural) oder Art. 13 EMRK prüft; vgl. EGMR, Urteil vom 12. April 2016, M.C. und A.C. v. Rumänien, Partly Dissenting Opinion Kūris. Aus denselben Gründen mit einem vergleichbaren Ansatz van der Wilt/Lyngdorf, S. 50.

${ }^{34}$ Peters/Altwicker, S. 173.

${ }^{35}$ EGMR, Urteil vom 30. Oktober 1991, Vilvarajah und andere v. Vereinigtes Königreich, § 122.

${ }^{36}$ Christoffersen, S. 302.

${ }^{37}$ Vgl. statt vieler EGMR, Urteil vom 7. März 2017, V.K. v. Russland, § 185.

${ }^{38}$ Christoffersen, S. 299.

${ }^{39}$ Peters/Altwicker, S. 173.

${ }^{40}$ Frowein/Peukert, Rn. 1 zu Art. 13 EMRK; Breuer, in: Kommentar EMRK, Rn. 11 zu Art. 13 EMRK.

${ }^{41}$ Vgl. EGMR, Urteil vom 7. Juli 2009, Zavoloka v. Lettland, § 35 a).
} 
Tragen kommen können, wenn eine materielle Verletzung von Art. 3 EMRK im Raume steht.

Für die Anwendbarkeit der prozeduralen Verpflichtungen kann allerdings nicht vorausgesetzt werden, dass schon eine Verletzung von Art. 3 EMRK festgestellt worden ist. Der Wortlaut von Art. 13 EMRK ließe eine solche Interpretation zwar zu. Schon in seiner frühen Rechtsprechung hat der EGMR jedoch klargestellt, dass Art. 13 EMRK schon im Vorfeld der Feststellung einer allfälligen materiellen Verletzung der EMRK von Bedeutung ist. ${ }^{42}$ Dies ist an sich selbstverständlich, dient Art. 13 EMRK doch gerade der Klärung der Frage, ob die Rüge einer Konventionsverletzung begründet ist. ${ }^{43}$ Eine anderweitige Auslegung liefe überdies darauf hinaus, dass eine Beschwerde immer schon nach materiellem Konventionsrecht begründet wäre, womit Art. 13 EMRK keinen eigenständigen Anwendungsbereich besäße. ${ }^{44}$ Aus denselben Gründen kommen auch die prozeduralen Verpflichtungen aus Art. 3 EMRK schon vor der allfälligen Feststellung einer Verletzung von Art. 3 EMRK zum Tragen.

Nach der mittlerweile gefestigten Rechtsprechung des EGMR ist für die Anwendbarkeit von Art. 13 EMRK und Art. 3 EMRK (prozedural) deshalb lediglich notwendig, dass eine Konventionsverletzung in vertretbarer Art und Weise geltend gemacht wird („lorsqu'un individu soutient de manière défendable avoir subi [...] un traitement contraire à l'article 3“). ${ }^{45,46}$ Der EGMR nimmt Vertretbarkeit an, wenn die Behauptung einer Konventionsverletzung nicht schon prima facie als unbegründet erscheint und sie deshalb eine vertiefte Prüfung durch die zuständigen nationalen Behörden verdient. ${ }^{47}$ Solches ist zumindest anzunehmen, wenn eine Beschwerdeführerin detailliert über konventionsrechtlich möglicherweise problematische Geschehnisse berichtet, involvierte Personen identifizieren kann, und die Schilderungen über die Zeit hinweg konsistent bleiben. ${ }^{48}$ Vertretbar geltend gemacht ist eine Konventionsverletzung im Falle behaupteter Übergriffe von Staatsoffiziellen beispielsweise dann, wenn durch medizinische Berichte Verletzungen dokumentiert sind, die zumindest durch eine unzulässige polizeiliche Gewaltanwendung verursacht worden sein könnten. ${ }^{49}$

Der Spruchpraxis des EGMR lässt sich darüber hinaus entnehmen, dass Vertretbarkeit klarerweise immer anzunehmen sei, wenn eine Konventionsverletzung vorliegt (clearly arguable).$^{50}$ Dies hilft allerdings nur in den Fällen weiter, in denen eine materielle Konventionsverletzung schon festgestellt worden ist. Im

\footnotetext{
${ }^{42}$ Grundlegend EGMR (Plenum), Urteil vom 6. September 1978, Klass v. Deutschland, § 64.

${ }^{43}$ Frowein/Peukert, Rn. 2 zu Art. 13 EMRK.

${ }^{44}$ Matscher, S. 319.

${ }^{45}$ Vgl. EGMR (Große Kammer), Mocanu und andere v. Rumänien, § 317.

${ }^{46}$ Vgl. zu Art. 13 EMRK EGMR, Urteil vom 25. März 1983, Silver und andere v. Vereinigtes Königreich, § 113.

${ }^{47}$ EGMR, Urteil vom 7. Juli 2015, V.M. und andere v. Belgien, § 188, m.w.H.

${ }^{48}$ Vgl. EGMR, Urteil vom 4. April 2017, Thuo v. Zypern, § 139.

${ }^{49}$ Vgl. EGMR, Urteil vom 24. Oktober 2017, Devyatkin v. Russland, § 32.

${ }^{50}$ Vgl. statt vieler EGMR, Urteil vom 2. Juni 2015, Ouabour v. Belgien, $\S 85$.
} 
Verfahrensablauf ist die durch Art. 13 EMRK und Art. 3 EMRK (prozedural) bezweckte Untersuchung einer behaupteten Konventionsverletzung dieser Feststellung vorgelagert, weshalb die Rechtsprechung des EGMR den Ablauf der Prüfung einer Konventionsverletzung in gewisser Hinsicht verdreht. Dasselbe gilt für die Rechtsprechung des EGMR, aus dem Vorliegen offensichtlicher Unbegründetheit im Sinne von Art. 35 Ziff. 3 Bst. a EMRK auf die Unvertretbarkeit einer geltend gemachten Konventionsverletzung zu schließen. ${ }^{51}$ Dem wird in der Literatur entgegengehalten, dass sich die offensichtliche Unbegründetheit in vielen Fällen erst aus einer längeren rechtlichen Erörterung in einem funktionierenden innerstaatlichen Beschwerdesystem ergebe; offensichtliche Unbegründetheit im Sinne von Art. 35 Ziff. 3 Bst. a EMRK sei deshalb nicht mit der Vertretbarkeit einer geltend gemachten Konventionsverletzung gleichzusetzen. ${ }^{52}$

Die dargelegte Kritik ist im Wesentlichen auf einen unterschiedlichen Standpunkt der betreffenden Autoren und des EGMR zurückzuführen. Betrachtet man die Situation ex ante, das heißt vor der materiellen Prüfung der vorgebrachten Behauptung einer materiellen Konventionsverletzung in den Mitgliedstaaten, implizieren Art. 13 EMRK und Art. 3 EMRK (prozedural) wohl schon anknüpfend an die bloße Behauptung einer Konventionsverletzung die Pflicht, wirksame Prüfungsmechanismen zur Verfügung zu stellen. ${ }^{53} \mathrm{Ob}$ die Behauptung einer Konventionsverletzung vertretbar ist, ergibt sich nämlich erst aus der Prüfung des Sachverhalts und der Rechtsfragen im jeweiligen Verfahren. ${ }^{54}$ Der EGMR hat denn auch selbst festgehalten, Betroffene müssten die Gelegenheit erhalten, die Vertretbarkeit ihres Vorbringens einer (drohenden) Konventionsverletzung darzulegen. ${ }^{55}$ Ohne die zumindest oberflächliche Prüfung sämtlicher Behauptungen von Konventionsverletzungen könnten die Mitgliedstaaten die vertretbaren Behauptungen nicht herausfiltern und würden folglich regelmäßig wegen Verletzungen von Art. 13 EMRK und Art. 3 EMRK (prozedural) verurteilt. In diesem Sinne verlangen diese Garantien von den Mitgliedstaaten nicht nur ein effektives Verfahren zur Abklärung einer vertretbar vorgebrachten Konventionsverletzung, sondern schon ein Verfahren zur Prüfung der Vertretbarkeit selbst. ${ }^{56}$

Die Rechtsprechung des EGMR basiert dagegen auf einer ex-post-Betrachtung. Die Frage der Vertretbarkeit wird in einem Zeitpunkt geprüft, in dem die beschwerdeführende Person das innerstaatliche Verfahren schon durchlaufen hat und die

${ }^{51}$ EGMR, Urteil vom 22. Juni 2006, Gökçe und Demirel v. Türkei, § 70; EGMR, Urteil vom 12. Dezember 2006, Dobál v. Slowakei, § 50.

${ }^{52}$ Frowein/Peukert, Rn. 3 zu Art. 13 EMRK.

${ }^{53}$ EGMR (Plenum), Urteil vom 6. September 1978, Klass v. Deutschland, § 64.

${ }^{54} \mathrm{Vgl}$. auch De Weck, S. 278, welche dies als ,right to a first determination“ bezeichnet.

${ }^{55}$ EGMR (Große Kammer), Urteil vom 21. Januar 2011, M.S.S. v. Belgien und Griechenland, $\S 389$.

${ }^{56}$ In diese Richtung weist auch EGMR, Urteil vom 23. Juni 2016, Kleutin v. Ukraine, § 62, wo explizit festgehalten wird, dass die ukrainischen Behörden zumindest die vorliegenden medizinischen Berichte hätten konsultieren müssen, um herauszufinden, ,whether there was a reasonable suspicion underlying the applicant's allegation which would engage the authorities' obligation effectively to investigate it“. 
Prüfung der Zulässigkeit einer Beschwerde an den EGMR vorzunehmen ist. Offensichtliche Unbegründetheit und damit Unzulässigkeit einer Beschwerde liegt dann vor, wenn eine Konventionsverletzung schon prima facie ausgeschlossen werden kann. ${ }^{57}$ Wie der EGMR zutreffend ausgeführt hat, kommt es deshalb nur in Ausnahmekonstellationen vor, dass ein in diesem Sinne materiell offensichtlich unbegründetes Vorbringen einer Konventionsverletzung zugleich vertretbar vorgebracht worden ist. ${ }^{58}$

Es wäre also ein Fehlschluss, aus dem fehlgeschlagenen Nachweis einer Konventionsverletzung die Unvertretbarkeit der geltend gemachten Konventionsverletzung abzuleiten. ${ }^{59}$ Aus der Akzessorietät von Art. 13 EMRK und Art. 3 EMRK (prozedural) folgt nicht, dass bei Nichtbeweisbarkeit einer materiellen Konventionsverletzung auch die Verletzung der prozeduralen Garantien ausgeschlossen werden kann. Es kommt regelmäßig vor, dass der EGMR eine materielle Konventionsverletzung aufgrund mangelnder Beweisbarkeit des Sachverhalts verneint, allerdings eine prozedurale Verletzung von Art. 3 EMRK oder eine solche von Art. 13 EMRK bejaht, weil die vertretbar vorgebrachte Rüge einer Konventionsverletzung nicht angemessen untersucht worden ist. ${ }^{60}$ In solchen Fällen wird die materielle Konventionsverletzung jedoch in der Regel erst nach eingängiger Auseinandersetzung mit dem Sachverhalt des Einzelfalls verneint und es liegt entsprechend materiell keine offensichtliche Unbegründetheit vor. In der Rechtsprechung ist es deshalb nur ganz vereinzelt zur Konstellation gekommen, dass eine Beschwerde in Bezug auf die Verletzung einer materiellen Konventionsgarantie als offensichtlich unbegründet abgewiesen, gleichzeitig aber eine Verletzung von Art. 13 EMRK beziehungsweise Art. 3 EMRK (prozedural) angenommen wurde. ${ }^{61}$ Die Rechtsprechung des EGMR, wonach offensichtliche Unbegründetheit einer Beschwerde in Bezug auf eine materielle Verletzung der Konvention nicht bedeutet, dass die Anwendbarkeit von Art. 13 EMRK mit Bezug auf die Behauptung dieser Verletzung immer ausgeschlossen wäre, ${ }^{62}$ hat damit praktisch gesehen kaum Relevanz.

Zusammenfassend lässt sich sagen, dass die Vertretbarkeit der Rüge einer materiellen Konventionsverletzung in der Praxis kaum je bejaht wird, wenn offensichtliche Unbegründetheit im Sinne von Art. 35 Ziff. 3 EMRK vorliegt; Art. 13 EMRK und Art. 3 EMRK (prozedural) finden in solchen Fällen nur sehr selten Anwendung. Die neuere Spruchpraxis des EGMR bestätigt dieses theoretisch entwickelte Bild des Verhältnisses zwischen der materiellen Komponente von Art. 3 EMRK einerseits

\footnotetext{
${ }^{57}$ EGMR, Urteil vom 9. Oktober 1979, Airey v. Irland, § 18.

${ }^{58}$ EGMR (Große Kammer), Urteil vom 27. April 1988, Boyle und Rice v. Vereinigtes Königreich, $\S 54$.

${ }^{59}$ So aber EGMR, Urteil vom 22. Uni 2006, Gökçe und Demirel v. Türkei, § 70.

${ }^{60}$ Vgl. z. B. EGMR, Urteil vom 31. Juli 2014, Tershiyev v. Aserbaidschan, §§ 70, 73; EGMR, Urteil vom 6. Juni 2013, Mohammed v. Österreich, §§ 85, 111; EGMR, Urteil vom 26. Juli 2007, Georgiev v. Bulgarien, § 67; EGMR, Urteil vom 22. Mai 2001, Sarli v. Türkei, §§ 70, 78.

${ }^{61}$ Vgl. aber EGMR, Urteil vom 26. Januar 2016, Alpar v. Türkei.

${ }^{62}$ EGMR (Große Kammer), Urteil vom 27. April 1988, Boyle und Rice v. Vereinigtes Königreich, $\S 54$.
} 
und den prozeduralen Gehalten von Art. 13 EMRK und Art. 3 EMRK anderseits. Die prozeduralen Garantien kommen im Prinzip nur dann zum Tragen, wenn in vertretbarer Art und Weise eine materielle Verletzung von Art. 3 EMRK geltend gemacht wird. Ist diese Schwelle überschritten, kommen die Teilgehalte jedoch unabhängig voneinander zur Anwendung: In der Rechtsprechung kommt es in diesem Sinne oft vor, dass kombinierte (also prozedurale und materielle) Verletzungen von Art. 3 EMRK festgestellt werden. ${ }^{63}$ Zuweilen wird aber unter Verneinung einer materiellen Verletzung auch nur eine prozedurale Verletzung bejaht ${ }^{64}$ oder werden umgekehrt prozedurale Verletzungen zwar verneint, materielle Verletzungen hingegen bejaht. ${ }^{65}$ Diese Rechtsprechung unterstreicht, dass den prozeduralen Garantien eine eigenständige Tragweite zukommt; münzt man sie auf die Tatsachenfeststellung um, kann auch insoweit von einem selbstständigen „Recht auf Wahrheit“ gesprochen werden. ${ }^{66}$

\section{c. Allgemeine Leitsätze zur Wirksamkeit des Rechtsbehelfs}

Art. 13 EMRK verlangt seinem Wortlaut nach die Möglichkeit, bei einer innerstaatlichen Instanz eine wirksame Beschwerde zu erheben. Mit den innerstaatlichen Instanzen sind dabei nicht nur Gerichte gemeint. Nachdem der Begriff der Beschwerde im schweizerischen Verfahrensrecht vor allem für den Weiterzug einer Rechtssache an ein Gericht verwendet wird ${ }^{67}$ ist es im Zusammenhang von Art. 13 EMRK und Art. 3 EMRK (prozedural) für den schweizerischen Kontext wohl passender, von einem wirksamen Rechtsbehelf zu sprechen. ${ }^{68} \mathrm{Im}$ Sinne eines Leitsatzes hat der EGMR festgehalten, die Wirksamkeit eines Rechtsbehelfs nach Art. 13 EMRK

\footnotetext{
${ }^{63}$ Vgl. statt vieler EGMR, Urteil vom 24. Oktober 2017, Devyatkin v. Russland (Fall von Polizeigewalt) sowie EGMR, Urteil vom 26. Januar 2016, R. v. Russland (Refoulement-Fall).

${ }^{64}$ Bei privaten Übergriffen kann es sich von vornherein nur um eine prozedurale Verletzung von Art. 3 EMRK handeln; interessant sind insofern nur jene Fälle, wo eine materielle Verletzung von Art. 3 EMRK auch denkbar wäre, vgl. aus jüngerer Zeit beispielsweise EGMR, Urteil vom 10. Oktober 2017, Tarjani v. Ungarn; EGMR, Urteil vom 13. Juni 2017, Daşlik v. Türkei; EGMR, Urteil vom 4. April 2017, Thuo v. Zypern; EGMR, Urteil vom 28. Februar 2017, Müftüoğlu und andere v. Türkei.

${ }^{65}$ Vgl. beispielsweise EGMR, Urteil vom 14. Februar 2017, Maslova v. Russland sowie EGMR, Urteil vom 16. Juli 2015, Ghedir und andere v. Frankreich.

${ }^{66} \mathrm{Vgl}$. schon oben, II. B.

${ }^{67}$ Vgl. zur Terminologie im öffentlichen Verfahrensrecht der Schweiz Kölz/Häner/Bertschi, Rn. 21. Neben dem öffentlichen Verfahrensrecht (vgl. auf Bundesebene Art. 31 VGG) findet sich der Beschwerdebegriff in der Schweiz als Bezeichnung für einen gerichtlichen Rechtsbehelf auch im Strafprozessrecht (Art. 393 ff. StPO) und im Zivilprozessrecht (Art. 319 ff. ZPO) wieder. Auch die ordentlichen Rechtsmittel an das Bundesgericht werden als Beschwerde bezeichnet (Art. $72 \mathrm{ff}$. BGG [Beschwerde in Zivilsachen], Art. 78 ff. BGG [Beschwerde in Strafsachen], Art. 82 ff. BGG [Beschwerde in öffentlich-rechtlichen Angelegenheiten]).

${ }^{68}$ In der Rechtsprechung zu Art. 3 EMRK (prozedural) braucht der EGMR die in diesem Sinne „,unverfänglicheren“ Begriffe der „procédure“ beziehungsweise der „enquête officielle“; vgl. beispielsweise EGMR (Große Kammer), Mocanu und andere v. Rumänien, §§ 316-317.
} 
beurteile sich nach den Kompetenzen der mit dem Rechtsbehelf befassten innerstaatlichen Instanz und den Verfahrensgarantien, die sie gewährleistet. ${ }^{69}$ Damit ist eine vorrangig institutionell-strukturelle Komponente angesprochen. Inhaltlich verlangen die prozeduralen Garantien, dass die betreffenden Behörden sich ernsthaft darum bemühen herauszufinden, was sich zugetragen hat (,s'efforc[ent] sérieusement de découvrir ce qui s'est passé [...].“). ${ }^{70}$

Der EGMR hat sich in Anwendung dieser Leitsätze mit verschiedenen Aspekten der prozeduralen Garantien von Art. 13 EMRK und Art. 3 EMRK auseinandergesetzt, welche im Folgenden indes nur insoweit vertieft aufgegriffen werden, als sie die Feststellung des konventionsrechtlich maßgeblichen Sachverhalts betreffen. Zu beachten ist dabei, dass die Anforderungen mit der Schwere der behaupteten Konventionsverletzung steigen können ${ }^{71}$ und deshalb die Frage der Wirksamkeit eines Rechtsbehelfs jeweils im Einzelfall zu beurteilen ist. Die Anforderungen, welche sich aus den nachfolgenden Kriterien ergeben, können insofern variieren. ${ }^{72}$ Der EGMR hat überdies schon früh statuiert, dass mehrere Rechtsbehelfe, welche für sich genommen den Anforderungen von Art. 13 EMRK nicht genügen, in einer Zusammenschau als wirksam gelten können. ${ }^{73}$ Dies vorausgeschickt ist im Folgenden darzustellen, welche konkreten Vorgaben sich für die Tatsachenfeststellung im innerstaatlichen Verfahren aus Art. 13 EMRK und Art. 3 EMRK (prozedural) ergeben.

\section{Systematisierung der Rechtsprechung des EGMR zu den prozeduralen Anforderungen an die innerstaatliche Tatsachenfeststellung}

Die durch Art. 13 EMRK und Art. 3 EMRK (prozedural) geforderte Auseinandersetzung mit der Substanz einer geltend gemachten Konventionsverletzung setzt auch die Feststellung des maßgeblichen Sachverhalts voraus. ${ }^{74}$ Ein wirksamer Rechtsbehelf im Sinne dieser Bestimmungen liegt nur dann vor, wenn die Tatsachenfeststellung bestimmten Anforderungen genügt. Diese These lässt sich bekräftigen, wenn

\footnotetext{
${ }^{69}$ EGMR (Plenum), Urteil vom 6. September 1978, Klass v. Deutschland, § 67, kürzlich wiedergegeben beispielsweise in EGMR (Große Kammer), Urteil vom 17. Juli 2014, Case of Centre for Legal Resources on Behalf of Valentin Càmpeanu v. Rumänien, § 149 oder EGMR, Urteil vom 12. Januar 2016, M.R.A. und andere v. Niederlande, § 114.

${ }^{70}$ Vgl. EGMR (Große Kammer), Urteil vom 13. Dezember 2012, El-Masri v. Mazedonien, § 183.

${ }^{71}$ EGMR (Große Kammer), Urteil vom 4. Juli 2006, Ramirez Sanchez v. Frankreich, § 165, wo aufgrund der schwerwiegenden Auswirkungen von Isolationshaft auf die Haftbedingungen eine justizielle Behörde für die Überprüfung der vorgebrachten Konventionsverletzung verlangt wurde. ${ }^{72}$ Lanter, S. 42.

${ }^{73}$ EGMR, Urteil vom 25. März 1983, Silver und andere v. Vereinigtes Königreich, § 113 c). Kritisch Breuer, in: Kommentar EMRK, Rn. 44 zu Art. 13 EMRK; Frowein/Peukert, Rn. 8 zu Art. 13 EMRK.

${ }^{74}$ Siehe explizit EGMR, Urteil vom 13. Januar 2015, Iustin Robertino Micu v. Rumänien, § 107.
} 
man sich den zeitlichen Ablauf der Durchsetzung der Konventionsrechte vor Augen führt: Aufgrund der Ausschöpfungsregel von Art. 35 Ziff. 1 EMRK verstreichen in der Regel Jahre zwischen der behaupteten Konventionsverletzung und der Möglichkeit, diese Konventionsverletzung vor dem EGMR geltend zu machen. ${ }^{75}$ Insbesondere die Sicherstellung relevanter Beweismittel ist nach einer solchen Zeitdauer aus verschiedenen Gründen massiv erschwert. Aufgrund der von der EMRK vorgesehenen Pflicht von Beschwerdeführerinnen, zuerst die (wirksamen) innerstaatlichen Instanzen zu durchlaufen, würde der Schutz der Konventionsrechte illusorisch, wenn die EMRK keine Vorgaben zur Verantwortlichkeit für die Ermittlung der Tatsachen beziehungsweise zur Beweiserhebung machen würde. ${ }^{76}$

In dieser Hinsicht haben Art. 3 EMRK (prozedural) und Art. 13 EMRK zumindest auch die Funktion, dem EGMR in einem allfälligen späteren Verfahren eine brauchbare Faktenbasis für seine Entscheidung zu liefern. Die Vorgaben, die sich aus Art. 13 EMRK für die Feststellung der Tatsachen im innerstaatlichen Verfahren ergeben, beziehen sich freilich nicht nur auf die Verpflichtung der Konventionsstaaten, im Hinblick auf ein allfälliges Verfahren vor dem EGMR von Amtes wegen gewisse Geschehnisse zu untersuchen (Beweisführungslast). ${ }^{77}$ Wie oben dargelegt wurde, zielen Art. 13 EMRK und Art. 3 EMRK (prozedural) in erster Linie darauf ab, den Rechtsschutz gegen Konventionsverletzungen einschließlich einer angemessenen Wiedergutmachung bereits auf Ebene der Konventionsstaaten zu gewährleisten; nur mittelbar wird hierdurch auch eine Entlastung des EGMR bezweckt. ${ }^{78}$ Wenn im innerstaatlichen Verfahren nun aber an sich aussagekräftige Beweismittel ohne nachvollziehbare Begründung für unzulässig erklärt werden und unberücksichtigt bleiben, kann nicht von einem wirksamen Rechtsbehelf die Rede sein, weil durch die Unzulässigkeitsregeln der Beweis der behaupteten Konventionsverletzung faktisch verunmöglicht wird. Dasselbe gilt für übersteigerte Beweismaßvorschriften, welche den Beweis der behaupteten Konventionsverletzung über Gebühr erschweren. In die Überlegungen einzubeziehen sind schließlich auch die Vorgaben, die sich aus Art. 13 EMRK und Art. 3 (prozedural) in Bezug auf die Beweiswürdigung und die Beweislastverteilung im innerstaatlichen Verfahren ergeben.

Die nachfolgende Analyse der Rechtsprechung des EGMR zu Art. 13 EMRK beschränkt sich - entsprechend der Ausrichtung der Arbeit - auf Fälle mit Bezug zu Art. 3 EMRK. Ein Schwergewicht wurde auf Refoulement-Fälle und auf Fälle behaupteter Übergriffe von Staatsoffiziellen gelegt, weil in diesen Konstellationen die Aufgabe der Tatsachenfeststellung besonders heikle Fragen aufwirft. ${ }^{79}$

\footnotetext{
${ }^{75} \mathrm{Vgl}$. dazu oben, III. B. 4. Etwas modifiziert stellt sich die Ausgangslage in den sogleich zu besprechenden Refoulement-Fällen dar, weil hier eine Konventionsverletzung oftmals noch nicht erfolgt ist, sondern aufgrund einer Wegweisungsverfügung lediglich latent im Raume steht.

${ }^{76} \mathrm{Zu}$ diesem Aspekt wurde unter dem Titel der „Untersuchungspflichten“ der EMRK-Staaten aus Art. 13 EMRK denn auch schon einiges publiziert, vgl. z. B. Altermann, S. 70 ff. oder van der Wilt/ Lyngdorf, S. $39 \mathrm{ff}$.

${ }^{77}$ Vgl. zu diesem Begriff Saladin, S. 121.

${ }^{78} \mathrm{Vgl}$. oben, III. B. 2. a.

${ }^{79} \mathrm{Vgl}$. dazu schon oben, I. D. 3.
} 
Im Schlussteil dieser Arbeit wird zu klären sein, inwiefern die gewonnenen Erkenntnisse auf weitere Fallkonstellationen unter Art. 3 EMRK sowie unter anderen Konventionsrechten übertragen werden können.

\section{a. Rechtsprechung zu Refoulement-Fällen}

Bereits oben ist herausgearbeitet worden, welche Wichtigkeit beweisrechtlichen Fragestellungen und damit dem innerstaatlichen Verfahren in Abschiebungsfällen zukommt. ${ }^{80}$ Der EGMR hat die Problematik ebenfalls früh erkannt und in verschiedenen Einzelfällen konkrete Vorgaben für die Risikoprüfung im innerstaatlichen Verfahren entwickelt. ${ }^{81}$ Im kürzlich ergangenen Leitentscheid J.K. und andere $v$. Schweden hat der EGMR die Chance ergriffen, seine bis dahin in Einzelfällen entwickelten Anforderungen an das innerstaatliche Verfahren in Refoulement-Fällen in ihrer ganzen Vielfältigkeit darzustellen.

Der Fall betraf die Wegweisung einer irakischen Familie nach Bagdad. Die Familie machte gegen den Vollzug der Wegweisung geltend, im Irak drohe ihr aufgrund des vormaligen beruflichen Engagements des Familienvaters für die amerikanischen Streitkräfte eine Verfolgung durch die radikalen Extremisten der Al-Qaida; der irakische Staat sei diesbezüglich nicht schutzfähig. ${ }^{82}$ Die schwedischen Behörden anerkannten zwar, dass die Familie bis zur Beendigung des beruflichen Engagements des Familienvaters im Jahr 2008 gravierenden Übergriffen durch die AlQaida ausgesetzt gewesen sei. Für die darauffolgende Zeit bis zu ihrer Ausreise im Jahr 2010 beziehungsweise 2011 hätten sie jedoch nicht aufzeigen können, weiterhin einer Verfolgung ausgesetzt gewesen zu sein. Ein entsprechendes Risiko sei auch für die Zukunft zu verneinen, zumal die irakischen Behörden diesbezüglich mittlerweile schutzfähig seien. ${ }^{83}$

aa. Untersuchungsgrundsatz, Mitwirkungspflichten und Zulässigkeit von Beweismitteln

Schon der Sachverhalt des Falls J.K. und andere v. Schweden macht deutlich, dass es zwei Aspekte sind, die im Hinblick auf die Zulässigkeit einer Abschiebung aus Sicht von Art. 3 EMRK beweisrechtlich von Bedeutung sein können: einerseits die spezifische (Verfolgungs-)Situation, der eine Person nach ihrer Rückkehr ausgesetzt wäre (hier: mögliche Übergriffe durch die Al-Qaida aufgrund des früheren beruflichen Engagements des Familienvaters); anderseits die allgemeine Situation,

\footnotetext{
${ }^{80} \mathrm{Vgl}$. oben, II. A.

${ }^{81}$ Vgl. beispielsweise EGMR, Urteil vom 11. Juli 2000, Jabari v. Türkei, §§ 39-41.

${ }^{82}$ EGMR (Große Kammer), Urteil vom 23. August 2016, J.K. und andere v. Schweden, § 13, $\S \S 61-66$.

${ }^{83}$ EGMR (Große Kammer), Urteil vom 23. August 2016, J.K. und andere v. Schweden, §§ 14-20, $\S \S 67-76$.
} 
mit welcher alle Bewohnerinnen des Zielstaats konfrontiert sind (hier: das angeblich fehlende Vermögen der irakischen Sicherheitsbehörden, Schutz vor privater Verfolgung zu gewährleisten). Während spezifische Wegweisungshindernisse oftmals nur durch die Mitwirkung der Schutzsuchenden dokumentiert werden können, stehen zur Dokumentation der allgemeinen Sicherheits- und Versorgungslage in einem Zielland in der Regel zahlreiche Berichte von Regierungs- und Nichtregierungsorganisationen zur Verfügung. Entsprechend dieser Ausgangslage unterscheidet der EGMR im Hinblick auf die Beweisführungslast. Für den Nachweis einer unmenschlichen Behandlung aus individuell-spezifischen Gründen ist im Grundsatz die Schutzsuchende verantwortlich; ${ }^{84}$ für die Beschaffung allgemeiner Lageberichte sind es die mitgliedstaatlichen Behörden. ${ }^{85}$

Selbst wo die Beweisführungslast bei den Schutzsuchenden liegt, ergeben sich aus Art. 3 EMRK jedoch gewisse Vorgaben für die Ausgestaltung des nationalen Verfahrensrechts. Namentlich in Asylverfahren wird zur Abklärung einer potenziell mit einer Abschiebung verbundenen individuell-spezifischen Bedrohung in der Regel eine Anhörung durchgeführt. ${ }^{86}$ Diese ist aufgrund der Vorgaben der EMRK in einer Sprache durchzuführen, die der Schutzsuchenden zugänglich ist; überhaupt ist diese über das anwendbare Verfahren so zu informieren, dass sie sich ein Bild über ihre Rechte und Pflichten machen kann ${ }^{87}$ Aufgrund der faktischen Schwierigkeiten von Schutzsuchenden, sich relevante Beweismittel aus dem Heimatstaat zukommen zu lassen, darf das anwendbare Verfahrensrecht überdies nicht so unflexibel ausgestaltet und angewendet werden, dass die Möglichkeit des Nachweises einer individuellen Verfolgung faktisch ausgeschlossen ist. ${ }^{88}$ In Umsetzung dieses Leitsatzes dürfte es beispielsweise nicht zulässig sein, ein Beweismittel aufgrund zeitlicher Verspätung aus dem Recht zu weisen, wenn dieses geeignet wäre, das ernsthafte Risiko einer Verletzung von Art. 3 EMRK zu beweisen. ${ }^{89}$ Dies bedeutet für die

\footnotetext{
${ }^{84}$ EGMR (Große Kammer), Urteil vom 23. August 2016, J.K. und andere v. Schweden, § 91. ${ }^{85}$ EGMR (Große Kammer), Urteil vom 23. August 2016, J.K. und andere v. Schweden, § 98. ${ }^{86} \mathrm{Vgl}$. für das schweizerische Asylverfahren Art. 29 AsylG.

${ }^{87}$ Beanstandet in EGMR, Urteil vom 14. März 2017, Ilias und Ahmed v. Ungarn, §§ 116, 124 (derzeit hängig vor der Großen Kammer), weil die Anhörung in einer für die Beschwerdeführerin kaum verständlichen Sprache durchgeführt worden war und die Beschwerdeführenden aufgrund ihres Illiteralismus zudem keine Möglichkeit hatten, sich ein Bild über das Verfahren zu machen.

${ }^{88}$ Insofern können verkürzte Asylverfahren, die sehr kurze Fristen zur Beibringung von Beweismitteln vorsehen, aus Sicht von Art. 13 und Art. 3 EMRK problematisch sein; vgl. beispielsweise die Diskussion in EGMR, Urteil vom 16. Juni 2016, R.D. v. Frankreich, §§ 46-64. Lesenswert außerdem EGMR, Urteil vom 19. Januar 2016, M.D. und M.A. v. Belgien, Dissenting Opinion Sajó: ,[...] À mon avis, la violation réside dans l'approche déraisonnablement rigide et extrêmement formaliste qu'ont suivie les autorités internes dans le traitement des éléments de preuve joints aux demandes d'asile. [...].“

${ }^{89}$ EGMR (Große Kammer), 21.01.2011, M.S.S. v. Belgien und Griechenland, § 389. Die ehemalige Schweizerische Asylrekurskommission hat in ihrer Rechtsprechung zu verspäteten Beweismitteleingaben im Revisionsverfahren ganz in diesem Sinne statuiert, dass das Verfahrensrecht so ausgelegt und angewendet werden muss, dass ,es zu keiner Verletzung des Gebotes des Non-refoulement [...] kommt“; vgl. EMARK 1995 Nr. 9 E. 7f und 7g. Diese Rechtsprechung der ehemaligen ARK hat bis heute Bestand; vgl. zuletzt Urteil des BVGer D-5991/2017 vom 22. Dezember 2017 E. 3.5.
} 
nationalen Behörden, dass sie auch bei der Anwendung verfahrensrechtlicher Regelungen immer die materielle Aussagekraft eines Beweismittels im Auge behalten müssen..$^{90}$

Fasst man diese Leitsätze zur Beweisführungslast zusammen, müssen die nationalen Behörden und Gerichte grundsätzlich von Amtes wegen sämtliche Informationen berücksichtigen, die im Hinblick auf die Beurteilung der konventionsrechtlichen Zulässigkeit einer Abschiebung von Bedeutung sein können ${ }^{91}$ Art. 3 EMRK verlangt von den nationalen Behörden zumindest in Bezug auf allgemein zugängliche Lageberichte ein Tätigwerden proprio motu (Untersuchungsgrundsatz). Dies impliziert nach hier vertretener Auffassung zwar nicht die Pflicht, dass die allgemein zugänglichen Informationen in jedem Entscheid einzeln aufgezählt werden müssen; erforderlich ist jedoch, dass sie zur Praxisbildung herangezogen werden und (idealerweise) zumindest in publizierten Leitentscheiden auch ausdrücklich genannt werden. Neben den Untersuchungspflichten der konventionsstaatlichen Behörden sind auch ergänzende Mitwirkungspflichten von Schutzsuchenden vorgesehen, bei deren Verletzung Schlüsse zu ihren Ungunsten gezogen werden können. Verweigert eine Schutzsuchende beispielsweise Angaben zu ihrem Herkunftsort, ist es nicht Aufgabe der nationalen Verwaltungsbehörden und Gerichte, von sich aus nach hypothetischen Wegweisungshindernissen zu forschen. ${ }^{92}$

Im Fall Ilias und Ahmed v. Ungarn hat der EGMR eine Verletzung des Untersuchungsgrundsatzes erkannt, weil die ungarischen Behörden in Anwendung einer Liste sicherer Drittstaaten die Wegweisung der beiden Beschwerdeführenden angeordnet hatten, ohne die zahlreich vorliegenden Berichte zu den Verhältnissen im serbischen Asylsystem zu konsultieren und das Risiko einer Kettenabschiebung zu prüfen. ${ }^{93}$ In ähnlicher Weise rügte der EGMR die russischen Behörden im Fall Allanazarova v. Russland dafür, dass sie trotz seiner gefestigten Rechtsprechung zur bedenklichen Menschenrechtssituation in Turkmenistan und ohne Referenzierung anderslautender Berichte die Zulässigkeit der Auslieferung der Beschwerdeführerin bejaht und sich diesbezüglich mit der Begründung begnügt hatten, die Befürchtungen der Beschwerdeführerin seien vorgeschoben.${ }^{94}$ In einem weiteren Fall

\footnotetext{
${ }^{90}$ Spijkerboer, 58. Dies entspricht im Übrigen auch der Praxis des Schweizerischen Bundesverwaltungsgerichts; vgl. Urteil des BVGer E-3839/2016 vom 31. August 2016 E. 4.2, m.w.H. auf die Rechtsprechung.

${ }^{91}$ EGMR (Große Kammer), Urteil vom 23. August 2016, J.K. und andere v. Schweden, §§ 14-20, $\S 87$.

${ }^{92} \mathrm{Vgl}$. in diesem Sinne zuletzt auch das Schweizerische Bundesverwaltungsgericht, Urteil E-6279/2015 vom 15. November 2017 E. 10.

${ }^{93}$ Vgl. EGMR, Urteil vom 14. März 2017, Ilias und Ahmed v. Ungarn, §§ 118, 124 (derzeit hängig vor der Großen Kammer).

${ }^{94}$ Vgl. EGMR, Urteil vom 14. Februar 2017, Allanazarova v. Russland, §§ 75, 103. Ähnlich EGMR, Urteil vom 14. Februar 2017, S.K. v. Russland, §§ 96-98, wo beanstandet wird, dass ohne Referenzierung einschlägiger nationaler oder internationaler Berichte einfach der Schluss gezogen worden sei, die Sicherheitslage in Syrien sei nicht derart prekär, dass temporäres Asyl gewährt werden müsste; lesenswert außerdem EGMR, Urteil vom 21. Mai 2015, Mukhitdinov v. Russland, $\S \S 49-50$, wo den russischen Behörden vorgeworfen wurde, der Auslieferung des Beschwerde-
} 
(Paposhvili v. Belgien) kritisierte die Große Kammer die belgischen Behörden, sie hätten es im Hinblick auf Art. 3 EMRK versäumt zu prüfen, ob die dokumentierten schwerwiegenden medizinischen Probleme des Beschwerdeführers auch in Georgien behandelbar seien. ${ }^{95}$ Auch abgesehen von diesen drei Fällen sind die prozeduralen Anforderungen, die sich aus Art. 13 EMRK und Art. 3 EMRK im Hinblick auf die Beweisführungslast ergeben, von großer praktischer Relevanz: Sie können insoweit als „Kernaspekt“ der beweisrechtlichen Verpflichtungen der Konventionsstaaten in Refoulement-Fällen bezeichnet werden.

\section{ba. Beweislastverteilung}

Von der Frage der eben angesprochenen Beweisführungslast zu unterscheiden ist die Frage der Beweislast. ${ }^{96}$ In Bezug auf die Refoulement-Konstellation stellt sich diesbezüglich konkret die Frage, zu wessen Nachteil es sich auswirken soll, wenn keine ernsthaften Gründe nachgewiesen werden können, die annehmen lassen würden, dass die betroffene Person nach Vollzug der Abschiebung Opfer einer unmenschlichen Behandlung würde. In den allgemeinen Erwägungen des Urteils im Fall J.K. und andere v. Schweden rief der EGMR diesbezüglich den allgemeinen Leitsatz in Erinnerung, ,[qu'] il appartient en principe au requérant de produire des éléments susceptibles de démontrer qu'il y a des raisons sérieuses de penser que, si la mesure incriminée était mis à éxécution, il serait exposé à un risque réel de se voir infliger un traitement contraire à l'article $3{ }^{6.97}$ Die objektive Beweislast liegt damit im Grundsatz bei den Schutzsuchenden (affirmanti incumbit probatio).

Allerdings kommt es unter Umständen zu einer Beweislastumkehr, wenn einer Schutzsuchenden der Nachweis gelingt, dass sie in der Vergangenheit bereits Opfer unmenschlicher Behandlung geworden ist: ,[L'] existence de mauvais traitements antérieurs fournit un indice solide d'un risque réel futur qu'un requérant subisse des traitements contraires à l'article 3 , dans le cas où il a livré un récit des faits globalement cohérent et crédible qui concorde avec les informations provenant de sources fiables et objectives sur la situation générale dans le pays concerné. Dans ces conditions, c'est au Gouvernement qu'il incombe de dissiper les doutes éventuels au sujet de ce risque. ${ }^{" 98}$ In einer Minderheitsmeinung ist der Wortlaut dieser Urteilspassage dahingehend beanstandet worden, dass von einem starken (statt einem ernsthaften) Indiz die Rede ist, das außerdem schon entstehen soll, wenn die Schilderungen einer

führers nach Usbekistan ohne Berücksichtigung der ihnen vorgelegten Berichte zur dortigen Menschenrechtslage und in vorschnellem Vertrauen auf die Zusicherung der usbekischen Behörde zugestimmt zu haben.

${ }^{95}$ Vgl. EGMR (Große Kammer), Urteil vom 13. Dezember 2016, Paposvhili v. Belgien, §§ 194-207.

${ }^{96}$ Vgl. zu diesem Begriff Saladin, S. 121.

${ }^{97}$ EGMR (Große Kammer) Urteil vom 23. August 2016, J.K. und andere v. Schweden, § 91.

${ }^{98}$ EGMR (Große Kammer), Urteil vom 23. August 2016, J.K. und andere v. Schweden, §§ 14-20, $\S 102$. 
Beschwerdeführerin generell als glaubhaft erscheinen. Tatsächlich wäre es im Spiegel der bisherigen Rechtsprechung richtiger gewesen $\mathrm{zu}$ sagen, dass ein von den konventionsstaatlichen Behörden zu widerlegendes ernsthaftes Indiz für eine künftige unmenschliche Behandlung erst dann vorliegt, wenn die Beschwerdeführerin eine solche für die Vergangenheit glaubhaft gemacht hat und aufgrund ihrer Schilderungen sowie der vorliegenden Lageberichte davon auszugehen ist, dass dieses Risiko auch weiterhin besteht. ${ }^{99}$ Allerdings ist derzeit noch unklar, ob die Mehrheit des EGMR in jenem Fall tatsächlich auf eine Verschiebung der Beweislast hin zu den nationalstaatlichen Behörden abgezielt hat oder ob es sich um rein semantische Anpassungen der bisherigen Leitsätze handelt. Keine Antwort liefert diesbezüglich jedenfalls das kurz darauf ergangene Urteil im Fall B.A.C. v. Griechenland, in welchem der EGMR in Anwendung der Beweislastumkehr beanstandete, dass die griechischen Behörden das Asylgesuch des Beschwerdeführers erstinstanzlich ohne nähere individuelle Begründung abgewiesen hatten, obwohl in verschiedenen früheren Verfahren eine Auslieferung des Beschwerdeführers in die Türkei abgelehnt worden war. ${ }^{100}$

\section{ca. Beweiswürdigung}

Im Hinblick auf die Beweiswürdigung schreibt der EGMR den nationalstaatlichen Behörden vor, dass sie im Zweifelsfall auf die Tatsachendarstellung der Schutzsuchenden abstellen müssen: „Eu égard à la situation particulière dans laquelle se trouvent souvent les demandeurs d'asile, il est fréquemment nécessaire de leur accorder le bénéfice du doute lorsque l'on apprécie la crédibilité de leurs déclarations

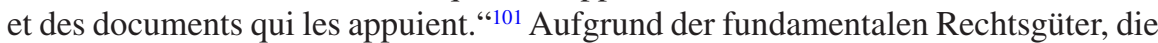
Art. 3 EMRK schützt, dürfte dieser Grundsatz nicht nur im Zusammenhang der Wegweisung von Asylsuchenden zur Anwendung gelangen (in dubio pro refugio). ${ }^{102}$ Vielmehr dürften Art. 3 EMRK und Art. 13 EMRK bei der Prüfung der Zulässigkeit einer Abschiebung generell gebieten, in Zweifelsfällen auf jene Tatsachen abzustellen, die für die Beschwerdeführerin günstiger sind. Dies bedeutet auch, dass aufgrund vereinzelter Unstimmigkeiten in den Aussagen von Schutzsuchenden jedenfalls nicht ohne weiteres ${ }^{103}$ auf das fehlende Risiko einer drohenden unmenschlichen Behandlung geschlossen werden darf. ${ }^{104}$

\footnotetext{
${ }^{99}$ Vgl. zum Ganzen EGMR (Große Kammer), Urteil vom 23. August 2016, J.K. und andere v. Schweden, Dissenting Opinion Ranzoni.

${ }^{100}$ EGMR, Urteil vom 13. Oktober 2016, B.A.C. v. Griechenland, §§ 61-67.

${ }^{101}$ EGMR (Große Kammer), Urteil vom 23. August 2016, J.K. und andere v. Schweden, $§ 93$.

${ }^{102}$ Vgl. Urteil des BVGer D-7201/2006 vom 7. September 2010 E. 4.6.1.

${ }^{103}$ Hilfreich ist jedenfalls, wenn Schutzsuchende mit allfälligen Ungereimtheiten konfrontiert werden; vgl. EGMR, Urteil vom 20. Juni 2017, M.O. v. Schweiz, § 78.

${ }^{104}$ Vgl. EGMR, Urteil vom 10. September 2015, R.H. v. Schweden, Joint Dissenting Opinion Zupančič und De Gaetano.
} 
Gewisse Kriterien hat der EGMR daneben auch für den Beweiswert allgemeiner Lageberichte von Regierungs- und Nichtregierungsorganisationen entwickelt. ${ }^{105}$ Maßgebliche Kriterien sind in jenem Bereich die Unabhängigkeit, die Vertrauenswürdigkeit und die Objektivität der Urheberin eines Berichts; berücksichtigt werden soll zudem die Qualität der einem Bericht zugrunde liegenden Untersuchung und der daraus gewonnenen Schlüsse. Von erhöhtem Beweiswert sind die Darstellungen eines Berichts, wenn sie durch andere Quellen gestützt werden, wobei insoweit wohl zusätzlich verlangt werden muss, dass die Informationen unabhängig voneinander erhoben worden sind.

Soweit ersichtlich, ist in der Rechtsprechung des EGMR noch kein Staat verurteilt worden, weil dessen Behörden in Verletzung dieser konventionsrechtlich vorgeschriebenen Beweiswürdigungsregeln entschieden hätten. Insoweit kommt den Beweiswürdigungsregeln, die sich aus Art. 3 und Art. 13 EMRK ergeben, in Abschiebungsfällen in der Praxis eine kleinere Bedeutung zu als dem Untersuchungsgrundsatz und der Beweislastverteilung.

\section{b. Rechtsprechung zu Übergriffen von Staatsoffiziellen}

Bereits oben ist die hervorragende Bedeutung herausgearbeitet worden, die einer effektiven Untersuchung behaupteter Menschenrechtsverletzungen im Hinblick auf die Ermittlung der Wahrheit auch und gerade bei behaupteten Übergriffen von Staatsoffiziellen zukommt. ${ }^{106}$ Daneben dienen die Untersuchungspflichten aus Art. 3 und Art. 13 EMRK in solchen Fällen insbesondere einer effektiven Durchsetzung der Rechtsbestimmungen zum Schutze vor Folter und unmenschlicher Behandlung. Sie sollen verhindern, dass sich Staatsoffizielle ihrer straf- und administrativrechtlichen Verantwortung aufgrund ihrer besonderen beruflichen Stellung entziehen können. ${ }^{107}$

Wegen der Betroffenheit von Staatsoffiziellen versteht sich von selbst, dass in der Rechtsprechung des EGMR die Unabhängigkeit der untersuchenden Behörde eine besonders wichtige Rolle spielt. ${ }^{108}$ Der EGMR verlangt diesbezüglich, dass die mit einer Untersuchung betrauten Personen gegenüber der behaupteten Urheberin einer Konventionsverletzung in keinem hierarchischen Weisungsverhältnis stehen ${ }^{109}$

\footnotetext{
${ }^{105} \mathrm{Vgl}$. dazu und zum Folgenden EGMR (Große Kammer), Urteil vom 23. August 2016, J.K. und andere v. Schweden, $\S \S 88-89$.

${ }^{106} \mathrm{Vgl}$. oben, II. B.

${ }^{107}$ EGMR (Große Kammer), Mocanu und andere v. Rumänien, § 318.

${ }^{108}$ Vgl. van der Wilt/Lyngdorf, S. 51.

${ }^{109}$ Beanstandet beispielsweise in EGMR, Urteil vom 26. April 2016, Amarandei und andere v. Rumänien, § 172, weil die Untersuchungsbeamten des Militärs in die militärische Struktur eingegliedert waren; vgl. auch EGMR, Urteil vom 11. Februar 2016, Pomilyayko v. Ukraine, § 55; EGMR, Urteil vom 24. November 2015, Siništaj und andere v. Montenegro, § 148.
} 
und auch sonst nicht institutionell mit ihr verbunden sind. ${ }^{110}$ Kritisch sieht er auch faktische Abhängigkeitsverhältnisse. ${ }^{111}$ Beispielsweise im Urteil Răzvan Laurențiu Constantinescu v. Rumänien hat sich der EGMR deshalb besorgt gezeigt, dass die ordentlichen rumänischen Strafverfolgungsbehörden bei der Untersuchung von Übergriffen von Polizeibeamtinnen und Polizeibeamten aufgrund der täglichen Zusammenarbeit mit letzteren zu wenig unabhängig sein könnten. ${ }^{112}$ Ein Indiz für eine fehlende faktische Unabhängigkeit erblickt der EGMR auch darin, dass ein Staatsanwalt ohne jede Begründung auf die Tatsachendarstellung beschuldigter Staatsoffizieller abgestellt hat und insofern den Verdacht mangelnder innerer Distanz aufkommen ließ. ${ }^{113}$

Der EGMR hat offen gelassen, ob unter bestimmten Umständen lediglich Gerichtsverfahren den Anforderungen von Art. 13 EMRK und Art. 3 EMRK (prozedural) genügen könnten, gleichzeitig aber festgehalten, dass Gerichte (auch) unter dem Blickwinkel der Unabhängigkeit hohe Gewähr für die Wirksamkeit eines Rechtsbehelfs bieten würden. ${ }^{114}$ Im Weiteren soll diese institutionelle Perspektive jedoch zugunsten einer Betrachtung der konkret für die Tatsachenfeststellung maßgeblichen Vorgaben aus Art. 13 EMRK und Art. 3 EMRK in den Hintergrund gerückt werden.

Im Sinne eines allgemeinen Leitsatzes verlangt der EGMR diesbezüglich für die Effektivität einer Untersuchung, ,que l'enquête [soit] à la fois rapide et approfondie, ce qui signifie que les autorités doivents toujours s'efforcer sérieusement de découvrir ce qui s'est passé et qu'elles ne doivent pas s'appuyer sur des conclusions hâtives ou mal fondées pour clore l'enquête ou fonder leur décision." 115 Oder umgekehrt formuliert: „,...] [T] oute carence de l'enquête affaiblissant sa capacité à établir les circonstances de l'affaire ou l'identité des responsables risque de faire conclure qu'elle ne répond pas à la norme d'effectivité requise." "116 Nachfolgend ist in einer systematischen Aufarbeitung der Rechtsprechung des

\footnotetext{
${ }^{110}$ Beanstandet beispielsweise in EGMR, Urteil vom 5. Juli 2016, Eğitim ve Vilim Emekçileri Sendikasi und andere v. Türkei, $\S 80$, weil die Administrativuntersuchung zur Rechtmäßigkeit der Gewaltanwendung gegenüber Demonstrantinnen und Demonstranten von Personen durchgeführt wurde, welche als Behördenleiter potenziell selbst von einem Strafverfahren hätten betroffen sein können. Vgl. auch EGMR, Urteil vom 23. Juni 2016, Kulyk v. Ukraine, § 107; EGMR, Urteil vom 15. März 2016, Hoalgă und andere v. Rumänien, § 82; EGMR, Urteil vom 7. Mai 2015, Emin Huseynov v. Aserbaidschan, $\$ 74$.

${ }^{111}$ Grundlegend zum Ganzen EGMR (Große Kammer), Urteil vom 28. September 2015, Bouyid v. Belgien, § 118 .

${ }^{112}$ Vgl. EGMR, Urteil vom 15. März 2016, Răzvan Laurențiu Constantinescu v. Rumänien, § 70.

${ }^{113}$ Vgl. beispielsweise EGMR, Urteil vom 14. September 2017, Matevosyan v. Armenien, § 77.

${ }^{114}$ EGMR (Große Kammer), Urteil vom 10. Mai 2001, Z. und andere v. Vereinigtes Königreich, $\S 110$.

${ }^{115}$ EGMR (Große Kammer), Urteil vom 13. Dezember 2012, El-Masri v. Mazedonien, § 183. Vgl. auch EGMR (Große Kammer), Urteil vom 28. September 2015, Bouyid v. Belgien, § 123.

${ }^{116}$ Vgl. zum Ganzen EGMR (Große Kammer), Urteil vom 28. September 2015, Bouyid v. Belgien, $\S 120$.
} 
EGMR herauszuarbeiten, was diese Leitsätze in Bezug auf die Untersuchung des massgeblichen Sachverhalts konkret von den innerstaatlichen Behörden verlangen.

aa. Untersuchungsgrundsatz und Beschleunigungsgebot

Der EGMR erwartet von den innerstaatlichen Behörden wie gesagt, dass sie den ernsthaften Versuch unternehmen herauszufinden, was sich tatsächlich zugetragen hat. ${ }^{117}$ Hierfür ist zunächst einmal von Amtes wegen ein Verfahren zu eröffnen, das die effektive Untersuchung der behaupteten unmenschlichen Behandlung überhaupt erlaubt. ${ }^{118}$ Im russischen Kontext hält der EGMR in konstanter Rechtsprechung fest, dass die Eröffnung einer Voruntersuchung gemäß Art. 144 der russischen Strafprozessordnung nicht genügt, weil im Rahmen solcher Voruntersuchungen nur beschränkte Beweiserhebungen möglich sind; ${ }^{119}$ ungenügend ist eine solche Voruntersuchung auch deshalb, weil die Strafbestimmungen für falsches Zeugnis und Zeugnisverweigerung keine Anwendung finden. ${ }^{120}$ Notwendig ist im Grundsatz die Durchführung einer ordentlichen Strafuntersuchung nach Art. 146 der russischen Strafprozessordnung. ${ }^{121}$ Ähnliche Vorbehalte hat der EGMR gegenüber Voruntersuchungen nach ukrainischem ${ }^{122}$ und rumänischem ${ }^{123}$ Strafprozessrecht angebracht.

Damit eine Untersuchung als effektiv angeschaut werden kann, ist erforderlich, dass sämtliche Beweise erhoben werden, welche vernünftigerweise zur Erhellung der tatsächlichen Geschehnisse beitragen können. ${ }^{124}$ Anzustreben ist dabei eine möglichst vollständige Rekonstruktion und Dokumentation ${ }^{125}$ der Abläufe. ${ }^{126}$ Der EGMR verlangt zu diesem Zweck die Befragung jener Zeuginnen und Zeugen, welche zum tatsächlichen Geschehensablauf etwas Substanzielles aussagen

\footnotetext{
${ }^{117}$ EGMR (Große Kammer), Mocanu und andere v. Rumänien, § 325.

${ }^{118}$ Vgl. EGMR, Urteil vom 26. Juli 2016, Adam v. Slowakei, §§ 77-78, wo der EGMR den slowakischen Behörden vorwarf, trotz Kenntnis der Misshandlungsvorwürfe nicht von Amtes wegen ein Strafverfahren aufgenommen zu haben.

${ }^{119}$ Vgl. nur EGMR, Urteil vom 24. Oktober 2017, Devyatkin v. Russland, § 34; EGMR, Urteil vom 16. Juli 2015, Aleksey Borisov v. Russland, § 60; EGMR, Urteil vom 2. Mai 2017, Olisov und andere v. Russland, $\S 81$.

${ }^{120}$ Vgl. EGMR, Urteil vom 3. Oktober 2017, Shevtsova v. Russland, § 42. Leitentscheid dazu ist derzeit EGMR, Urteil vom 24. Juli 2014, Lyapin v. Russland, namentlich §§ 133-140.

${ }^{121}$ Vgl. EGMR, Urteil vom 15. November 2016, Zolotarev v. Russland, § 49.

${ }^{122}$ Vgl. EGMR, Urteil vom 28. März 2017, Grigoryan und Sergeyeva v. Ukraine, § 61.

${ }^{123}$ Vgl. EGMR, Urteil vom 31. Mai 2016, Gheorghița und Alexe v. Rumänien, § 53.

${ }^{124}$ EGMR (Große Kammer), Mocanu und andere v. Rumänien, § 319: ,[L'article 3 exige] l'adoption de toutes les mesures raisonnables propres à assurer la conduite d'une enquête effective [...].“

${ }^{125}$ Vgl. EGMR, Urteil vom 5. Juli 2016, Rahmi Şahin v. Türkei, § 45, wo die Staatsanwaltschaft auf Tatsachen abstellte, die sich nicht auf die Akten stützen ließen.

${ }^{126}$ Vgl. EGMR, Urteil vom 28. März 2017, Grigoryan und Sergeyeva v. Ukraine, § 64; EGMR, Urteil vom 26. April 2017, Seagal v. Zypern, § 120.
} 
können. ${ }^{127} \mathrm{Zu}$ befragen sind neben allen Beschuldigten ${ }^{128}$ zumindest die Opfer der behaupteten Misshandlung. ${ }^{129}$ Oft ist auch die Befragung von Angehörigen hilfreich, weil durch ihr Zeugnis - bei Fehlen entsprechender medizinischer Gutachten - festgestellt werden kann, ob und gegebenenfalls in welchem Zeitraum Verletzungen entstanden sind. ${ }^{130}$ Wenn jemand behauptet in der Lage zu sein, die für eine Misshandlung verantwortlichen Beamtinnen und Beamten identifizieren zu können, ist eine Konfrontation durchzuführen. ${ }^{131}$ In Frage kommen kann daneben unter gewissen Umständen auch eine Besichtigung der Lokalitäten, namentlich wenn das Wissen um deren Beschaffenheit maßgeblich zur Aufklärung der Geschehensabläufe beitragen kann. ${ }^{132}$ Bestehen Videoaufnahmen von einem Vorfall, müssen diese von den untersuchenden Behörden zu Beweiszwecken gesichert werden, ${ }^{133}$ wobei zur Verhinderung von Manipulationen nur die Sicherstellung des Originals den Anforderungen aus Art. 13 und Art. 3 EMRK gerecht wird. ${ }^{134}$

In der Regel sollten die konventionsstaatlichen Behörden in Polizeigewahrsam genommene Personen vor einer Entlassung einem Arzt oder einer Ärztin vorführen, damit diese deren Gesundheitszustand überprüfen können. Sehen die Konventionsstaaten von systematischen Haftaustrittskontrollen ab, müssen sie alle zumutbaren Schritte unternehmen, um im Falle nachträglicher Misshandlungsvorwürfe zu untersuchen, ob die Verletzungen in Polizeigewahrsam entstanden sind. ${ }^{135}$ Verlangt ist in diesem Zusammenhang insbesondere die Erhebung medizinischer Gutachten, welche neben der Dokumentation der erlittenen Verletzungen die Fragen klären können, wann diese entstanden sind und worauf sie zurückzuführen sein könnten. ${ }^{136}$

\footnotetext{
${ }^{127}$ Vgl. EGMR, Urteil vom 12. Oktober 2017, Tiziana Pennino v. Italien, § 51; EGMR, Urteil vom 10. Oktober 2017, Tarjani v. Ungarn, § 57; EGMR, Urteil vom 5. Oktober 2017, Ostrovengecs v. Lettland, § 78 .

${ }^{128}$ Vgl. EGMR, Urteil vom 4. Februar 2016, Hilal Mammadov v. Aserbaidschan, § 96, wo die aserbaidschanischen Behörden dafür gerügt wurden, nur vier der sieben der an der Verhaftung des Beschwerdeführers beteiligten Polizeibeamten überhaupt befragt zu haben. Zur Vorladung der Angeschuldigten sind alle strafprozessual zulässigen Mittel anzuwenden; vgl. EGMR, Urteil vom 13. Januar 2015, Uğur v. Türkei, § 103.

${ }^{129}$ EGMR, Urteil vom 14. September 2017, Matevosyan v. Armenien, § 79; EGMR, Urteil vom 3. März 2016, Kapustyak v. Ukraine, $\S 80$.

${ }^{130}$ Vgl. EGMR, Urteil vom 31. Oktober 2017, M.F. v. Ungarn, § $53 \mathrm{f}$.

${ }^{131} \mathrm{Vgl}$. EGMR, Urteil vom 13. November 2014, Aktürk v. Türkei, § 41.

${ }^{132}$ Vgl. EGMR, Urteil vom 2. Mai 2017, Kondakov v. Russland, § 33, in dem es sich aufgedrängt hätte, einen Augenschein der Treppe zu nehmen, die der Beschwerdeführer nach Darstellung der Polizeibeamten selbstverschuldet hinuntergestürzt war.

${ }^{133}$ Vgl. EGMR, Urteil vom 5. Oktober 2017, Ostrovenecs v. Lettland, § 77; EGMR, Urteil vom 2. Mai 2017, Sitnikov v. Russland, §36; EGMR, Urteil vom 24. November 2016, Mustafa Hajiliv. Aserbaidschan, § 51 .

${ }^{134}$ Vgl. EGMR, Urteil vom 15. März 2016, Ciorap v. Moldawien (Nr. 5), §§ 65-66.

${ }^{135}$ Vgl. EGMR, Urteil vom 15. November 2016, Zolotarev v. Russland, § 50.

${ }^{136}$ Insoweit ungenügende medizinische Berichte lagen vor in EGMR, Urteil vom 19. September 2017, Zolotorev v. Russland, § 52; EGMR, Urteil vom 14. September 2017, Matevosyan v. Armenien, $\S 80$; EGMR, Urteil vom 13. Juni 2017, Daşlik v. Türkei, §§ 58-64. Überhaupt keine medizinische Expertise in Auftrag gegeben wurde in EGMR, Urteil vom 21. Juni 2016, Oleynik v. Russland, § 66.
} 
Nachträglich erhobene medizinische Gutachten müssen dabei lege artis angefertigt werden. ${ }^{137}$ Namentlich müssen sie innert nützlicher Frist in Auftrag gegeben werden, damit eine plausible Erhebung der erlittenen Verletzungen überhaupt noch möglich ist. ${ }^{138}$ Anzustreben ist, dass die betroffene Person persönlich ${ }^{139}$ und in Abwesenheit von Polizeibeamtinnen und Polizeibeamten ${ }^{140}$ untersucht werden kann. Zudem müssen die begutachtenden Ärztinnen und Ärzte die Grundlagen ihrer Folgerungen darlegen und mögliche Gründe für die von einem behaupteten Misshandlungsopfer erlittenen Verletzungen aufzeigen. Werden medizinische Gutachten diesen Anforderungen nicht gerecht, können sie nicht als entscheidende Beweismittel herangezogen werden. ${ }^{141}$ In Frage kommt neben der Einholung von Gutachten auch die Befragung behandelnder Ärztinnen und Ärzte. ${ }^{142}$ Im Fall Shevtsova v. Russland rügte der EGMR die russischen Behörden dafür, dass sie die Eröffnung eines Strafverfahrens schon verweigert hatten, bevor ihnen die bereits in Auftrag gegebene medizinische Expertise überhaupt zur Kenntnis gebracht worden war. ${ }^{143}$

Ganz generell kommt der Schnelligkeit der Anhandnahme und der Durchführung eines Verfahrens entscheidende Bedeutung zu: „[...] une réponse rapide des autorités lorsqu'il s'agit d'enquêter sur le recours illégal à la force ou sur des allégations de mauvais traitements peut généralement être considérée comme essentielle pour préserver la confiance du public dans le respect du principe de légalité et éviter toute apparence de complicité ou de tolérance relativement à des actes illégaux." "144 Es geht dabei nicht nur um die Aufrechterhaltung des öffentlichen Vertrauens in die Rechtsstaatlichkeit, sondern auch um die Möglichkeit, Beweismittel zu sichern. ${ }^{145}$ Der EGMR hat wiederholt unterstrichen, dass die Effektivität einer Untersuchung

\footnotetext{
${ }^{137}$ Vgl. EGMR, Urteil vom 16. Dezember 2014, Mehmet Fidan v. Türkei, § 45, wo solches verneint wurde, weil die räumlichen Dimensionen der vom Beschwerdeführer erlittenen Verletzungen nicht dokumentiert worden seien.

${ }^{138}$ Verspätet war ein mit dreimonatiger Verzögerung eingeholtes rechtsmedizinisches Gutachten; vgl. EGMR, Urteil vom 1. Juni 2017, Mindadze und Nemsitsverdidze v. Georgien, § 106. Der EGMR hat aber auch schon bei einmonatiger Verzögerung auf die Verletzung von Art. 3 EMRK (prozedural) geschlossen; vgl. EGMR, Urteil vom 21. Juni 2016, Igoshin v. Russland, § 68; vergleichbar sind EGMR, Urteil vom 5. Oktober 2017, Ostroveņecs v. Lettland, § 78; EGMR, Urteil vom 15. November 2016, Tudoroaie v. Rumänien, § 87.

${ }^{139}$ Vgl. beispielsweise EGMR, Urteil vom 1. Juni 2017, Mindadze und Nemsitsverdidze v. Georgien, § 106; EGMR, Urteil vom 11. April 2017, Morgunov v. Russland, § 36; EGMR, Urteil vom 4. November 2014, Flămînzeanu v. Rumänien (Nr. 2), § 86.

${ }^{140}$ Vgl. EGMR, Urteil vom 5. Januar 2016, Minikayev v. Russland, § 69.

${ }^{141} \mathrm{Vgl}$. EGMR, Urteil vom 10. Oktober 2017, Tarjani v. Ungarn, § 58.

${ }^{142}$ Vgl. EGMR, Urteil vom 25. Februar 2016, Zyakun v. Ukraine, § 45.

${ }^{143}$ Vgl. EGMR, Urteil vom 3. Oktober 2017, Shevtsova v. Russland, $§ 44$.

${ }^{144}$ Vgl. EGMR (Große Kammer), Mocanu und andere v. Rumänien, § 323. Vgl. zum Ganzen EGMR (Große Kammer), Urteil vom 28. September 2015, Bouyid v. Belgien, § 121. Vergleichbar der Leitsatz in EGMR, Urteil vom 18. Oktober 2016, Ali Aba Talipoğlu v. Türkei, § 34: ,,[...] [L]a prompte réaction des autorités est capitale pour maintenir la confiance du public et son adhésion à l'Etat de droit et pour prévenir toute apparence de tolérance d'actes illégaux ou de collusion dans leur perpétration.“

${ }^{145}$ Vgl. statt vieler EGMR, Urteil vom 12. November 2015, Zakharin und andere v. Russland, § 68.
} 
nur sichergestellt werden kann, wenn sie innert nützlicher Frist in die Wege geleitet wird. ${ }^{146}$ Die Grenze ist deutlich überschritten, wenn die Behörden mit der Eröffnung einer Untersuchung mehr als ein Jahr zuwarten, nachdem sie Kenntnis von einem möglichen Übergriff erhalten haben. ${ }^{147}$

Auch die Beweisabnahmen sind in einem angemessenen Zeitraum durchzuführen. ${ }^{148} \mathrm{Im}$ Fall Enver Aydemir v. Türkei beurteilte der EGMR die Einvernahme des mutmaßlichen Opfers erst einen Monat nach der Anzeige als verspätet. ${ }^{149} \mathrm{Im}$ Fall Smolentsev v. Russland verneinte der EGMR die Effektivität der Untersuchung, weil die beschuldigten Polizisten zu spät einvernommen worden waren - nämlich erst 2, 8 und 32 Monate nach Einreichung der Strafanzeige. ${ }^{150}$ Mit den prozeduralen Vorgaben unvereinbar sein kann auch der Umstand, dass ein Verfahren immer wieder ohne triftige Gründe unterbrochen ${ }^{151}$ oder von Berufungsinstanzen wiederholt an die erste Instanz zurückgewiesen wird ${ }^{152}$ und deshalb unverhältnismäßig lange andauert. ${ }^{153}$ Wird ein Verfahren zur Vervollständigung des Sachverhalts an eine untere Instanz zurückgewiesen, ist diese zur Sicherstellung der Effektivität der Untersuchung gehalten, die Weisungen der übergeordneten Instanz zu befolgen, ${ }^{154}$ um eine exzessive Verlängerung des Verfahrens zu vermeiden. ${ }^{155}$

Beschwert sich eine Beschwerdeführerin vor den innerstaatlichen Instanzen erst mit maßgeblicher Verspätung auf eine durch Staatsoffizielle verursachte Verletzung von Art. 3 EMRK, kann dies einen negativen Einfluss auf die Effektivität einer

\footnotetext{
${ }^{146}$ Vgl. EGMR, Urteil vom 15. November 2016, Tudoroaie v. Rumänien, § 89 (Einleitung der Strafuntersuchung wegen schwerer Körperverletzung acht Jahre nach dem Vorfall); EGMR, Urteil vom 24. Mai 2016, Manzhos v. Russland, §§ 38-40 (Einleitung der Strafuntersuchung dreieinhalb Jahre nach Kenntnis der Misshandlungsvorwürfe).

${ }^{147}$ Vgl. EGMR, Urteil vom 4. April 2017, Thuo v. Zypern, § 129. Vergleichsweise knapp bemessen ist im Lichte der übrigen Rechtsprechung die einmonatige Verzögerung, welche der EGMR in einem Urteil für die Verletzung von Art. 3 EMRK hat ausreichen lassen; vgl. EGMR, Urteil vom 15. März 2016, Ciorap v. Moldawien (Nr. 5), §§ 61-62.

${ }^{148}$ Vgl. EGMR, Urteil vom 15. November 2016, Tudoroaie v. Rumänien, § 86.

${ }^{149}$ Vgl. EGMR, Urteil vom 7. Juni 2016, Enver Aydemir v. Türkei, § 66.

${ }^{150}$ Vgl. EGMR, Urteil vom 25. Juli 2017, Smolentsev v. Russland, § 73; in einem ähnlichen Zeitrahmen bewegten sich die Einvernahmen der beschuldigten Polizisten in EGMR, Urteil vom 13. Juni 2017, Daşlik v. Türkei, § 57, EGMR, Urteil vom 28. April 2016, Balajevs v. Lettland, § 103, sowie EGMR, Urteil vom 5. Mai 2015, Doiciu v. Rumänien, § 63.

${ }^{151}$ Vgl. EGMR, Urteil vom 16. Mai 2017, Romanescu v. Rumänien, § 24.

${ }^{152}$ Vgl. EGMR, Urteil vom 13. Juni 2017, Kosteckas v. Litauen, § 43 (Effektivität eines Verfahrens verneint, weil nach einem mehr als viereinhalbjährigen Prozess die Verjährung eingetreten war); EGMR, Urteil vom 18. Juni 2015, Ushakov und Ushakova v. Ukraine, § 91 (achtmalige Rückweisung des Verfahrens).

${ }^{153}$ Vgl. EGMR, Urteil vom 28. Februar 2017, Müftüoğlu und andere v. Türkei, § 76 (17 Jahre ohne verbindliches Urteil); EGMR, Urteil vom 17. Januar 2017, Barakhoyev v. Russland, § 36 (neun Jahre ohne verbindliches Urteil). Der EGMR hat auch schon eine dreijährige Verfahrensdauer als überlange qualifiziert, weil keine komplexen Fragen vorgelegen hatten; vgl. EGMR, Urteil vom 9. Juni 2016, Popovi v. Bulgarien, § 74.

${ }^{154} \mathrm{Vgl}$. EGMR, Urteil vom 15. Dezember 2015, Şerban Marinescu v. Rumänien, § 66. ${ }^{155}$ Vgl. EGMR, Urteil vom 10. Dezember 2015, Asllani v. Mazedonien, §§ 62-67.
} 
Untersuchung haben. ${ }^{156}$ Ein Ausschluss der Verantwortlichkeit für eine prozedurale Verletzung von Art. 3 EMRK kann indes nur angenommen werden, wenn die Verzögerung von der Beschwerdeführerin verschuldet ist und schon prima facie die Feststellung der Wahrheit verhindert. ${ }^{157}$ Wenn die Behörden auch ohne die ausdrückliche Meldung einer Misshandlung genügend Indizien für die Einleitung einer Untersuchung besessen hätten, können sie sich nicht auf eine verspätete Anzeige berufen. ${ }^{158}$ Unverschuldet ist die Verzögerung einer Anzeige auch dann, wenn einer in Haft befindlichen Person während längerer Zeit kein Zugang zur Außenwelt gewährt wird und sie sich insofern niemandem anvertrauen kann.

Im Fall Mindadze und Nemsitsverdidze v. Georgien hielt der EGMR in diesem Sinne fest, dass dem Beschwerdeführer nicht vorgeworfen werden könne, dreieinhalb Wochen mit den Misshandlungsvorwürfen zugewartet zu haben: ,[I]t is plausible that prior to that date he was discouraged from making any complaints as he had been left alone in the hands of police officers whom he directly accused of torture and of prison staff who, in his opinion, might have had close official links with the presumed perpetrators, all the time without any meaningful assistance from the outside world." ${ }^{159}$ Im Fall Zolotorev v. Russland hat der EGMR dem Beschwerdeführer umgekehrt vorgehalten, eine der behaupteten Misshandlungen nicht früher gemeldet zu haben, zumal er kurz nach dem angeblichen Vorfall mit seinen Anwälten Kontakt gehabt habe. ${ }^{160}$

ba. Beweiswürdigung und Begründungspflichten

Ist ein Verfahren eröffnet worden, das grundsätzlich den Anforderungen der Effektivität gerecht wird, ist erforderlich, dass die Behörden nicht vorschnell ${ }^{161}$ und ohne zureichende Begründung auf die Tatsachendarstellung der beschuldigten

\footnotetext{
${ }^{156}$ Interessant in diesem Zusammenhang auch EGMR (Große Kammer), Mocanu und andere v. Rumänien, Partly Dissenting Opinion Silvis (gefolgt von Streteanu), Ziff. 3. In Abweichung von der Gerichtsmehrheit war Richter Silvis der Meinung, dass der EGMR auf die Beschwerde nicht hätte eintreten dürfen, soweit sie den Beschwerdeführer Stoica betraf. Seiner Meinung nach wäre Stoica nämlich verpflichtet gewesen, die Misshandlungsvorwürfe den rumänischen Behörden zeitnaher zur Kenntnis zu bringen, ,,pour qu'ils [aurait pu] être tranchés correctement et equitablement“. Eine elfjährige Verspätung sei in dieser Hinsicht nicht zu akzeptieren.

${ }^{157}$ Vgl. EGMR, Urteil vom 4. April 2017, Thuo v. Zypern, § 128 (Vorliegen einer solchen Unmöglichkeit verneint). Ähnlich EGMR, Urteil vom 23. Juni 2016, Kulyk v. Ukraine, §§ 104-105 (einmonatige Verzögerung des Beschwerdeführers); EGMR, Urteil vom 31. Mai 2016, Beortegui Marinez v. Spanien, $\$ 43$ (Verzögerung von dreieinhalb Monaten).

${ }^{158}$ Vgl. EGMR, Urteil vom 30. April 2015, Shamardakov v. Russland, § 120, wo von einem ,climat d'indifférence générale" die Rede ist.

${ }^{159}$ Vgl. EGMR, Urteil vom 1. Juni 2017, Mindadze und Nemsitsverdidze v. Georgien, § 105.

${ }^{160}$ Vgl. EGMR, Urteil vom 19. September 2017, Zolotorev v. Russland, § 60.

${ }^{161}$ Vgl. beispielsweise EGMR, Urteil vom 31. Oktober 2017, M.F. v. Ungarn, § 52. Hier kam der EGMR zum Schluss, dass die innerstaatlichen Behörden die beschuldigten Beamten vorschnell entlastet hätten, weil deren Alibis nicht die ganze Zeit abdeckten, für die der Beschwerdeführer geltend machte, Übergriffen ausgesetzt gewesen zu sein.
} 
Beamtinnen und Beamten abstellen. ${ }^{162}$ Vorsicht in der Würdigung der Aussagen der involvierten Staatsoffiziellen ist insbesondere deshalb geboten, weil diese selbst alles Interesse daran haben, die Tatsachen in einem für sie günstigen Licht darzustellen. ${ }^{163}$ Schon im Grundsatz sollte daher vermieden werden, ihren Aussagen entscheidendes Gewicht beizumessen. ${ }^{164}$ Besondere Zurückhaltung drängt sich jedoch auf, wenn die Tatsachendarstellungen der beschuldigten Beamtinnen und Beamten selbst inkohärent sind, ${ }^{165} \mathrm{zu}$ anderen Beweismitteln im Widerspruch stehen ${ }^{166}$ oder wenn gewisse Beteiligte die Aussage verweigern und daher kein vollständiges Bild eines Vorfalls gezeichnet werden kann. ${ }^{167}$ Kaum Beweiswert haben auch Aussagen von Beamtinnen und Beamten, die bis in die Einzelheiten fast wörtlich übereinstimmen, zumal Absprachen in solchen Fällen offensichtlich sind. ${ }^{168}$ Im Fall Sitnikov v. Russland beanstandete der EGMR in Anwendung dieser Grundsätze, dass auf die Aussage des beschuldigten Ermittlers abgestellt worden war, obwohl dieser in offensichtlichem Widerspruch zu einem medizinischen Gutachten behauptet hatte, der Beschwerdeführer habe nach einer Einvernahme keine Anzeichen irgendwelcher Verletzungen aufgewiesen. ${ }^{169}$

Erforderlich ist so oder anders immer, dass die Darstellung einer Beschwerdeführerin jener der beschuldigten Beamtinnen und Beamten gegenübergestellt ${ }^{170}$ und

${ }^{162}$ Vgl. EGMR, Urteil vom 4. April 2017, Thuo v. Zypern, § 139; EGMR, Urteil vom 12. Oktober 2017, Tiziana Pennino v. Italien, § 49; EGMR, Urteil vom 14. September 2017, Matevosyan v. Armenien, § 77; EGMR, Urteil vom 14. Juni 2016, Stepanian v. Rumänien, § 72; EGMR, Urteil vom 27. Januar 2015, Ciorcan und andere v. Rumänien, § 143.

${ }^{163}$ van der Wilt/Lyngdorf, S. 53.

${ }^{164}$ Vgl. EGMR, Urteil vom 2. Mai 2017, Sitnikov v. Russland, § 36; EGMR, Urteil vom 6. Dezember 2016, Mikhail Nikolayev v. Russland, § 99. Das Abstellen auf deren Darstellung ist zwar nicht per se ausgeschlossen, bedarf jedoch einer vertieften Begründung; vgl. EGMR, Urteil vom 31. Mai 2016, Ersin Erkuş und andere v. Türkei, § 85; EGMR, Urteil vom 5. Januar 2016, Minikayev v. Russland, § 68 .

${ }^{165}$ Vgl. EGMR, Urteil vom 4. April 2017, Thuo v. Zypern, § 132; EGMR, Urteil vom 10. Oktober 2017, Tarjani v. Ungarn, § 57; EGMR, Urteil vom 2. Mai 2017, Olisov und andere v. Russland, $\S$ 84; EGMR, Urteil vom 12. Juli 2016, Gedrimas v. Litauen, § 82; EGMR, Urteil vom 12. November 2015, Rustam Khodzayev v. Russland, § 66.

${ }^{166}$ Vgl. EGMR, Urteil vom 15. Januar 2015, Lolayev v. Russland, § 87.

${ }^{167}$ Vgl. EGMR, Urteil vom 4. April 2017, Thuo v. Zypern, § 134.

${ }^{168}$ Vgl. EGMR, Urteil vom 4. Oktober 2016, Yusiv v. Litauen, § 73; EGMR, Urteil vom 5. Juli 2016, Rahmi Şahin v. Türkei, § 46; EGMR, Urteil vom 4. Februar 2016, Hilal Mammadov v. Aserbaidschan, § 96 .

${ }^{169}$ Vgl. EGMR, Urteil vom 2. Mai 2017, Sitnikov v. Russland, § 36. Vergleichbar EGMR, Urteil vom 6. Dezember 2016, Mikhail Nikolayev v. Russland, § 99.

${ }^{170}$ Vgl. EGMR, Urteil vom 10. Oktober 2017, Tarjani v. Ungarn, § 56, wo der EGMR eine unausgewogene Abwägung feststellte, weil die ungarischen Behörden zur Würdigung der Aussagen des Beschwerdeführers maßgeblich auf ein medizinisches Gutachten abgestellt hatten, das ihm für den Vorfallszeitpunkt ein fehlendes Erinnerungsvermögen infolge übermäßigen Alkoholkonsums attestierte, ohne aber darzulegen, wie ein solcher Schluss mehr als vier Monate nach dem Vorfall noch möglich wäre. 
substanziiert ${ }^{171}$ Stellung bezogen wird, warum eine der Darstellungen überzeugender erscheint als die andere. ${ }^{172}$ Dabei kann es durchaus auch als Argument gelten, dass eine Beschwerdeführerin im Verlauf des Verfahrens verschiedene Versionen zu Protokoll gegeben hat; nur muss dies auch ausdrücklich in der Würdigung der Beweismittel angeführt werden. ${ }^{173}$ Im Fall Mustafa Hajili v. Aserbaidschan war die prozedurale Verletzung von Art. 3 EMRK maßgeblich darauf zurückzuführen, dass in der Einstellungsverfügung des Strafverfahrens mit keinem Wort begründet worden war, warum auf die einsilbige Darstellung der Polizeibeamten abgestellt worden war anstatt auf die differenzierten Aussagen von zwei Zeugen, welche die Schilderungen des Beschwerdeführers stützten. ${ }^{174}$ In Yusiv v. Litauen war zwar eine medizinische Expertise eingeholt worden; der dortigen Feststellung, dass die Verletzungen des Beschwerdeführers durch Einsatz eines Knüppels verursacht worden seien, war jedoch in der weiteren Untersuchung - auch bei den Befragungen der beteiligten Polizisten - keinerlei Beachtung geschenkt worden. ${ }^{175}$

Bevor ein innerstaatliches Gericht zum Schluss kommt, dass die gegenüber einer Person angewendete Gewalt zulässig war, muss es zumindest festgestellt haben, welche Form von Gewalt angewendet worden ist ${ }^{176}$ und ob tatsächlich eine Situation gegeben war, in der es notwendig war, sich einer Person durch Gewalt zu behändigen. ${ }^{177}$ Aufgrund der Begründung eines Entscheids muss es möglich sein, die dokumentierten Verletzungen in ein Verhältnis zu setzen zum angeblichen körperlichen Widerstand einer in Polizeigewahrsam genommenen Person und zu den dokumentierten Maßnahmen der Beamtinnen und Beamten. ${ }^{178}$ Ganz allgemein wird vorausgesetzt, dass eine allfällige Einstellungsverfügung in einem Strafverfahren zumindest minimal begründet wird, ${ }^{179}$ was voraussetzt, dass sie eine plausible

\footnotetext{
${ }^{171}$ Verneint in EGMR, Urteil vom 12. Oktober 2017, Tiziana Pennino v. Italien, § 46, weil nicht spezifisch abgeklärt worden war, worauf die Fraktur des Fingers der Beschwerdeführerin zurückzuführen war.

${ }^{172}$ Vgl. EGMR, Urteil vom 4. April 2017, Thuo v. Zypern, § 136.

${ }^{173}$ Vgl. EGMR, Urteil vom 6. Juli 2017, Sadkov v. Ukraine, § 97.

${ }^{174}$ Vgl. EGMR, Urteil vom 24. November 2016, Mustafa Hajili v. Aserbaidschan, § 52.

${ }^{175}$ Vgl. EGMR, Urteil vom 4. Oktober 2016, Yusiv v. Litauen, § 72.

${ }^{176}$ Vgl. EGMR, Urteil vom 4. April 2017, Thuo v. Zypern, § 135.

${ }^{177}$ Vgl. EGMR, Urteil vom 24. Oktober 2017, Devyatkin v. Russland, §§ 33, 36; EGMR, Urteil vom 25. Juli 2017, Annenkov und andere v. Russland, § 98; EGMR, Urteil vom 5. Juli 2016, Eğitim ve Vilim Emekçileri Sendikasi und andere v. Türkei, § 83; EGMR, Urteil vom 28. April 2016, Balajevs v. Lettland, §§106-107.

${ }^{178}$ Vgl. EGMR, Urteil vom 25. Juli 2017, Annenkov und andere v. Russland, § 97; EGMR, Urteil vom 14. März 2017, Barysheva v. Ukraine, § 60; EGMR, Urteil vom 23. Februar 2016, Aleksandr Andreyev v. Russland, $\S 64$.

${ }^{179}$ Vgl. EGMR, Urteil vom 6. Juli 2017, Sadkov v. Ukraine, § 94; nicht genügend war insofern der vage Verweis auf ein „Handgemenge“, weil aufgrund medizinischer Berichte anzunehmen war, dass der Beschwerdeführer Schläge und Tritte an Kopf und Oberkörper erlitten hatte. Vgl. auch EGMR, Urteil vom 13. November 2014, Cüneyt Polat v. Türkei, § 43.
} 
Erklärung für allfällig erlittene Verletzungen enthält ${ }^{180}$ und sich zumindest rudimentär zur Verhältnismäßigkeit polizeilicher Gewaltanwendung äußert. ${ }^{181}$ Dieser Vorgabe ist nicht Genüge getan, wenn lediglich Standardformulare verwendet werden, die kaum einen Bezug zum jeweiligen Einzelfall aufweisen. ${ }^{182}$

Auch eine antizipierte Beweiswürdigung in Form der Abweisung eines vom behaupteten Opfer gestellten Beweisantrags bedarf zumindest einer summarischen Begründung. ${ }^{183}$ Im Fall Nasrettin Aslan und Zeki Aslan v. Türkei beispielsweise hat der EGMR die türkischen Behörden dafür gerügt, dass sie die plausiblen Beweisanträge der Beschwerdeführenden einfach mit der Begründung abgewiesen hatten, diese seien weder notwendig noch nützlich. ${ }^{184}$

\section{ca. Beteiligung des Opfers am Verfahren}

Wiederholt hat der EGMR es schließlich für problematisch erachtet, wenn ein Strafverfahren wegen möglichen Übergriffen von Staatsoffiziellen unter Ausschluss des Opfers stattfand und damit einer „öffentlichen Kontrolle“ entzogen wurde. ${ }^{185} \mathrm{Im}$ Fall Zinovchik v. Russland bemängelte er in diesem Sinne, dass dem Beschwerdeführer während des laufenden Strafverfahrens keine Einsicht in die Ermittlung gewährt worden war; zudem war dieser über die vorläufige Suspendierung des Verfahrens nur mit maßgeblicher Verspätung unterrichtet worden. ${ }^{186}$ Generell ist das Resultat einer Strafuntersuchung deshalb ohne Verzug auch dem möglichen Opfer eines Übergriffs mitzuteilen. ${ }^{187}$ Die Beteiligung des möglichen Opfers am innerstaatlichen Verfahren hat in Bezug auf die Feststellung der maßgeblichen Tatsachen eine Kontrollfunktion.

\section{c. Allgemeine Leitsätze}

Die eben dargelegten Grundsätze beziehen sich spezifisch auf Fälle, in denen die konventionsrechtliche Zulässigkeit einer Abschiebung beziehungsweise von (körperlichem) Zwang von Staatsoffiziellen zu beurteilen ist. Sie lassen sich deshalb

\footnotetext{
${ }^{180}$ Vgl. EGMR, Urteil vom 14. März 2017, Barysheva v. Ukraine, § 60; EGMR, Urteil vom 16. Februar 2016, Caracet v. Moldawien, $\S 44$.

${ }^{181}$ Vgl. EGMR, Urteil vom 26. Januar 2016, Alpar v. Türkei, § 49.

${ }^{182}$ EGMR, Urteil vom 12. Oktober 2017, Tiziana Pennino v. Italien, § 52.

${ }^{183}$ EGMR, Urteil vom 12. Oktober 2017, Tiziana Pennino v. Italien, § 53; EGMR, Urteil vom 31. Mai 2016, Beortegui Marinez v. Spanien, § 40; EGMR, Urteil vom 4. Februar 2016, Hilal Mammadov v. Aserbaidschan, § 96; EGMR, Urteil vom 5. Mai 2015, Arratibel Garciandia v. Spanien, $\S 38$.

${ }^{184}$ Vgl. EGMR, Urteil vom 30. August 2016, Nasrettin Aslan und Zeki Aslan v. Türkei, § 57.

${ }^{185}$ Vgl. beispielsweise EGMR, Urteil vom 4. Februar 2016, Hilal Mammadov v. Aserbaidschan, § 97.

${ }^{186} \mathrm{Vgl}$. EGMR, Urteil vom 9. Februar 2016, Zinovchik v. Russland, §§ 62-64. Ähnlich EGMR, Urteil vom 26. November 2015, Basenko v. Ukraine, §§ 68-71.

${ }^{187}$ EGMR, Urteil vom 12. November 2015, Rustam Khodzayev v. Russland, $\S 68$.
} 
nicht unbesehen auf andere Fallkonstellationen übertragen. Abstrakt gesprochen ist jedoch in diesen wie in anderen Fällen erforderlich, ,[que] les autorités [entreprennent toutes] [1]es démarches appropriées pour établir ce qui s'est passé [...]." ${ }^{\text {"188 In }}$ Refoulement-Fällen geht es dabei weniger um Vorfälle in der Vergangenheit als um eine Risikoprognose für die Zukunft. Die Grundaussage bleibt jedoch dieselbe: Es sind alle angemessenen verfahrensrechtlichen Schritte anzuordnen, die zur Erhellung des rechtserheblichen Sachverhalts beitragen können; und die innerstaatlichen Urteile sind (auch) in Bezug auf den maßgeblichen Sachverhalt angemessen zu begründen. ${ }^{189}$ Was dabei als angemessen anzusehen ist, ergibt sich aus den konkreten Umständen des Einzelfalls und lässt sich nur schwerlich generalisieren.

Veranschaulichen lässt sich dieser Gedanke beispielsweise an der Entwicklung neuer technischer Hilfsmittel, die zur Untersuchung (auch) von Konventionsverletzungen herangezogen werden können. Weil es heute üblich ist, gewisse Teile von Haftanstalten mit Video zu überwachen, verlangt der EGMR zu Recht, dass im Rahmen der Untersuchung möglicher Übergriffe gegenüber Häftlingen bestehende Videoaufnahmen zu konsultieren sind. ${ }^{190}$ Nicht alle technischen Hilfsmittel sind jedoch derart einfach und kostengünstig zugänglich wie Videoaufnahmen. In diesem Sinne stellt sich bei der Prüfung der Angemessenheit einer Untersuchungsmaßnahme wohl auch eine Machbarkeits- und Kostenfrage. Unter dem Blickwinkel von Art. 3 EMRK kann man sich beispielsweise mit guten Gründen die Frage stellen, ob zur Untersuchung eines (privaten) Übergriffs ${ }^{191}$ zwingend ein Antennensuchlauf durchzuführen ist, der ohne weiteres mehrere hunderttausend Franken kosten kann. ${ }^{192}$ Antworten auf solche Fragen ergeben sich aus der Rechtsprechung des EGMR vorderhand nicht.

Jedenfalls steigen aber die Anforderungen mit der Schwere der behaupteten Konventionsverletzung. ${ }^{193} \mathrm{Je}$ schwerer eine mögliche Konventionsverletzung wiegt, desto eher ist die Angemessenheit (und Erforderlichkeit) auch komplexer und weitreichender Untersuchungen zu bejahen. Dies zeigt sich beispielsweise an der

\footnotetext{
${ }^{188}$ Vgl. statt vieler EGMR, Urteil vom 19. September 2017, Zolotorev v. Russland, § 48.

${ }^{189} \mathrm{Vgl}$. allgemein zur Begründungspflicht Müller Amrei, S. $23 \mathrm{ff}$.

${ }^{190}$ Vgl. EGMR, Urteil vom 5. Oktober 2017, Ostrovenecs v. Lettland, § 77; EGMR, Urteil vom 2. Mai 2017, Sitnikov v. Russland, § 36; EGMR, Urteil vom 24. November 2016, Mustafa Hajili v. Aserbaidschan, § 51 .

${ }^{191}$ Vgl. zur Anwendbarkeit von Art. 3 EMRK in diesem Kontext oben, I. D. 3.

${ }^{192}$ Vgl. Urteil des BVGer A-5625/2016 vom 20. Dezember 2017. Das Urteil betraf einen von der StA des Kantons Aargau beim EJPD in Auftrag gegebenen Antennensuchlauf im Zusammenhang der Untersuchung eines in der Schweiz medial stark beachteten Tötungsdelikts. Für den Antennensuchlauf wurde der zuständigen Staatsanwaltschaft eine Rechnung über Fr. 631.200.- gestellt. Tötungsdelikte fallen zwar nicht in den Anwendungsbereich von Art. 3 EMRK, wohl aber sexuelle Übergriffe, für welche ähnliche Untersuchungsmaßnahmen auch schon angeordnet worden sind; vgl. beispielsweise Medienmitteilung StA Luzern zum Emmener Vergewaltigungsfall.

${ }^{193}$ Vgl. EGMR (Große Kammer), Urteil vom 4. Juli 2006, Ramirez Sanchez v. Frankreich, § 165, wo aufgrund der schwerwiegenden Auswirkungen von Isolationshaft auf die Haftbedingungen eine justizielle Behörde für die Überprüfung der vorgebrachten Konventionsverletzung verlangt wird.
} 
Rechtsprechung zu enforced-disappearance-Fällen: Die Durchführung einer umfassenden Untersuchung hat hier besondere Bedeutung, weil häufig erst die fehlende Dokumentation beziehungsweise der fehlende (politische) Wille zu einer (nachträglichen) Rekonstruktion der Geschehnisse das Klima schafft, dass Personen unter Mitwirkung von Staatsoffiziellen verschwinden. ${ }^{194}$ Völlig zu Recht hält der EGMR vor diesem Hintergrund fest, allein die Unterlassung einer flächendeckenden ordnungsgemäßen Dokumentierung von Inhaftierungen ,,must be considered a most serious failing, since it enables those responsible [...] to conceal their involvement in a crime, to cover their tracks and to escape accountability for the fate of the detainee. “195

Auch diese prozedurale Verpflichtung bezieht sich freilich konkret auf enforceddisappearance-Fälle und kann nicht generalisiert werden. Nachfolgend soll deshalb der Blick weg vom konkreten Inhalt der konstellationsabhängigen Untersuchungspflichten unter der EMRK hin zum (generellen) subsidiaritätsrechtlichen Zusammenhang zwischen der Qualität des innerstaatlichen Verfahrens und dem Kontrollmaßstab des EGMR gerichtet werden.

\section{Variabler Kontrollmaßstab des EGMR bezüglich der innerstaatlichen Tatsachenfeststellung}

Das Beweisrecht des EGMR ist in der EMRK und der EGMR-VerfO nur rudimentär geregelt. ${ }^{196}$ Art. 38 EMRK sieht lediglich vor, ,[que] [1]a Cour examine l'affaire de façon contradictoire avec les représentants des parties et, s'il y a lieu, procède à une enquête pour la conduite efficace de laquelle les Hautes Parties contractantes intéressées fourniront toutes facilités nécessaires“. Daraus lässt sich ableiten, dass im Verfahren vor dem EGMR der Untersuchungsgrundsatz gilt; der EGMR ist also nicht an die von den Parteien eingereichten Beweismittel gebunden, sondern vielmehr befugt, sämtliche Massnahmen anzuordnen, die er zur Klärung des Sachverhalts für nötig erachtet. ${ }^{197}$ Im Rahmen solcher Anordnungen sind die Konventionsstaaten gehalten, dem EGMR auf Verlangen hin Akten zu edieren. ${ }^{198}$

Im Übrigen hat der EGMR das Beweisrecht im Wesentlichen durch seine Rechtsprechung entwickelt ${ }^{199}$ und dabei immer wieder hervorgehoben, dass es in einem engen Konnex zu seiner Funktion stehe; allein deshalb kann das anwendbare Beweisrecht nicht mit den allgemeinen straf- oder zivilprozessualen Beweisregeln

\footnotetext{
${ }^{194}$ van der Wilt/Lyngdorf, S. $54 \mathrm{f}$.

${ }^{195}$ Vgl. EGMR, Urteil vom 5. April 2007, Baysayeva v. Russland, § 146.

${ }^{196} \mathrm{Vgl}$. dazu schon oben, II. C. 2.

${ }^{197} \mathrm{Vgl}$. auch Schabas, S. 805.

${ }^{198}$ Vgl. beispielsweise EGMR, Urteil vom 26. Januar 2017, Khamidkariyev v. Russland, §§ 105-107.

${ }^{199} \mathrm{Vgl}$. überblicksweise zum Beweisrecht des EGMR Jötten, S. 136 ff.
} 
insbesondere des common law ${ }^{200}$ verglichen werden. ${ }^{201}$ Eine prägnante Zusammenfassung der anwendbaren Grundsätze zum Beweismass, zur Beweiswürdigung, zur Zulässigkeit von Beweismitteln und zur Beweislast findet sich im Urteil Nasr und Ghali v. Italien:

„[La Cour] rappelle que, pour l'appréciation des éléments de preuve, elle retient le critère de la preuve «au-delà de tout doute raisonnable». [...]. Dans le cadre de la procédure devant elle, il n'existe aucun obstacle procédural à la recevabilité d'éléments de preuve ni de formules prédéfinies applicables à leur appréciation. Elle adopte les conclusions qui, à son avis, se trouvent étayées par la libre appréciation de l'ensemble des éléments de preuve, y compris les déductions qu'elle peut tirer des faits et des observations des parties. Conformément à sa jurisprudence constante, la preuve peut résulter d'un faisceau d'indices, ou de présomptions non réfutées, suffisamment graves, précis et concordants. En outre, le degré de conviction nécessaire pour parvenir à une conclusion particulière et, à cet égard, la répartition de la charge de la preuve sont intrinsèquement liés à la spécificité des faits, à la nature de l'allégation formulée et au droit conventionnel en jeu. La Cour est également attentive à la gravité d'un constat selon lequel un État contractant a violé des droits fondamentaux [...]. Par ailleurs, la Cour rappelle que la procédure prévue par la Convention ne se prête pas toujours à une application rigoureuse du principe affirmanti incumbit probatio [...]. Elle renvoie à sa jurisprudence relative aux articles 2 et 3 de la Convention selon laquelle, lorsque les événements en cause sont connus exclusivement des autorités, comme dans le cas des personnes soumises à leur contrôle en garde à vue, tout dommage corporel ou décès survenu pendant cette période de détention donne lieu à de fortes présomptions de fait. La charge de la preuve pèse dans ce cas sur les autorités, qui doivent fournir une explication satisfaisante et convaincante. En l'absence d'une telle explication, la Cour est en droit de tirer des conclusions pouvant être défavorables au gouvernement défendeur [...]. “202

Subsidiaritätsrechtlich ist überdies insbesondere von Interesse, über welche „Kognition“ der EGMR in Tatsachenfragen gegenüber den nationalen Instanzen verfügt. ${ }^{203}$ Aufgrund des Fehlens konkreterer Vorgaben der EMRK beziehungsweise der EGMR-VerfO muss sich der EGMR diesbezüglich massgeblich am Subsidiaritätsgrundsatz orientieren. Als Strukturmerkmal der EMRK durchzieht dieser nämlich die Rechtsprechungstätigkeit des EGMR querschnittsartig und findet auch und gerade auf seine Tatsachenfeststellungsfunktion Anwendung. ${ }^{204}$

\footnotetext{
${ }^{200} \mathrm{Vgl}$. dazu auch Loucaides, S. $1433 \mathrm{ff}$.

${ }^{201}$ Vgl. beispielsweise EGMR, Urteil vom 23. Februar 2016, Nasr und Ghali v. Italien, § 219: ,[La Cour] n'a toutefois jamais eu pour dessein d'emprunter la démarche des ordres juridiques nationaux qui appliquent ce critère. Il lui incombe de statuer non pas sur la culpabilité en vertu du droit pénal ou sur la responsabilité civile, mais sur la responsabilité des États contractants au regard de la Convention. La spécificité de la tâche que lui attribue l'article 19 de la Convention - assurer le respect par les Hautes Parties contractantes de leur engagement consistant à reconnaître les droits fondamentaux consacrés par cet instrument - conditionne sa façon d'aborder les questions de preuve."

${ }^{202}$ Vgl. EGMR, Urteil vom 23. Februar 2016, Nasr und Ghali v. Italien, §§ 219-220.

${ }^{203}$ Dem hier verwendeten Begriff der „Kognition“ ist insofern mit Vorsicht zu begegnen, als es sich beim EGMR nicht um ein Instanzengericht der nationalen Gerichte handelt; vgl. dazu auch oben, I. A.

${ }^{204} \mathrm{Vgl}$. dazu oben, II. C. 2. und III. B. 4. und IV. 1.
} 
Aus subsidiaritätsrechtlicher Sicht kommt dabei als Kriterium für die Festlegung der Kontrolldichte nur die Qualität des innerstaatlichen Verfahrens in Frage. $^{205}$

Vor der materiellen Beurteilung eines Falls prüft der EGMR in diesem Sinne oftmals, ob die innerstaatlichen Behörden in ihren Verfahren die prozeduralen Anforderungen eingehalten haben, die sich namentlich aus Art. 3 oder Art. 13 EMRK ergeben. ${ }^{206}$ Ist den prozeduralen Vorgaben von Art. 3 und Art. 13 EMRK im innerstaatlichen Verfahren Genüge getan worden, stellt der EGMR in der Regel auf die Tatsachenfeststellung der nationalen Gerichte ab und korrigiert diese nur im Falle offensichtlicher Unrichtigkeit. ${ }^{207}$ Sind die nationalen Gerichte der ihnen primär zugewiesenen Aufgabe einer methodisch nachvollziehbaren Tatsachenfeststellung hingegen nur unzureichend oder überhaupt nicht nachgekommen, liegen jene „Zwingenden Gründe“ vor, die gebieten, dass der EGMR eingreift und eigene Feststellungen trifft. ${ }^{208}$

Soweit ein innerstaatliches Verfahren stattgefunden hat, liegen dem EGMR in der Regel immerhin gewisse Beweise vor; zur Gewährleistung eines effektiven Schutzes der Konventionsrechte genügt in solchen Fällen oftmals eine neuerliche Prüfung der bereits innerstaatlich erhobenen Beweismittel. ${ }^{209}$ Die Ausgangslage präsentiert sich insoweit anders, wenn die nationalen Behörden und Gerichte die Eröffnung eines Verfahrens ganz verweigert haben. In solchen Fällen findet die Tatsachenfeststellung durch den EGMR gewissermassen im „luftleeren“ Raum und alleine aufgrund der Beweismittel statt, welche die Beschwerdeführerin einreichen konnte. Eine gewisse Abhilfe schafft in solchen Fällen der Untersuchungsgrundsatz, der es dem EGMR erlaubt, proprio motu weitere (öffentlich zugängliche) Informationen zu verarbeiten. Angesichts der dennoch eingeschränkten Beweiserhebungsmöglichkeiten des EGMR erfordert diese Spezialsituation kompensatorische beweisrechtliche Instrumente, welche der EGMR auf dem Wege der Rechtsprechung im Verlaufe der Zeit entwickelt hat. ${ }^{210}$

Zur Veranschaulichung der angedeuteten Zusammenhänge genügt es vorderhand, die Rechtsprechung des EGMR zu den oben schon in den Vordergrund gerückten Abschiebungs- und Polizeigewaltfällen zu untersuchen. Die Frage des abstrakten Gehalts dieser Rechtsprechung und ihrer Ausweitung auf weitere Fallkonstellationen wird jedoch im Schlussteil der vorliegenden Arbeit noch aufzugreifen sein. ${ }^{211}$

\footnotetext{
${ }^{205}$ Vgl. dazu oben, IV. A.

${ }^{206}$ EGMR, Urteil vom 6. Juli 2017, Sadkov v. Ukraine, § 90, mit zahlreichen Hinweisen auf die Rechtsprechung. Vgl. auch EGMR, Urteil vom 28. Juni 2016, Kulyk v. Ukraine, § 75.

${ }^{207} \mathrm{Vgl}$. dazu nachfolgend, IV. C. 1.

${ }^{208} \mathrm{Vgl}$. dazu oben, IV. A.

${ }^{209} \mathrm{Vgl}$. dazu nachfolgend, IV. C. 2.

${ }^{210} \mathrm{Vgl}$. dazu nachfolgend, IV. C. 3.

${ }^{211} \mathrm{Vgl}$. nachfolgend, VI.
} 


\section{Willkürkontrolle}

In verschiedenen in jüngerer Zeit entschiedenen Refoulement-Fällen kommt die prozedurale Herangehensweise des EGMR besonders gut zum Ausdruck. Anstatt aufgrund einer eigenständigen Feststellung des rechtserheblichen Sachverhalts eine neuerliche Prognoseentscheidung zu treffen, prüfte der EGMR mitunter lediglich, ob das innerstaatliche Verfahren den oben herausgearbeiteten prozeduralen Anforderungen genügt hatte und unterzog die innerstaatlich festgestellten Tatsachen dann nur noch einer Willkürprüfung. Ausdrücklich geht dies aus dem Urteil im Fall Sow v. Belgien hervor:

„[...] [L]a Cour note qu'après un examen circonstancié et approfondi de la première demande d'asile, les instances compétentes ont conclu, d'une part, que le récit de la requérante n'était pas crédible et, d'autre part, qu'elle ne courait pas de risque d'être soumise à une ré-excision en cas de renvoi vers la Guinée. Pour arriver à une telle conclusion, le CGRA s'est basé notamment sur un rapport duquel il ressortait que la ré-excision n'était pratiquée que dans des cas déterminés en Guinée, dans lesquels la requérante ne tombait pas. En outre, sur ce point, le CCE considéra que la requérante n'avait fourni aucune information ou indication crédible ou un quelconque commencement de preuve pour établir sa crainte [...]. La Cour ne voit aucun élément du dossier ou des rapports internationaux sur la situation générale en Guinée consultés [...] permettant de penser que les conclusions auxquelles sont parvenues les instances d'asile nationales en l'espèce étaient arbitraires ou manifestement déraisonnables. " 212

Inhaltlich entspricht der im letzten Satz dieser Urteilspassage ausdrücklich verwendete Willkürmaßstab dem Vorgehen des EGMR in verschiedenen weiteren Fällen. Im Fall R.M. und andere v. Frankreich, der die Wegweisung abgewiesener tschetschenischer Asylsuchender nach Russland zum Gegenstand hatte, äusserte der EGMR in diesem Sinne, dass es angesichts der überaus detailliert begründeten Entscheidungen der innerstaatlichen Instanzen nicht seiner Funktion entspreche, „de substituer sa propre vision des faits à celle des juridictions internes. "213 In einem jüngeren Schweizer Fall zur Zulässigkeit einer Wegweisung nach Eritrea hat der EGMR in ähnlicher Art und Weise festgehalten, dass die innerstaatlichen Tatsachenfeststellungen adäquat erschienen, ausreichend begründet seien und sich auf aussagekräftige Länderinformationen stützten; die innerstaatliche Entscheidung sei deshalb zu stützen. ${ }^{214}$ Auch im Fall Nasr und Ghali v. Italien, der die Verschleppung eines ägyptischen Staatsangehörigen durch die CIA zum Gegenstand hatte, stellte der EGMR im Wesentlichen auf die Feststellungen der italienischen Gerichte ab. ${ }^{215}$ Völlig zu Recht hielt er fest, dass sich die Beschwerdesache massgeblich von den Fällen El-Masri v. Mazedonien, Husayn (Abu Zubaydah) v. Polen und Nashiri v. Polen unterscheide,

\footnotetext{
${ }^{212}$ Vgl. EGMR, Urteil vom 19. Januar 2016, Sow v. Belgien, § 66.

${ }^{213}$ Vgl. EGMR, Urteil vom 12. Juli 2016, R.M. und andere v. Frankreich, § 55.

${ }^{214}$ Vgl. EGMR, Urteil vom 20. Juni 2017, M.O. v. Schweiz, § 80. Ähnlich in der Formulierung EGMR, Urteil vom 19. Dezember 2017, A. v. Schweiz, § 45 sowie EGMR, Urteil vom 10. September 2015, R.H. v. Schweden, § 61 .

${ }^{215}$ Vgl. EGMR, Urteil vom 23. Februar 2016, Nasr und Ghali v. Italien, §§ 231-234.
} 
,[parce que] les faits de la cause ont fait l'objet d'une reconstitution par les juridictions nationales. " ${ }^{216}$ Es dürfte keinem Zufall entsprechen, dass im Rahmen so begründeter Urteile zuweilen der Subsidiaritätsgrundsatz referenziert wird. ${ }^{217}$

Der Willkürmaßstab in Bezug auf die Tatsachengrundlagen kommt freilich nicht nur in Abschiebungsfällen, sondern auch in Fällen von Polizeigewalt zum Tragen. Im Fall Morgoci v. Moldawien benannte der EGMR den angewendeten Maßstab zwar nicht; aufgrund der knappen Begründung des Urteils ist jedoch klar, dass er in der Substanz einfach auf die Feststellungen der moldawischen Gerichte abstellte, was auch deshalb unproblematisch war, weil bereits diese die Misshandlung des Beschwerdeführers anerkannt hatten. ${ }^{218}$ Auch in seinen Urteilen zur Polizeigewalt anlässlich des G8-Gipfels in Genua im Jahr 2001 hat der EGMR ohne grosses Hinterfragen auf die Tatsachen abgestellt, die bereits von den italienischen Gerichten festgestellt worden waren. Dabei spielte wohl auch eine Rolle, dass sowohl die Beschwerdeführenden als auch die italienische Regierung diese Feststellungen akzeptierten und der Streit sich im Wesentlichen um die Frage drehte, ob die strafrechtliche Aufarbeitung durch die italienischen Behörden als effektiv angeschaut werden konnte. Der EGMR hat aber ausdrücklich darauf hingewiesen, dass die Tatsachenfeststellungen der italienischen Gerichte differenziert ausgefallen und gut begründet worden seien ${ }^{219}$ und deshalb keine triftigen Gründe für eine Abweichung vom innerstaatlich festgestellten Sachverhalt bestünden. ${ }^{220}$

Dies legt nahe, dass der Willkürmaßstab auch in Fällen von Polizeigewalt nicht nur zugunsten, sondern auch zulasten einer Beschwerdeführerin Anwendung finden kann. Bestätigt wird diese These durch den Fall Józef Woś v. Polen, in dem der EGMR der Einschätzung der innerstaatlichen Gerichte unter anderem deshalb zustimmte, weil in seinem eigenen Verfahren keine Beweise beigebracht worden waren, welche die Schlüsse der innerstaatlichen Instanzen hätten in Frage stellen können. ${ }^{221}$ Interessant ist diese materielle Bewertung insbesondere vor dem Hintergrund der prozeduralen Erwägung, ,[that] there [is no] indication that the prosecutor used his statutory discretion - which allows him to evaluate the material before him in order to decide whether or not to charge the alleged perpetrators with a criminal offence - in an arbitrary manner." ${ }^{\text {222 }}$

\footnotetext{
${ }^{216}$ Vgl. EGMR, Urteil vom 23. Februar 2016, Nasr und Ghali v. Italien, § 228.

${ }^{217}$ Vgl. EGMR, Urteil vom 20. Juni 2017, M.O. v. Schweiz, § 80: „Having regard to the above, and reiterating that the Convention system is founded on the principle of subsidiarity, and that it is not the Court's task to substitute its own assessment of the facts for that of the domestic courts, which are, as a general principle, best placed to assess the evidence before them, the Court is satisfied that the assessment made by the domestic authorities was adequate, sufficiently reasoned, and supported by material originating from reliable and objective sources [...]. It endorses the assessment by the Swiss authorities that the applicant failed to substantiate that he would face a real risk of being subjected to treatment contrary to Article 3 of the Convention if forced to return to Eritrea."

${ }^{218}$ Vgl. EGMR, Urteil vom 12. Januar 2016, Morgoci v. Moldawien, § 57.

${ }^{219}$ Vgl. EGMR, Urteil vom 22. Juni 2017, Bartesaghi Gallo und andere v. Italien, § 114.

${ }^{220} \mathrm{Vgl}$. beispielsweise EGMR, Urteil vom 26. Oktober 2017, Blair und andere v. Italien, $\S 96$.

${ }^{221}$ Vgl. EGMR, Urteil vom 28. Juni 2016, Józef Woś v. Polen, § 45.

${ }^{222}$ Vgl. EGMR, Urteil vom 28. Juni 2016, Józef Woś v. Polen, § 54.
} 
Teilweise wird in der Rechtsprechung neben dem Willkürmaßstab das Kriterium der offensichtlichen Unrichtigkeit (manifestly unreasonable) als Schwelle für eine Abweichung vom innerstaatlich festgestellten Sachverhalt herangezogen. ${ }^{223}$ So oder anders dürfte die Schwelle für eine Abweichung aber sehr hoch angesetzt sein, wenn das innerstaatliche Verfahren den prozeduralen Vorgaben der EMRK entsprochen hat. Angelehnt an die Rechtsprechung des Bundesgerichts, dessen Kognition in Bezug auf Tatsachenfragen im Wesentlichen ebenfalls auf eine Willkürprüfung beschränkt ist (Art. 105 Abs. 2 BGG), lässt sich sagen, dass es für eine Abweichung vom innerstaatlich festgestellten Sachverhalt jedenfalls nicht genügt, dass eine andere Würdigung ebenfalls vertretbar erscheint. ${ }^{224}$

\section{De-novo-Prüfung der innerstaatlich festgestellten Tatsachen}

Anders präsentiert sich die Rechtslage, wenn das innerstaatliche Verfahren den prozeduralen Vorgaben aus Art. 3 und Art. 13 EMRK hinsichtlich der Tatsachenfeststellung nicht genügt hat. In einer Concurring Opinion ist kürzlich ausgeführt worden, dass für den EGMR nur dann Anlass besteht, die innerstaatlichen Sachverhaltsfeststellungen erneut einer vollumfänglichen Prüfung zu unterziehen, ,when the national authorities have not conducted a Convention-compliant assessment of the concrete circumstances of the case [...]." ${ }^{\text {225 }}$ Das Urteil betraf dabei einen Abschiebungsfall, in dem eine solche de-novo-Prüfung schließlich durchgeführt wurde.

\section{a. Anwendungsbereich der de-novo-Prüfung}

Im Lichte der obenstehenden Ausführungen zu den Implikationen des Subsidiaritätsgrundsatzes für die Tatsachenfeststellungsfunktion des EGMR ${ }^{226}$ besteht jedoch kein Grund, den beschriebenen Mechanismus auf Refoulement-Fälle zu beschränken. Bevor der EGMR die innerstaatlichen Sachverhaltsfeststellungen erneut einer vollumfänglichen Prüfung unterzieht, muss er demnach ganz generell zum Schluss kommen, dass die nationalen Behörden den prozeduralen Garantien der EMRK bei

\footnotetext{
${ }^{223}$ Vgl. beispielsweise EGMR, Urteil vom 2. Mai 2017, Golubar v. Kroatien, § 43 und EGMR, Urteil vom 20. Oktober 2015, Balázs v. Ungarn, § 75. Ersterer Fall betraf die Frage, ob die medizinische Versorgung eines Häftlings konventionsrechtlich adäquat gewesen sei, letzterer einen womöglich rassistisch motivierten Übergriff Privater. Im Entwurf zu einer Kopenhagen-Erklärung ist ganz Allgemein von „strong reaons“ die Rede (vgl. dort Ziff. 24).

${ }^{224}$ Vgl. statt vieler Urteil des BGer 6B_701/2017 vom 12. Januar 2018, E. 1.2 und 2.3 (m.w.H. auf die Rechtsprechung).

${ }^{225}$ Vgl. EGMR (Große Kammer), Urteil vom 23. August 2016, J.K. v. Schweden, Concurring Opinion Bianku.

${ }^{226} \mathrm{Vgl}$. oben, IV. A.
} 
der Feststellung des massgeblichen Sachverhalts nicht vollumfänglich Rechnung getragen haben. ${ }^{227}$

Sobald dies aber der Fall ist, ist der EGMR nicht nur berechtigt, sondern sogar verpflichtet, sämtliche ihm vorliegenden Beweismittel im Hinblick auf die in Frage stehende Konventionsverletzung einer neuerlichen Prüfung zuzuführen. Dabei kann kaum gefordert werden, dass lediglich die konkrete Unzulänglichkeit des innerstaatlichen Verfahrens ausgebessert werde; abgesehen davon, dass dies oftmals praktisch gar nicht möglich ist, ${ }^{228}$ muss aufgrund der gegenseitigen Abhängigkeit der verschiedenen beweisrechtlichen Teilschritte in jedem Fall eine neue Gesamtwürdigung aller Beweismittel Platz greifen.

In der konkludenten Umsetzung dieses Maßstabs äussert sich der EGMR bei Vorliegen einer prozeduralen Verletzung von Art. 3 oder Art. 13 EMRK in der Regel relativ ausführlich zum massgeblichen Sachverhalt und wendet mitunter spezifische Beweislastregeln an. Zum Beleg dieser These könnten alleine zu Art. 3 EMRK mehrere dutzend Urteile aus jüngerer Zeit zitiert werden. ${ }^{229}$ Für die Zwecke der vorliegenden Arbeit genügt es indessen, den Mechanismus nachfolgend anhand zweier besonders einprägsamer Fälle darzustellen.

\section{b. Darstellung des Wirkungsmechanismus am Beispiel zweier Fälle}

Der Fall M.A. v. Schweiz betraf die Wegweisung eines Iraners in seinen Heimatstaat. ${ }^{230}$ M.A. war 2011 in die Schweiz gelangt und hatte dort ein Asylgesuch gestellt. ${ }^{231} \mathrm{Er}$ begründete dieses im Wesentlichen damit, sich nach den iranischen Präsidentschaftswahlen vom 12. Juni 2009 bis im März 2011 verschiedentlich an regimekritischen Demonstrationen beteiligt und dabei auch gewisse organisatorische

\footnotetext{
${ }^{227}$ Es würde sich für den EGMR deshalb generell aufdrängen, die Frage einer materiellen Verletzung von Art. 3 EMRK erst nach der Frage einer prozeduralen Verletzung von Art. 3 EMRK oder von Art. 13 EMRK zu prüfen. Der EGMR folgt dieser Denklogik freilich nicht immer; vgl. beispielsweise zuletzt EGMR, Urteil vom 31. Oktober 2017, M.F. v. Ungarn.

${ }^{228} \mathrm{Vgl}$. Keller/Heri, S. 741, die darauf hinweisen, dass es dem EGMR beispielsweise nicht möglich ist, Zeuginnen und Zeugen verbindlich vorzuladen. Auch abgesehen davon sind die Möglichkeiten des EGMR zur Erhebung von Beweismitteln stark beschränkt. Um nur zwei weitere Beispiele zu nennen: Die versäumte ärztliche Untersuchung kann Jahre nach einem behaupteten Übergriff nicht mehr sinnvoll nachgeholt werden; auch die mangelhafte Befragung einer Asylsuchenden zu einer möglichen Verfolgung im Heimatstaat kann auf Ebene des EGMR kaum sinnvoll durchgeführt werden.

${ }^{229}$ Vgl. statt vieler EGMR, Urteil vom 5. Oktober 2017, Ostrovenecs v. Lettland; EGMR, Urteil vom 19. September 2017, Zolotorev v. Russland; EGMR, Urteil vom 25. Juli 2017, Smolentsev v. Russland; EGMR, Urteil vom 6. Juli 2017, Sadkov v. Ukraine; EGMR, Urteil vom 2. Mai 2017, Olisov und andere v. Russland; EGMR, Urteil vom 2. Mai 2017, Sitnikov v. Russland; EGMR, Urteil vom 2. Mai 2017, Kondakov v. Russland; EGMR, Urteil vom 11. April 2017, Morgunov v. Russland; EGMR, Urteil vom 4. April 2017, Thuo v. Zypern.

${ }^{230}$ Vgl. EGMR, Urteil vom 18. November 2014, M.A. v. Schweiz.

${ }^{231}$ Vgl. zum Sachverhalt EGMR, Urteil vom 18. November 2014, M.A. v. Schweiz, §§ 7-24 und Urteil des BVGer D-2785/2013 vom 2. Juli 2013, S. 2-4.
} 
Aufgaben übernommen zu haben. Im März 2011 seien verschiedene seiner Freunde verhaftet und im Gewahrsam der iranischen Sicherheitskräfte misshandelt worden. Er selbst sei am 10. Mai 2011 einer Verhaftung durch den Nachrichtendienst Ettelaad an seinem Wohnort in Karaj nur deshalb entgangen, weil er zufällig bei seiner Schwester in Teheran zu Besuch gewesen sei. Einer Gerichtsvorladung für den 12. Mai 2011 habe er aus Angst vor einer Inhaftierung keine Folge geleistet. Am 13. Mai 2011 hätten die Geheimdienstmitarbeiter deshalb seinen Vater in Haft genommen und während mehrerer Stunden zu seinem Verbleib befragt. Aus Angst vor Repressalien habe er sich in der Folge weiterhin bei seiner Schwester versteckt und sei im Juni 2011 illegal ausgereist.

Erstinstanzlich wurde das Asylgesuch von M.A. von den schweizerischen Asylbehörden abgewiesen und die Wegweisung angeordnet; begründet wurde die Verfügung vom 10. April 2013 im Wesentlichen mit der Unglaubhaftigkeit der Verfolgungsvorbringen von M.A. Die Gerichtsvorladung liege nur in Kopie vor und M.A. habe widersprüchliche Angaben zu zentralen Verfolgungsvorbringen gemacht; insbesondere seine Schilderungen des 10. Mai 2011 hätten im Verlaufe des Verfahrens erheblich divergiert. Mit Beschwerde vom 15. Mai 2013 hielt M.A. dem entgegen, dass seine Schilderungen des 10. Mai 2011, die er notabene im Abstand von fast zwei Jahren getätigt habe, miteinander vereinbart werden könnten. Zudem orientierte er das Bundesverwaltungsgericht darüber, dass er am 7. Mai 2013 vom Revolutionsgericht in Teheran in absentia zu sieben Jahren Haft und 70 Peitschenhieben verurteilt worden sei. Er übermittelte dem Gericht eine Kopie des Urteils und erklärte, seine Familienangehörigen könnten ihm das Urteil im Original derzeit nicht zustellen, weil ihr Briefverkehr womöglich überwacht werde. Gleichzeitig forderte er das Gericht auf, bei Zweifeln über die Echtheit des Urteils die Authentizität des Dokuments durch die schweizerische Botschaft in Teheran überprüfen zu lassen. Ohne eine Vernehmlassung der Vorinstanz einzuholen oder die Botschaft in Teheran zu konsultieren, wies das Bundesverwaltungsgericht die Beschwerde am 2. Juli 2013 als offensichtlich unbegründet ab. Es stellte sich im Wesentlichen auf den Standpunkt, das Urteil und die Gerichtsvorladung hätten keinen Beweiswert, weil sie lediglich als Fotokopien vorlägen. In Anbetracht der Widersprüche der Aussagen von M.A. während der erstinstanzlichen Anhörungen entstehe der Eindruck, dass er die geltend gemachte Verfolgungssituation erfunden habe. ${ }^{232}$

Der EGMR verwarf diese Sichtweise im Wesentlichen mit zwei Argumenten: Einerseits seien die Widersprüche in den Aussagen von M.A. nicht derart grundlegend, dass sie seine gesamten Verfolgungsvorbringen in Frage stellen würden. ${ }^{233}$ Vor allem aber habe das Bundesverwaltungsgericht überspannte Beweisanforderungen gestellt, indem es den Kopien der Gerichtsvorladung und des Urteils des Revolutionsgerichts jeden Beweiswert abgesprochen habe. Der Beschwerdeführer habe plausibel erklärt, dass es vorläufig unmöglich sei, die Originale zu beschaffen. Insbesondere vor diesem Hintergrund sei es für das Bundesverwaltungsgericht nicht statthaft gewesen, auf eine Überprüfung der Echtheit der Dokumente gänzlich zu

\footnotetext{
${ }^{232}$ Vgl. Urteil des BVGer D-2785/2013 vom 2. Juli 2013, S. 7.

${ }^{233}$ Vgl. EGMR, Urteil vom 18. November 2014, M.A. v. Schweiz, § 65.
} 
verzichten, zumal ihm entsprechende Möglichkeiten offen gestanden hätten. ${ }^{234}$ Aus diesen - offensichtlich prozeduralen - Verfehlungen des Bundesverwaltungsgerichts schloss der EGMR nun interessanterweise, dass der Beschwerdeführer im Lichte der allgemeinen Lageberichte zur Behandlung von Oppositionellen im $\operatorname{Iran}^{235}$ nachgewiesen habe, bei einer Rückkehr ernsthaft befürchten zu müssen, einer unmenschlichen Behandlung ausgesetzt zu werden. ${ }^{236}$ Der EGMR verzichtete dabei sogar darauf, sich selbst auf die Echtheit der Gerichtsvorladung und des Urteils des Revolutionsgerichts festzulegen. ${ }^{237}$

Man kann zwar mit guten Gründen die Auffassung vertreten, dass der EGMR seine abweichende Würdigung der Aussagen von M.A. in den erstinstanzlichen Anhörungen nicht ausreichend begründet hat. ${ }^{238}$ Die neuerliche Würdigung aller Beweismittel im Lichte der ihm vorliegenden Akten ist jedoch subsidiaritätsrechtlich nicht zu beanstanden. Im Gegenteil: Aufgrund der offensichtlichen Unzulänglichkeiten im Verfahren vor dem Bundesverwaltungsgericht war der EGMR subsidiaritätsrechtlich sogar gehalten, kompensatorisch tätig zu werden. Das Bundesverwaltungsgericht hatte sich mit den plausiblen Beweisanträgen von M.A. nämlich nicht einmal ansatzweise auseinandergesetzt, obwohl ihm verschiedene Wege aufgezeigt worden waren, die Authentizität der als Kopien eingereichten amtlichen Dokumente zu überprüfen. Deshalb war es dem EGMR unbenommen, sämtliche Beweismittel im Lichte der ihm vorliegenden Akten neu zu würdigen. Angesichts der hohen Bedeutung des nun im Original vorliegenden Urteils eines iranischen Revolutionsgerichts erschienen auch die anderen erhobenen Beweise plausibler als zuvor. Wie der Fall M.A. v. Schweiz insofern deutlich macht, können einzelne prozedurale Versäumnisse sich auf die Würdigung sämtlicher Beweise und damit auf das Gesamtergebnis der Tatsachenfeststellung auswirken.

Dem Fall Zakharin und andere v. Russland lag ein Strafverfahren wegen verschiedener Tötungsdelikte zugrunde. ${ }^{239}$ Bei einer Hausdurchsuchung am 5. September 2003 war der zweite Beschwerdeführer Pyotr Lunkin in der Wohnung eines Opfers bewaffnet aufgegriffen und zur Befragung auf eine Polizeistation gebracht worden. Dort blieb er bis zum 7. September 2003. Lunkins Angaben zufolge schlugen ihn die befragenden Polizisten auf seine (einzige) Niere und drängten ihn auf eine Fensterbank, wo er das Gleichgewicht verlor und drei Stöcke in die Tiefe fiel. Aufgrund multipler innerer und äußerer Verletzungen verbrachte er in der Folge einen Monat in der traumatologischen Abteilung des Spitals von Angarsk. Am 8. September 2003 zeigte Lunkin die Polizisten an. Die Staatsanwaltschaft der Region Irkutsk verweigerte jedoch die Eröffnung eines Strafverfahrens mit Verfügung vom 2. Oktober 2003.

\footnotetext{
${ }^{234}$ Vgl. EGMR, Urteil vom 18. November 2014, M.A. v. Schweiz, §§ 66-68.

${ }^{235}$ Vgl. EGMR, Urteil vom 18. November 2014, M.A. v. Schweiz, §§ 35-38.

${ }^{236}$ Vgl. EGMR, Urteil vom 18. November 2014, M.A. v. Schweiz, § 64.

${ }^{237}$ Vgl. EGMR, Urteil vom 18. November 2014, M.A. v. Schweiz, § 64.

${ }^{238}$ Vgl. EGMR, Urteil vom 18. November 2014, M.A. v. Schweiz, Dissenting Opinion Kjølbro, § 6. ${ }^{239}$ Vgl. zum Sachverhalt EGMR, Urteil vom 12. November 2015, Zakharin und andere v. Russland, §§5-43.
} 
Im Verlaufe der weiteren Ermittlungen wurden Mikhail Zakharin, Vladislavovich Zyryanov und Pavel Bazhenov am 14. Oktober 2003 als Tatverdächtige verhaftet. Alle drei beklagten sich schon kurz nach ihrer Verhaftung über Misshandlungen der befragenden Beamten. Ärztliche Berichte vom 15. Oktober 2003 bescheinigten Zakharin und Zyryanov Prellungen und Schürfungen im Gesicht und am Oberkörper; zudem war Bazhenovs Nase gebrochen. Auch im weiteren Verfahren beschwerten sich Zakharin, Zyryanov und Bazhenov wiederholt über Misshandlungen von Polizeibeamten und anderen Gefängnisinsassen, die im Auftrag der Ermittler Druck auf sie ausgeübt hätten. Zakharin unternahm während dieser Zeit erfolglos zwei Suizidversuche. Zyryanov stürzte sich während einer Befragung am 11. November 2003 aus dem Fenster, weil er die Misshandlungen nicht mehr ausgehalten habe. Auf Anzeige hin verweigerte die Staatsanwaltschaft der Region Irkutsk am 20. November 2003 die Eröffnung eines Strafverfahrens gegen die Ermittler. Sie erwog in Übereinstimmung mit den Aussagen der beteiligten Polizisten, die Verletzungen der Beschwerdeführer seien auf ihren Widerstand während der Festnahme zurückzuführen. Es seien keine weiteren Verletzungen dokumentiert, die auf Misshandlungen zurückgehen könnten. Zyryanov sei am 11. November 2003 aus dem Fenster des dritten Stocks gesprungen, weil er habe flüchten wollen.

Die Verfügung vom 20. November 2003 wurde am 4. März 2004 zwar aufgehoben und ein Strafverfahren eröffnet. Dieses verlief jedoch im Sande und wurde am 8. August 2006 eingestellt. Die Tatsachendarstellung in der Verfügung vom 20. November 2003 wurde auch im erstinstanzlichen Strafurteil gegen Zakharin und Zyryanov gestützt, als es um die Verwertbarkeit ihrer Aussagen ging. Bazhenov hatte sich zwischenzeitlich das Leben genommen; vor dem EGMR wurden seine Interessen durch seine Partnerin Natalya Batskova wahrgenommen.

Aufgrund des Ausschöpfungsgrundsatzes (Art. 35 Ziff. 1 EMRK) führte der EGMR in seinem Urteil lediglich die Misshandlungsvorwürfe von Zakharin und Zyryanov einer materiellen Prüfung zu. In Bezug auf die Effektivität der Untersuchung hielt er fest, dass die russischen Behörden mehr als vier Monate mit der Eröffnung einer Strafuntersuchung zugewartet hätten, nachdem sie von den Misshandlungsvorwürfen Kenntnis erhalten hatten. ${ }^{240}$ Dies habe die Möglichkeiten zur Erhebung der maßgeblichen Beweismittel erheblich eingeschränkt. Aufgrund des Versäumnisses der russischen Regierung, sämtliche Akten offenzulegen, sei zudem nicht klar, was in dem später eingestellten Strafverfahren unternommen worden sei, um dieses Versäumnis zu korrigieren. Es liege deshalb eine prozedurale Verletzung von Art. 3 EMRK vor.

Bei der Prüfung einer materiellen Verletzung von Art. 3 EMRK hielt der EGMR zunächst fest, dass auch Misshandlungsvorwürfe grundsätzlich ,beyond reasonable doubt" zu beweisen seien. ${ }^{241}$ Allerdings komme es zu einer Beweislastumkehr, wenn eine Person nachweisen könne, dass sie in Polizeigewahrsam Verletzungen erlitten habe; diesfalls obliege es dem Staat, eine plausible Erklärung dafür zu liefern, wie

\footnotetext{
${ }^{240}$ Vgl. dazu und zum Folgenden EGMR, Urteil vom 12. November 2015, Zakharin und andere v. Russland, §§ 66-69.

${ }^{241}$ Vgl. Urteil vom 12. November 2015, Zakharin und andere v. Russland, § 75.
} 
die Verletzungen entstanden seien. ${ }^{242}$ Nachdem aufgrund zweier Arztberichte vom 15. Oktober 2003 dokumentiert war, dass Zakharin und Zyryanov verschiedene Verletzungen erlitten hatten, die aus den Stunden ihrer Festnahme stammten, betrachtete der EGMR die Voraussetzungen für eine Anwendung der Beweislastumkehr als erfüllt. Er berücksichtigte dabei ausdrücklich auch den Umstand, dass die Untersuchung der Geschehnisse durch die russischen Behörden nicht als effektiv angeschaut werden konnte. ${ }^{243}$ Die auf die Verfügung vom 20. November 2003 gestützte Erklärung der russischen Regierung, die Verletzungen von Zakharin und Zyryanov seien auf ihren während der Verhaftung geleisteten Widerstand zurückzuführen, akzeptierte der EGMR auch deshalb nicht, weil die russische Regierung trotz Aufforderung durch den EGMR die Akten des innerstaatlichen Verfahrens nicht vollständig ediert hatte. ${ }^{244}$ Trotz erheblicher tatsächlicher Unsicherheiten ${ }^{245}$ schloss der EGMR daher neben der prozeduralen Verletzung auch auf eine materielle Verletzung von Art. 3 EMRK. ${ }^{246}$

\section{Beweisrecht als Instrument eines effektiven Schutzes der Konventionsrechte}

Das eben erläuterte Beispiel des Urteils im Fall Zakharin und andere v. Russland macht deutlich, dass der EGMR in bestimmten Konstellationen bereit ist, Konventionsverletzungen auch dann zu bejahen, wenn die Beweislage äußerst dünn ist. ${ }^{247}$ In Umkehrung des Grundsatzes actori incumbit probatio überbürdete der EGMR der russischen Regierung den Beweis für die Unrichtigkeit der Tatsachendarstellung der Beschwerdeführer. ${ }^{248}$ Weil die russische Regierung diesen Beweis nicht erbringen konnte, genügte für die Annahme einer Konventionsverletzung schon der Nachweis, dass Zakharin und Zyryanov in Polizeigewahrsam Verletzungen erlitten hatten. Ungeklärt blieb hingegen die genaue Ursache dieser Verletzungen. Faktisch kam es in diesem wie in anderen Fällen durch die Beweislastumkehr also zu einer erheblichen Herabsetzung des Beweismaßes zugunsten der Beschwerdeführenden. Funktional vergleichbar hat der EGMR in anderen Fällen dem Umstand Rechnung getragen, dass ein Konventionsstaat im Straßburger Verfahren trotz einer Anordnung nach Art. 38 EMRK die Offenlegung von Dokumenten verweigert und damit die Aufarbeitung des Geschehenen erschwert hatte; auch die

\footnotetext{
${ }^{242}$ Vgl. Urteil vom 12. November 2015, Zakharin und andere v. Russland, § 76.

${ }^{243}$ Vgl. Urteil vom 12. November 2015, Zakharin und andere v. Russland, § 78.

${ }^{244}$ Vgl. Urteil vom 12. November 2015, Zakharin und andere v. Russland, §§ 80-81.

${ }^{245}$ Vgl. Urteil vom 12. November 2015, Zakharin und andere v. Russland, § 63.

${ }^{246}$ Vgl. Urteil vom 12. November 2015, Zakharin und andere v. Russland, $\S 82$.

${ }^{247}$ Vgl. dazu auch Rudolf, S. 498.

${ }^{248} \mathrm{Vgl}$. zur häufig schwammigen Differenzierung zwischen Beweislast, Beweismaß und Beweiswürdigung im Völkerrecht Kokott, Burden of Proof, S. 177 ff., S. 196 f., S. 207 f.
} 
daraus gezogenen Tatsachenvermutungen hatten letztlich eine Herabsetzung des Beweismaßes zur Folge. ${ }^{249}$

\section{a. Subsidiaritätsrechtliche Begründung}

Der Einsatz solcher beweisrechtlicher Instrumente hängt einerseits mit der besonderen institutionellen Stellung des EGMR und anderseits mit seiner Wächterfunktion für die Konventionsrechte zusammen. Konfrontiert mit den begrenzten eigenen Möglichkeiten zur Erhebung von Beweismitteln ${ }^{250}$ erscheint das Vorgehen des EGMR als einzig denkbarer Weg, um den effektiven Schutz der Konventionsrechte trotz der Unzulänglichkeiten des innerstaatlichen Verfahrens sicherzustellen und das Risiko einer unzutreffenden Tatsachenfeststellung unter den Parteien angemessen zu verteilen. ${ }^{251}$ Insoweit lässt sich sagen, dass der Einsatz der genannten Instrumente notwendig ist, um einen effektiven Menschenrechtsschutz auch dann sicherzustellen, wenn die innerstaatlichen Instanzen bei der Untersuchung der maßgeblichen Vorfälle versagen oder eine solche sogar aktiv verhindern..$^{252}$

Der enge Zusammenhang zwischen der Qualität der innerstaatlichen Untersuchung und dem Einsatz besonderer beweisrechtlicher Instrumente zeigt sich an einem Prüfungsschema, das der EGMR in jüngeren Urteilen zu Misshandlungsvorwürfen gegenüber den russischen Strafverfolgungsbehörden angewendet hat: ${ }^{253}$ In einem ersten Schritt prüfte er jeweils, ob den Beschwerdeführern der Nachweis gelungen war, in Polizeigewahrsam Verletzungen erlitten zu haben. War dieser Nachweis erfolgt, untersuchte er in einem zweiten Schritt, ob die innerstaatliche Untersuchung der Misshandlungsvorwürfe den prozeduralen Vorgaben von Art. 3 EMRK genügt hatte. In einem dritten Schritt hielt der EGMR dann jeweils fest, dass es der Regierung gerade wegen der prozeduralen Verletzung nicht gelungen sei, die Vorwürfe der Beschwerdeführer zu entkräften. In Anwendung der Beweislastumkehr und vor dem Hintergrund des Ungenügens der innerstaatlichen Untersuchung stellte er mithin auf die Tatsachendarstellung der Beschwerdeführer ab, obwohl allein aufgrund der Beweismittel kaum „au-delà de tout doute raisonnable“ auf eine Misshandlung hätte geschlossen werden können.

\footnotetext{
${ }^{249}$ Vgl. beispielsweise EGMR, Urteil vom 26. Januar 2017, Khamidkariyev v. Russland, §§ 105107; EGMR, Urteil vom 2. Juni 2016, Yunusova und Yunusov v. Aserbaidschan, §§ 105-120.

${ }^{250} \mathrm{Vgl}$. zu den eingeschränkten Beweiserhebungsmöglichkeiten auch EGMR (Große Kammer), Urteil vom 4. Mai 2001, McKerr v. Vereinigtes Königreich, §§ 116-117.

${ }^{251}$ Vgl. auch Keller/Heri, S. 749 f., die völlig zu Recht herausstreichen, dass der EGMR die Versäumnisse der nationalen Behörden nicht umfassend kompensieren kann.

${ }^{252} \mathrm{Vgl}$. zur Rechtfertigung des Einsatzes dieser beweisrechtlichen Instrumente auch Keller/Heri, S. 741, m.w.H.

${ }^{253}$ Vgl. EGMR, Urteil vom 11. April 2017, Morgunov v. Russland, §§ 33-41; EGMR, Urteil vom 2. Mai 2017, Olisov und andere v. Russland, §§ 75-85; EGMR, Urteil vom 2. Mai 2017, Sitnikov v. Russland, §§ 31-41; EGMR, Urteil vom 2. Mai 2017, Kondakov v. Russland, §§ 26-36.
} 
Die Begründung in diesen wie in anderen Fällen legt nahe, dass der EGMR im Falle einer zureichenden innerstaatlichen Untersuchung das Vorliegen einer plausiblen Erklärung für die Verletzungen der Beschwerdeführer bejaht und seinen Urteilen damit den von der Regierung behaupteten Sachverhalt zugrunde gelegt hätte. Die teilweise kritisierte beweisrechtliche Herangehensweise des EGMR folgt also einer genuin subsidiaritätsrechtlichen Logik: Konfrontiert mit innerstaatlichen Verfahrensmängeln wendet der EGMR Instrumente an, die zwar aus dem nationalen Verfahrensrecht nicht geläufig, im Hinblick auf einen effektiven Schutz der Konventionsrechte auf der Ebene des EGMR aber unentbehrlich sind. ${ }^{254}$ Diese kompensatorische Funktion des Beweisrechts des EGMR lässt sich besonders gut an einem Fall veranschaulichen, in dem die nationalen Behörden eine Aufarbeitung des Geschehenen unter Berufung auf nationale Sicherheitsinteressen de facto verweigert haben. Bekannt geworden ist der Fall El-Masri v. Mazedonien vor allem deshalb, weil er die geheimdienstliche Terrorbekämpfung und damit ein medial wie politisch stark beachtetes Thema zum Gegenstand hatte; im Hinblick auf die hier vorliegende Fragestellung interessieren jedoch vor allem die nicht minder bedeutsamen beweisrechtlichen Implikationen des Urteils. ${ }^{255}$

\section{b. Der Fall El-Masri v. Mazedonien}

Wie in vielen anderen Fällen zu Art. 3 EMRK standen sich auch im Fall El-Masri v. Mazedonien zwei konträre Schilderungen gegenüber: Nach Darstellung des Beschwerdeführers El-Masri hatten die mazedonischen Grenzbehörden ihm am Silvesterabend 2003 wegen Zweifeln an der Echtheit seiner Reisedokumente die Einreise nach Mazedonien verweigert. ${ }^{256}$ Er sei an der Grenze stundenlang durch den mazedonischen Geheimdienst verhört und dann in ein Hotel in Skopje verbracht worden. Dort sei er die nächsten Wochen von mazedonischen Agenten informell festgehalten und wiederholt befragt worden. Nach drei Wochen sei er vom Hotel an den Flughafen von Skopje gebracht und dort - gefesselt und mit verdeckten Augen - einem rendition team der CIA übergeben worden. Dieses habe ihn noch am Flughafen einer ,,medizinischen Untersuchung“ unterzogen; die Agenten hätten ihm die Kleider vom Leib geschnitten, die Unterwäsche gewaltsam entfernt und einen Gegenstand in den Anus geschoben. Als ihm die Augenbinde entfernt worden sei, habe er sich acht schwarz gekleideten und maskierten Personen gegenübergesehen. Diese hätten ihn in ein gechartertes Flugzeug geführt, ihm ein

\footnotetext{
${ }^{254}$ Vgl. auch EGMR (Große Kammer), Urteil vom 13. Dezember 2012, El-Masri v. Mazedonien, $\S 151:,[\ldots]$ La spécificité de la tâche que lui attribue l'article 19 de la Convention - assurer le respect par les Hautes Parties contractantes de leur engagement consistant à reconnaître les droits fondamentaux consacrés par cet instrument - conditionne sa façon d'aborder les questions de preuve. [...].“

${ }^{255}$ Vgl. in diesem Sinne auch Meyer/Więckowska, Rechtsprechung 2012, S. 254 f.; Orpiszewska, S. $1189 \mathrm{ff}$.

${ }^{256}$ Vgl. dazu und zum Folgenden EGMR (Große Kammer), Urteil vom 13. Dezember 2012, ElMasri v. Mazedonien, §§ 16-36.
} 
Beruhigungsmittel injiziert, die Sicht verdeckt, Kopfhörer aufgesetzt und ihn daraufhin über Bagdad nach Kabul geflogen. Die nächsten Monate habe er in der Gewalt der CIA in einer stillgelegten Fabrik in der Nähe des Flughafens von Kabul verbracht, wo noch andere Terrorverdächtige während längerer Zeit informell festgehalten und unter Anwendung von Folter wiederholt verhört worden seien. Er selber habe sich dieser Behandlung mittels Hungerstreik widersetzen wollen, sei jedoch zwangsernährt worden. Ende Mai 2004, als für die CIA klar geworden sei, dass ihr keiner der gesuchten Terroristen ins Netz gegangen sei, habe man ihn nach Albanien transportiert und nahe der serbischen Grenze ausgesetzt.

El-Masris detaillierte Behauptungen konnten nach seiner Rückkehr durch verschiedene Straf- und Administrativuntersuchungen deutscher und spanischer Behörden plausibilisiert werden. Durch Aufzeichnungen von Flugdaten war beispielsweise erstellt, dass ein in den Vereinigten Staaten immatrikuliertes Flugzeug am 23. Januar 2004 ohne Fluggast von Palma de Mallorca herkommend in Skopje gelandet und von dort mit einem Passagier über Bagdad nach Kabul weitergeflogen war. Die im deutschen Strafverfahren entnommenen Haarproben El-Masris zeigten, dass sich dieser in der relevanten Zeitspanne tatsächlich in einem südasiatischen Land aufgehalten hatte; überdies stützten sie seine Behauptung, zwei Mal in den Hungerstreik getreten zu sein. Weiter vermochte El-Masri eine Skizze des Gefängnisses in Afghanistan anzufertigen, die von einem anderen dort inhaftierten Terrorverdächtigen sofort wiedererkannt wurde. Neben zahlreichen zusätzlichen Indizien konvergierten El-Masris Schilderungen aber vor allem auch mit den Ergebnissen dreier Untersuchungen von Ausschüssen der Parlamentarischen Versammlung des Europarates sowie des Europäischen Parlaments. ${ }^{257}$ Nach diesen Berichten war die Entführung von Terrorverdächtigen Teil eines Maßnahmenpakets, das die amerikanische Regierung nach den New Yorker Terroranschlägen vom 11. September 2001 unter dem Schlagwort des war on terror beschlossen hatte. El-Masris Entführung sei unter dem extraordinary rendition programme erfolgt, welches in seinem Ablauf stark formalisiert sei und vor allem der Informationsbeschaffung diene. Der Schweizer Europaratsabgeordnete Dick Marty beispielsweise bezeichnete das Programm als ,globales Spinnennetz“, welches über Jahre hinweg durch die USA aufgebaut worden sei und an welchem verschiedene (auch europäische) Staaten mindestens in Hilfsfunktionen mitgewirkt hätten. ${ }^{258}$ Neben El-Masri seien zahlreiche weitere Terrorverdächtige in Länder verschleppt worden, in denen die USA black sites betrieben hätten. Dort seien sie unter Anwendung von Folter und ohne rechtsförmiges Verfahren während Monaten festgehalten und verhört worden, ohne auch nur ihre Angehörigen über den eigenen Verbleib informieren zu können.

Nachdem trotz dieser Last von Indizien mehrere mazedonische Verfahren ohne Ergebnis geendet hatten, ${ }^{259}$ stritt die mazedonische Regierung die Vorwürfe von El-Masri auch im Verfahren vor dem EGMR ab. Die Regierung negierte namentlich,

\footnotetext{
${ }^{257}$ Vgl. die Marty-Berichte 2006 und 2007 sowie den Fava-Bericht.

${ }^{258} \mathrm{Vgl}$. Marty-Bericht 2006, S. $13 \mathrm{ff}$.

${ }^{259}$ Vgl. EGMR (Große Kammer), Urteil vom 13. Dezember 2012, El-Masri v. Mazedonien, §§ 64-73.
} 
dass ihr Geheimdienst in das rendition programme der CIA verwickelt gewesen sei. ${ }^{260}$ Zwar bestätigte sie, dass El-Masri am Silvesterabend 2003 wegen des Verdachts gefälschter Reisedokumente am Grenzübergang Tabanovče festgehalten worden sei. Nach fünf Stunden sei ihm jedoch ohne weitere Auflagen die Einreise nach Mazedonien ermöglicht worden. El-Masri sei daraufhin selbstständig nach Skopje gereist und habe dort in einem Hotel eingecheckt. Bis zum 23. Januar 2004 habe er sich in diesem Hotel aufgehalten und dann Mazedonien am Grenzübergang Blace in Richtung Kosovo verlassen.

Aufgrund der konträren Tatsachendarstellungen fand sich der EGMR faktisch in der Rolle eines erstinstanzlichen Tatsachengerichts wieder. ${ }^{261}$ Entsprechend widmete er einen längeren Abschnitt seines Urteils der Feststellung der maßgeblichen Tatsachen. ${ }^{262}$ Weil die mazedonischen Behörden unter Berufung auf sicherheitspolitische Geheimhaltungsinteressen keine ausreichende innerstaatliche Untersuchung des Vorfalls vorgenommen hatten, ${ }^{263}$ stützte der EGMR sich dabei insbesondere auf die erwähnten indirekten Beweise, welche die Schilderungen El-Masris stützten. Überdies berücksichtigte er die beglaubigte Aussage des vormaligen mazedonischen Innenministers H.K., welcher die Schilderungen El-Masris in der Sache bestätigte, jedoch eine Verantwortung Mazedoniens für dessen Behandlung in Afghanistan abstritt. ${ }^{264}$

Auf Grundlage des dichten Netzes indirekter Beweise kam der EGMR zum Schluss, dass ,un commencement de preuve“ die für sich genommen glaubwürdigen Schilderungen El-Masris bestätige; deshalb überbürdete er die Beweislast der mazedonischen Regierung. ${ }^{265}$ Diese vermochte jedoch nicht plausibel zu entkräften, dass die Geschehnisse sich so zugetragen hatten, wie El-Masri behauptete. ${ }^{266} \mathrm{Ge}$ stützt auf El-Masris Schilderung der maßgeblichen Tatsachen stellte der EGMR deshalb eine dreifache materielle Verletzung von Art. 3 EMRK fest: Erstens, weil El-Masri während gut drei Wochen informell in einem Hotel in Skopje festgehalten worden war, ohne dass ihm die Möglichkeit gewährt worden wäre, Angehörige zu kontaktieren oder die deutsche Botschaft zu benachrichtigen; zweitens, weil El-Masri am Flughafen von Skopje auf mazedonischem Staatsgebiet und in Anwesenheit mazedonischer Beamten dem capture shock treatment der CIA-Agenten

\footnotetext{
${ }^{260}$ Vgl. dazu und zum Folgenden EGMR (Große Kammer), Urteil vom 13. Dezember 2012, ElMasri v. Mazedonien, $\S \S 37-41$.

${ }^{261}$ EGMR (Große Kammer), Urteil vom 13. Dezember 2012, El-Masri v. Mazedonien, § 155.

${ }^{262}$ Vgl. EGMR (Große Kammer), Urteil vom 13. Dezember 2012, El-Masri v. Mazedonien, $\S \S 149-167$.

${ }^{263}$ Vgl. auch EGMR (Große Kammer), Urteil vom 13. Dezember 2012, El-Masri v. Mazedonien, $\S \S 186-192$, §§ 258-262. Vgl. zur Problematik der staatlichen Geheimhaltung von konventionsrechtlich relevanten Informationen unter Berufung auf öffentliche Sicherheitsinteressen auch Vedaschi, S. $177 \mathrm{ff}$.

${ }^{264}$ EGMR (Große Kammer), Urteil vom 13. Dezember 2012, El-Masri v. Mazedonien, § 74.

${ }^{265}$ EGMR (Große Kammer), Urteil vom 13. Dezember 2012, El-Masri v. Mazedonien, § 165.

${ }^{266}$ EGMR (Große Kammer), Urteil vom 13. Dezember 2012, El-Masri v. Mazedonien, $\S \S 167-168$.
} 
ausgesetzt war; und drittens, weil seine Übergabe an die CIA eine Verletzung des Refoulement-Verbots darstellte. ${ }^{267}$

Beweisrechtlich ist der Fall El-Masri in verschiedener Hinsicht interessant. Er zeigt paradigmatisch auf, dass der EGMR nur beschränkt in der Lage ist, in größerem Umfang neue Beweise zu erheben. Diesbezügliche Limiten ergaben sich auch im Fall El-Masri vor allem aus der zeitlichen Distanz zu den maßgeblichen Geschehnissen und aus den beschränkten Beweiserhebungsmöglichkeiten des EGMR. Beispielsweise wäre es diesem nicht möglich gewesen, den ehemaligen Innenminister Mazedoniens für eine Aussage verbindlich vorzuladen; der EGMR war diesbezüglich vielmehr auf H.K.s Bereitschaft angewiesen, aufgrund des doch erheblichen internationalen Drucks von sich aus eine notariell beglaubigte schriftliche Aussage einzureichen. Die Verurteilung Mazedoniens wäre letztlich kaum möglich gewesen, wenn nicht auch deutsche Behörden und zwei Ausschüsse der Parlamentarischen Versammlung des Europarates beziehungsweise des Europäischen Parlaments sich schon vorher des Falls angenommen und die Schilderungen des Beschwerdeführers durch ein dichtes Netz von Indizien gestützt hätten. ${ }^{268}$ Selbst unter Zuhilfenahme dieser Indizien wäre zumindest in Bezug auf die Verwicklung mazedonischer Agenten wohl zudem kaum „au-delà de tout doute raisonnable“ nachgewiesen gewesen, dass sich die Geschehnisse so zugetragen hatten, wie von El-Masri behauptet. Hätte man die Beweislast bei El-Masri belassen, wäre ein solcher Beweis insbesondere an der Verweigerungshaltung der mazedonischen Behörden gescheitert. Allein diese wären nämlich aufgrund ihres anfangs ausschließlichen Zugriffs auf El-Masri in der Lage gewesen, aussagekräftige Dokumente zu edieren. Weil sie die Herausgabe solcher Dokumente aber unter Berufung auf sicherheitsrelevante Staatsgeheimnisse verweigerten, entstand subsidiaritätsrechtlich gesprochen jenes beweisrechtliche Vakuum, das der EGMR letztlich durch Anwendung der Beweislastumkehr und durch die Zulassung der notariell beglaubigten Aussage von H.K. als Beweismittel völlig zu Recht ausgefüllt hat.

\section{Subsidiaritätsrechtliche Würdigung der herrschenden Praxis des EGMR}

Wie oben aufgezeigt worden ist, hält der Subsidiaritätsgrundsatz den EGMR im Grundsatz dazu an, in seinem Verfahren auf die Tatsachenfeststellungen der nationalen Gerichte abzustellen und diese nur im Falle offensichtlicher Unrichtigkeit zu korrigieren. Solche Zurückhaltung ist jedoch nur insoweit angebracht, als die nationalen Instanzen der ihnen primär zugewiesenen Aufgabe einer methodisch nachvollziehbaren Tatsachenfeststellung nachgekommen sind. Haben sie bei der Untersuchung einer behaupteten Konventionsverletzung die prozeduralen Anforderungen

\footnotetext{
${ }^{267}$ Vgl. EGMR (Große Kammer), Urteil vom 13. Dezember 2012, El-Masri v. Mazedonien, $\S \S 199-223$.

${ }^{268} \mathrm{Vgl}$. in diesem Sinne auch Bernard, S. 601.
} 
aus Art. 3 und Art. 13 EMRK hingegen außer Acht gelassen, liegen jene ,zwingenden Gründe" vor, die gebieten, dass der EGMR in die innerstaatliche Tatsachenfeststellung eingreift und eigene Feststellungen trifft.

Einzelne Urteile des EGMR wurden im Lichte dieser Grundsätze zu Recht kritisiert. ${ }^{269}$ Im Fall Ioan Pop v. Rumänien etwa hat der EGMR zugunsten der Beschwerdeführenden Tatsachen festgestellt, die kaum ,au-delà de tout doute raisonnable“ bewiesen waren. Das Urteil im Fall Dembele v. Schweiz warf die Frage auf, ob sich eine de-novo-Prüfung der maßgeblichen Tatsachen wirklich in allen Fällen aufdrängt, in denen das innerstaatliche Verfahren den prozeduralen Vorgaben von Art. 3 und Art. 13 EMRK nicht genügt hat; insoweit bestünde womöglich Differenzierungsbedarf. Dies gilt auch für die Beweislastumkehr, deren Anwendung im Fall Sadkov v. Ukraine zu einem unbefriedigenden Resultat geführt hat. Die mitunter berechtigte Kritik an einzelnen Urteilen darf jedoch nicht dazu verleiten, das Gesamtbild aus den Augen zu verlieren. Verfolgt man in diesem Sinne die großen Linien, konvergiert die Rechtsprechung des EGMR ganz zweifellos mit den Vorgaben des Subsidiaritätsgrundsatzes. ${ }^{270}$

\section{Problematische Einzelfälle}

\section{a. Beweis ,au-delà de tout doute raisonnable". Der Fall Ioan Pop v. Rumänien}

Dem Fall Ioan Pop und andere v. Rumänien lag im Ausgangspunkt eine zivilrechtliche Streitigkeit zugrunde: Ein Zivilgericht hatte mit Urteil vom 10. November 2006 die Ausweisung der Familie Pop aus ihrer Wohnung verfügt. ${ }^{271}$ Weil die Familie der Ausweisungsverfügung keine Folge leisten wollte, ordnete die zuständige rumänische Behörde für den 4. Juli 2007 die Zwangsexekution des Urteils an. Bei Eintreffen der Polizisten war der Zugang zur Wohnung allerdings verbarrikadiert. Der Familienvater Ioan Pop hatte die Wohnungstür elektrifiziert und sich zudem mit einer Axt und einer Keule bewaffnet. Vor den Augen der Ehefrau und des Sohnes von Ioan Pop gelang es den Polizisten, sich des Beschwerdeführers durch Einsatz massiver Gewalt zu behändigen. Anschließend wurden er und seine Ehefrau wegen des geleisteten Widerstands zum nächsten Polizeiposten gebracht. Der damals zwölfjährige Sohn blieb derweil an ihrem Wohnort zurück. Insoweit waren sich die Parteien im Sachverhalt einig; umstritten war jedoch, was in den folgenden Stunden geschah:

\footnotetext{
${ }^{269} \mathrm{Vgl}$. dazu nachfolgend, IV. D. 1.

${ }^{270} \mathrm{Vgl}$. dazu nachfolgend, IV. D. 2.

${ }^{271}$ Vgl. zum Sachverhalt EGMR, Urteil vom 6. Dezember 2016, Ioan Pop und andere v. Rumänien, $\S \S 5-34$.
} 
Die Beschwerdeführenden behaupteten im Verfahren vor dem EGMR, der Sohn sei nach der Mitnahme der Eltern fast zwölf Stunden auf sich allein gestellt gewesen und dadurch schwer traumatisiert worden. ${ }^{272}$ Die rumänische Regierung hingegen machte geltend, der Sohn sei in dieser Zeit in der Obhut seiner Tanten verblieben; wenn überhaupt von einer Traumatisierung auszugehen sei, müsse diese auf das Miterleben der gewaltsamen Immobilisierung seines Vaters zurückzuführen sein. ${ }^{273}$ Die rumänische Regierung stützte sich dabei insbesondere auf die Aussagen der Zeugin C.M., die während des Strafverfahrens gegen Ioan Pop ausgesagt hatte, nach der Räumung der Wohnung die Schwestern der Beschwerdeführerin angerufen zu haben, damit sich diese um das Kind kümmerten.

Der EGMR hielt in seinem Urteil im Hinblick auf die divergierenden Tatsachenbehauptungen zunächst fest, dass die Beweislast grundsätzlich bei den Beschwerdeführenden liege und ein Beweis ,,au-delà de tout doute raisonnable“ erforderlich sei, dass der Sohn so lange alleingeblieben sei. ${ }^{274}$ Ohne sich mit allfälligen Beweisvorbringen der Beschwerdeführenden zu befassen, hielt er weiter fest, die rumänischen Gerichte hätten die Zeugenaussage von C.M. nicht gewürdigt, sondern - trotz entsprechender Beweisanträge der Familie Pop - lediglich festgehalten, dass der Sohn „unter der Aufsicht der Dorfbewohner verblieben“ sei. ${ }^{275}$ Diese Formulierung sei vage, unpräzise und lasse unbeantwortet, wer konkret sich während welcher Zeit um ihn gekümmert habe. Die Aussagen verschiedener Zeuginnen und Zeugen würden nahelegen, dass eine allfällige Betreuung jedenfalls nicht durch die intervenierenden Polizeibeamten sichergestellt worden sei.

Wenngleich aufgrund dieser Erwägungen nicht klar nachgewiesen schien, wer konkret sich um den Sohn gekümmert hatte, wäre zu erwarten gewesen, dass der EGMR einen über jeden vernünftigen Zweifel erhabenen Nachweis des Alleinbleibens des Sohnes und damit auch eine Verletzung von Art. 3 EMRK verneint hätte. Anders sah dies der EGMR : Ohne nähere Begründung kam er zum Schluss, ,[qu'il est] suffisamment établi, que, le 4 juillet 2007, le troisième requérant a été laissé seul, pendant plusieurs heures, sans qu'il soit confié à la surveillance d'un adulte, alors que ses parents avaient été conduits au poste de police. ${ }^{\text {"276 }}$ Diese Wendung überrascht schon für sich genommen, zumal im Urteil kein einziger Beweis für die Richtigkeit dieser Version der Geschehnisse genannt wird. Besonders unverständlich wird die Einschätzung des EGMR jedoch, wenn man die weiteren Beweismittel berücksichtigt, die ihm vorlagen: Neben C.M. hatten zwei weitere Zeugen ausgesagt, dass der Bub nach der Mitnahme seiner Eltern von Nachbarn beziehungsweise Familienangehörigen betreut worden sei. ${ }^{277}$

\footnotetext{
${ }^{272}$ Vgl. EGMR, Urteil vom 6. Dezember 2016, Ioan Pop und andere v. Rumänien, § 49.

${ }^{273}$ Vgl. EGMR, Urteil vom 6. Dezember 2016, Ioan Pop und andere v. Rumänien, §§ 50-52.

${ }^{274}$ Vgl. EGMR, Urteil vom 6. Dezember 2016, Ioan Pop und andere v. Rumänien, §§ 56-57.

${ }^{275}$ Vgl. dazu und zum Folgenden EGMR, Urteil vom 6. Dezember 2016, Ioan Pop und andere v. Rumänien, §§ 58-59.

${ }^{276}$ EGMR, Urteil vom 6. Dezember 2016, Ioan Pop und andere v. Rumänien, § 60.

${ }^{277}$ Vgl. EGMR, Urteil vom 6. Dezember 2016, Ioan Pop und andere v. Rumänien, § 20.
} 
Auch ein abweichender Richter sah dies so und kritisierte die Gerichtsmehrheit dafür, das anwendbare Beweismaß aus den Augen verloren zu haben. ${ }^{278}$ Die faktische Herabsetzung des Beweismaßes wirkte sich freilich auch auf die Beweislastverteilung aus: Praktisch gesehen hätte nunmehr die rumänische Regierung beweisen müssen, dass die Geschehnisse sich nicht so zugetragen hatten wie von den Beschwerdeführenden behauptet. Im Unterschied zu Geschehnissen, die sich unter der ausschließlichen Kontrolle von Staatsoffiziellen zutragen, bestand für eine solche Beweislastumkehr jedoch vorliegend kein plausibler Grund, zumal verschiedene unabhängige Zeuginnen und Zeugen sich zum Verbleib des Jungen geäußert hatten.

Das Vorgehen des EGMR lässt vermuten, dass im Hinblick auf ein gewünschtes Ergebnis ein Sachverhalt konstruiert worden ist, der mit der Wirklichkeit aller Wahrscheinlichkeit nach nicht zu vereinbaren ist. Abgesehen vom Vorwurf fehlender methodischer Sorgfältigkeit setzt sich der EGMR damit unnötigerweise der Vorhaltung aus, um jeden Preis Verletzungen der EMRK feststellen zu wollen und damit in gewissem Sinne vorbefasst zu sein. ${ }^{279}$ Unabhängig von solcher Kritik ruft der Fall Ioan Pop und andere v. Rumänien in Erinnerung, dass das Beweisrecht für den materiellen Ausgang der Verfahren vor dem EGMR von zentraler Bedeutung ist. Zur Sicherstellung der Akzeptanz seiner Urteile muss der EGMR besonders darauf achten, sein Beweisrecht methodisch sorgfältig anzuwenden. Gerade nationale Richterinnen und Richter, denen der EGMR zu Recht mitunter vorhält, prozedural unsorgfältig vorzugehen, sollten sich am EGMR insoweit ein Vorbild nehmen können.

\section{b. Grenzen des prozeduralen Kriteriums bei der Bemessung des Kontrollmaßstabs in Tatsachenfragen. Der Fall Dembele v. Schweiz.}

Zumindest in der Schweiz stark beachtet wurde das Urteil des EGMR im Fall Dembele gegen Schweiz. ${ }^{280}$ Zwei Genfer Polizisten hatten am 2. Mai 2005 auf dem vormals besetzten Artamis-Areal der Stadt Genf die Identität von Kalifa Dembele überprüfen wollen, einem Staatsangehörigen von Burkina Faso. Dabei war es zu einem Handgemenge gekommen, bei welchem sich Dembele gemäß einem Gutachten des Universitätsspitals Genf vom 4. Mai 2005 das rechte Schlüsselbein gebrochen hatte..$^{281}$

\footnotetext{
${ }^{278}$ Vgl. EGMR, Urteil vom 6. Dezember 2016, Ioan Pop und andere v. Rumänien, Partly Dissenting Opinion Sajó, § 3.

${ }^{279} \mathrm{Vgl}$. beispielsweise Schubarth, S. 369 f., der „Menschenrechtlern“ vorwirft, „,euphorisch überall Menschenrechte zu sehen und vor allem eine Verletzung dieser Rechte zu wittern" und beim EGMR „Menschenrechtsaktivismus“ verortet.

${ }^{280}$ Vgl. EGMR, Urteil vom 24. September 2013, Dembele v. Schweiz. Kritisch dazu auch Rüefli, S. 92 f. und Schürer, S. 515. Weitere Urteilsbesprechungen finden sich bei Meyer/Więckowska, Rechtsprechung 2013, S. 374 f. und Rietiker, S. 668 ff.

${ }^{281}$ EGMR, Urteil vom 24. September 2013, Dembele v. Schweiz, § 6.
} 
Es folgten Strafanzeigen der Beamten gegen Dembele und von Dembele gegen die Beamten. Dembele behauptete, die Polizisten hätten ihn ohne jeden Anlass dazu gezwungen, sich auf den Boden zu legen. Als er sich dieser Aufforderung widersetzt habe, hätten die Polizisten ihn mit ihren Knüppeln zu schlagen begonnen; einer der Knüppel sei dabei geborsten. ${ }^{282}$ Nach einem missratenen Fluchtversuch sei er durch den unverhältnismäßigen Einsatz von Gewalt immobilisiert worden, wobei er einen der Polizisten bei dieser Gelegenheit gebissen habe. Zudem hätten die Beamten ihn rassistisch beleidigt und mit dem Tod bedroht. Die Polizisten hingegen brachten vor, physischen Zwang erst angewendet zu haben, als Dembele sich stark gestikulierend geweigert habe, Ausweispapiere vorzuweisen und seine Zigarette wegzuwerfen. ${ }^{283}$ Durch einen einmaligen Knüppelschlag in die Kniekehle habe einer von ihnen versucht, den Beschwerdeführer zu immobilisieren. Diesem sei jedoch kurzzeitig die Flucht gelungen. Mithilfe des Einsatzes des Knüppels sei es ihnen trotz heftiger Gegenwehr jedoch kurz darauf gelungen, sich des Beschwerdeführers zu behändigen. Beide Polizisten stritten ab, Dembele rassistisch beleidigt oder bedroht zu haben.

Der zuständige Generalstaatsanwalt verfügte am 27. August 2007 ein erstes Mal die Nichtanhandnahme des Strafverfahrens gegen die beiden Polizisten; er begründete dies im Wesentlichen damit, aufgrund des Gutachtens des Universitätsspitals Genf vom 4. Mai 2005 und der Anhörungen von Dembele und der beiden Polizeibeamten lasse sich nicht erhärten, dass diese mit unverhältnismäßiger Gewalt vorgegangen seien. ${ }^{284}$ Die Nichtanhandnahmeverfügung wurde von der Anklagekammer mit Urteil vom 9. Januar 2008 gestützt, vom Bundesgericht hingegen am 27. November 2008 ausdrücklich mit der Begründung zurückgewiesen, dass den prozeduralen Vorgaben aus Art. 3 EMRK nicht Genüge getan worden sei. ${ }^{285}$ Die zuständige Instruktionsrichterin ordnete in der Folge ergänzende Beweisabnahmen an: Am 12. Oktober 2009 befragte sie den begutachtenden Arzt des Universitätsspitals Genf sowie zwei der Pfleger, mit denen der Beschwerdeführer am 2. Mai 2005 in Kontakt gekommen war. Alle drei sagten aus, dass Dembele bei seiner Kontrolle am 2. Mai 2005 neben der Fraktur des Schlüsselbeins keine weiteren Verletzungen aufgewiesen und sich auch nicht über solche beklagt habe. Der Arzt äußerte außerdem, dass Schlüsselbeinfrakturen oft durch Stürze verursacht würden. Am 2. und am 12. März 2010 folgten weitere Einvernahmen der Ehefrau und eines Freundes von Dembele. Während die Ehefrau zu Protokoll gab, ihr Ehemann habe nach dem Vorfall zahlreiche weitere Verletzungen am Kopf, am Rücken und an einem Bein aufgewiesen, äußerte der Freund, Dembele habe sich nur über den Bruch des Schlüsselbeins beklagt.

\footnotetext{
${ }^{282}$ Zur Tatsachendarstellung von Dembele EGMR, Urteil vom 24. September 2013, Dembele v. Schweiz, § 5 .

${ }^{283}$ Zur Tatsachendarstellung der Polizisten EGMR, Urteil vom 24. September 2013, Dembele v. Schweiz, § 8 .

${ }^{284}$ Vgl. dazu und zum Folgenden EGMR, Urteil vom 24. September 2013, Dembele v. Schweiz, $\S \S 8-29$.

${ }^{285}$ Vgl. Urteil des BGer 6B_110/2008 vom 27. November 2008, namentlich E. 3.
} 
Der Generalstaatsanwalt verfügte daraufhin am 22. November 2010 erneut die Nichtanhandnahme des Strafverfahrens gegen die Polizeibeamten. Auf erneute Beschwerde hin hielt die Anklagekammer fest, das Verhalten von Dembele - namentlich sein Widerstand gegen die Personenkontrolle und der Biss gegenüber einem Polizeibeamten - habe den Einsatz von Gewalt gerechtfertigt. Sein Schlüsselbeinbruch sei aller Wahrscheinlichkeit nach auf einen Sturz im Zusammenhang mit seinem Fluchtversuch zurückzuführen, zumal gemäß dem übereinstimmenden Bericht verschiedener Zeugen keinerlei weitere Verletzungen dokumentiert seien, die auf den Einsatz von Knüppeln hätten zurückgehen können. Auf die beantragte Einholung einer Expertise zum Grund des Bruchs des Schlagstocks des einen Polizisten verzichtete die Anklagekammer, weil auch durch eine solche Expertise nicht geklärt werden könne, wie oft und wie stark der Beschwerdeführer damit geschlagen worden sei. Das Bundesgericht schützte diesen Entscheid mit Urteil vom 14. September 2011. ${ }^{286}$ Es hielt dabei namentlich auch fest, dass trotz des Zeitverlusts durch die Rückweisung der ersten Einstellungsverfügung letztlich die Erhebung sämtlicher relevanten Beweismittel möglich gewesen sei. ${ }^{287}$

Auf Beschwerde von Dembele hin stellte der EGMR sowohl eine prozedurale als auch eine materielle Verletzung von Art. 3 EMRK fest. In prozeduraler Hinsicht war eine Mehrheit von fünf Richterinnen und Richtern der Auffassung, dass die Dauer von einem Jahr und elf Monaten zwischen dem Rückweisungsentscheid des Bundesgerichts und der neuerlichen Einstellungsverfügung zu lange gewesen sei; ${ }^{288}$ außerdem sei zu Unrecht auf die Einholung eines Gutachtes zum Grund des Schlagstockbruchs verzichtet worden. ${ }^{289}$ In einer insofern konsequenten neuerlichen Würdigung sämtlicher Beweismittel kam der EGMR überdies mit sechs Stimmen zu einer Stimme zum Schluss, dass der Einsatz eines Schlagstocks per se nicht verhältnismäßig gewesen sei, weil der Beschwerdeführer unbewaffnet gewesen sei und zunächst nur passiven Widerstand geleistet habe. ${ }^{290}$

Sowohl in prozeduraler als auch in materieller Hinsicht vermag diese Begründung nicht zu überzeugen. Misst man den Sachverhalt des Falls Dembele an den Anforderungen, die der EGMR an die Tatsachenfeststellung im innerstaatlichen Verfahren stellt, präsentiert sich das schweizerische Verfahren im Hinblick auf die Implementierung der EMRK-Vorgaben geradezu als vorbildlich. Wohl musste eine erste Nichtanhandnahmeverfügung zur ergänzenden Feststellung des maßgeblichen Sachverhalts vom Bundesgericht zurückgewiesen werden. Allerdings entspricht eine solche Rückweisung gerade dem rechtsstaatlichen Grundsatz, dass untere Instanzen kontrolliert werden sollen. Es ist fraglich, ob alleine aufgrund der innerstaatlichen Rückweisung einer Angelegenheit durch eine übergeordnete Instanz Zweifel am innerstaatlich festgestellten Sachverhalt angebracht sind. Im Fall Gedrimas v.

\footnotetext{
${ }^{286}$ Vgl. Urteil des BGer 1B_105/2011 vom 14. September 2011.

${ }^{287}$ Vgl. Urteil des BGer 1B_105/2011 vom 14. September 2011, E. 3.2.

${ }^{288}$ Vgl. EGMR, Urteil vom 24. September 2013, Dembele v. Schweiz, § 66.

${ }^{289}$ Vgl. EGMR, Urteil vom 24. September 2013, Dembele v. Schweiz, § 67.

${ }^{290}$ Vgl. EGMR, Urteil vom 24. September 2013, Dembele v. Schweiz, § 47.
} 
Litauen hat der EGMR denn auch festgehalten, dass nur wiederholte Rückweisungsentscheidungen (,repetition of such decisions“) den Schluss auf eine mangelhafte Untersuchung zuließen. ${ }^{291}$

Besondere Erwähnung verdient im Zusammenhang des Dembele-Verfahrens auch, dass sich das Bundesgericht in seiner Rückweisungsentscheidung ausdrücklich auf Art. 3 EMRK stützte. ${ }^{292}$ In der Folge wurden im Zeitrahmen von 15 Monaten - ein Zeitrahmen, der entgegen dem Passivitätsvorwurf der Gerichtsmehrheit des EGMR ${ }^{293}$ durchaus als angemessen bezeichnet werden kann - zahlreiche zusätzliche Beweise erhoben. Neben der Anhörung unabhängiger Zeugen - dem behandelnden Arzt und den Pflegern des Universitätsspitals Genf - wurden sogar die Ehefrau und ein Freund des Beschwerdeführers befragt, welche die Geschehnisse beide nicht als Augenzeugen miterlebt hatten. Wie die abweichende Schweizer Richterin deshalb völlig zu Recht festhielt, waren damit alle vernünftigerweise zu erwartenden Beweise erhoben worden. ${ }^{294}$ Soweit in antizipierter Beweiswürdigung auf die Einholung eines unabhängigen Berichts zum Grund des Schlagstockbruchs verzichtet wurde, begründeten die innerstaatlichen Instanzen im Einklang mit der allgemeinen Rechtsprechung des EGMR ${ }^{295}$ absolut plausibel, warum hierdurch im Hinblick auf den Prozessgegenstand keine neuen Schlüsse zu erwarten seien.

Bei dieser Ausgangslage wäre m. E. eine prozedurale Verletzung von Art. 3 EMRK klar zu verneinen gewesen. Schon insoweit hätte also kein Anlass bestanden, von den wohlbegründeten Tatsachenfeststellungen der innerstaatlichen Instanzen im Hinblick auf die Verhältnismäßigkeit der von den beiden Polizeibeamten angewendeten Gewalt abzuweichen. ${ }^{296}$ Ein Anlass für eine solche Abweichung wäre $m$. E. freilich selbst dann zu verneinen gewesen, wenn man das Vorliegen einer prozeduralen Verletzung - wie der EGMR - bejahen wollte: Die Beweiswürdigung der innerstaatlichen Instanzen war überzeugend, und es gibt keinerlei Anhaltspunkte dafür, dass die vom EGMR nun vorgenommenen Feststellungen zutreffender wären als jene der nationalen Gerichte. Insofern lässt sich anhand dieses Falls paradigmatisch aufzeigen, dass selbst bei Vorliegen einer prozeduralen Verletzung nicht immer auf eine freie Tatsachenkognition des EGMR geschlossen werden darf. Namentlich wenn die prozedurale Verletzung wie hier maßgeblich auf der übermäBigen Dauer des nationalen Verfahrens beruht, ist damit noch nichts über die Qualität der Tatsachenfeststellungen der nationalen Instanzen ausgesagt.

\footnotetext{
${ }^{291}$ Vgl. EGMR, Urteil vom 12. Juli 2016, Gedrimas v. Litauen, § 83.

${ }^{292}$ Vgl. auch EGMR, Urteil vom 24. September 2013, Dembele v. Schweiz, Dissenting Opinion Keller, $\S 18:,[\ldots]$ A mon avis, c'est une forme de réception parfaite de la Convention par la jurisprudence nationale qui est tout à fait dans l'esprit de la subsidiarité au sens large telle qu'inscrite dans la Déclaration de Brighton. [...].“

${ }^{293}$ Vgl. EGMR, Urteil vom 24. September 2013, Dembele v. Schweiz, § 66.

${ }^{294}$ Vgl. EGMR, Urteil vom 24. September 2013, Dembele v. Schweiz, Dissenting Opinion Keller, $\S 23$ (unterstützt auch von Richter Sajó, vgl. dessen summarische Partly Dissenting Opinion).

${ }^{295} \mathrm{Vgl}$. dazu oben, IV. B. 2. a. ba.

${ }^{296}$ So im Ergebnis auch EGMR, Urteil vom 24. September 2013, Dembele v. Schweiz, Dissenting Opinion Keller, § 12.
} 


\section{c. Beweislastumkehr in Grauzonenfällen. Der Fall Sadkov v. Ukraine}

Im Fall Sadkov v. Ukraine hatte der EGMR die Misshandlungsvorwürfe eines ukrainischen Staatsangehörigen zu beurteilen. ${ }^{297}$ Am Abend des 11. Juni 2004 war der ehemalige Polizeibeamte in einem nach Moldawien fahrenden Zug festgenommen worden, weil er verdächtigt worden war, an verschiedenen Raubüberfällen und einem Tötungsdelikt beteiligt gewesen zu sein. In den folgenden Verhören hatten die Ermittler nach Darstellung des Beschwerdeführers massive Gewalt gegen ihn angewandt, um ein Geständnis zu erpressen. Schon am 12. Juni 2004 zeigte er die angebliche Folter bei der zuständigen Staatsanwaltschaft an. Ein am selben Tag konsultierter Mediziner stellte verschiedene Hämatome im Gesicht und am Körper des Beschwerdeführers fest. Der Experte kam außerdem zum Schluss, dass seine „geringfügigen Verletzungen“ durch Schläge und Tritte verursacht worden sein könnten. Am 29. Juni 2004 zog der Beschwerdeführer seine Vorwürfe jedoch schriftlich zurück und gab zu Protokoll, seine Verletzungen in anderem Zusammenhang und jedenfalls nicht im Rahmen der Verhöre erlitten zu haben. Nachdem der zuständige Ermittler ihn am 30. Juni 2004 in Anwesenheit seines Anwalts befragt hatte, wurden die Ermittlungen gegen die Polizisten eingestellt. Ein Bericht des regionalen Polizeidepartements vom 17. August 2004 kam zum Schluss, dass die Polizeibeamten im Rahmen der Verhaftung des Beschwerdeführers rechtmäßigen Gebrauch von Nahkampftechniken gemacht und zudem Handschellen benutzt hätten. Später erneuerte der Beschwerdeführer seine Misshandlungsvorwürfe zwar wiederholt; sämtliche dadurch angestoßenen Verfahren wurden jedoch vorzeitig eingestellt. Bei der Einsicht seines Dossiers versuchte der Beschwerdeführer am 29. September 2005 erfolglos, die Aufzeichnung seiner Aussagen vom 29. Juni 2004 zu zerstören. Im Strafverfahren gegen den Beschwerdeführer war im Hinblick auf die Verwertbarkeit seines Geständnisses erneut die Frage zu prüfen, ob er nach seiner Verhaftung misshandelt worden sei. Das Gericht verwies diesbezüglich maßgeblich auf eine Einstellungsverfügung der zuständigen Staatsanwaltschaft vom 11. Februar 2006, wonach aufgrund der Aussagen der verschiedenen beteiligten Polizeibeamten und des Rückzugs der Misshandlungsvorwürfe Ende Juni 2004 nicht von einem strafrechtlich relevanten Verhalten der Polizisten auszugehen sei.

In seinen Eintretenserwägungen kam der EGMR zum Schluss, dass weite Teile der Misshandlungsvorwürfe des Beschwerdeführers sich nicht auf Beweise stützen könnten und deshalb als offensichtlich unbegründet zurückzuweisen seien. ${ }^{298}$ Dies gelte insbesondere für die Vorwürfe, auch nach dem 12. Juni 2004 noch misshandelt worden zu sein. Materiell zu prüfen sei lediglich, ob er im Rahmen seiner Verhaftung vom 11. Juni 2004 oder in den darauffolgenden Verhören eine unmenschliche Behandlung erlitten habe. Auch diesbezüglich stellte der EGMR jedoch fest, dass keine Indizien dafür bestünden, dass sich die Ereignisse so zugetragen hätten wie vom Beschwerdeführer behauptet.

\footnotetext{
${ }^{297}$ Vgl. zum Sachverhalt EGMR, Urteil vom 6. Juli 2017, Sadkov v. Ukraine, §§ 6-65. ${ }^{298} \mathrm{Vgl}$. dazu und zum Folgenden EGMR, Urteil vom 6. Juli 2017, Sadkov v. Ukraine, §§ 81-84.
} 
In seinen materiellen Erwägungen stellte der EGMR bezüglich der Untersuchung der Vorfälle vom 11. und 12. Juni 2004 zunächst eine prozedurale Verletzung von Art. 3 EMRK fest. ${ }^{299}$ Die Einstellungsverfügung vom 11. Februar 2006 sei ebenso wie der Bericht vom 17. August 2004 mangelhaft begründet gewesen. Namentlich sei unzureichend ausgeführt worden, wie der Beschwerdeführer im Rahmen seiner Verhaftung konkret immobilisiert worden sei, und ob die eingesetzte Gewalt als rechtmäßig qualifiziert werden könne. Zudem gehe aus den Dokumenten nicht klar hervor, welches Gewicht den Aussagen des Beschwerdeführers vom 29. und 30. Juni 2004 zugemessen worden sei. Diese Versäumnisse seien auch im Strafverfahren gegen den Beschwerdeführer nicht kompensiert worden.

Diese Begründung der prozeduralen Verletzung lässt es nicht als zwangsläufig erscheinen, dass der EGMR zu einer de-novo-Prüfung des maßgeblichen Sachverhalts überging, fokussierte sie doch stark auf eine ungenügende Begründung und weniger auf ein allfälliges Versäumnis, maßgebliche Beweismittel zu erheben oder diese willkürlich gewürdigt zu haben. ${ }^{300}$ Die Frage soll hier jedoch nicht erneut vertieft werden. Aufzugreifen ist am Beispiel des vorliegenden Falls vielmehr ein Problem, das sich aus der uniformen Anwendung der oben beschriebene Beweislastumkehr $^{301}$ auf fast alle Misshandlungsfälle ergibt, die nicht als ,manifestement infonde`“ zurückgewiesen werden. Aufgrund der Verletzungen des Beschwerdeführers, die aufgrund des Arztberichts vom 12. Juni 2004 tatsächlich ,au-delà de tout doute raisonnable" bewiesen waren, war nur logisch, dass der EGMR auch hier die Beweislastumkehr anwandte. ${ }^{302}$ In seinen Erwägungen zum Vorliegen einer materiellen Verletzung von Art. 3 EMRK hielt der EGMR zwar fest, dass er den Tatsachendarstellungen des Beschwerdeführers keinen Glauben schenke. Allerdings sei von der Regierung nicht ausreichend dargelegt worden, dass der Gewalteinsatz gegen den Beschwerdeführer auf einer gesetzlichen Grundlage beruht habe und verhältnismäßig gewesen sei. Die ukrainische Regierung war also der Verpflichtung, ihrerseits ,au-delà de tout doute raisonnable“ darzulegen, dass keine Misshandlung vorgelegen habe, nicht nachgekommen. Der EGMR kam deshalb zum Schluss, dass der Beschwerdeführer unmenschlich behandelt worden sei und eine Verletzung von Art. 3 EMRK vorliege.

Selbst die Gerichtsmehrheit gab mit ihrem Hinweis auf die Zweifel an den Darstellungen des Beschwerdeführers jedoch zu verstehen, dass dessen Beschwerde bezüglich Art. 3 EMRK nur knapp die Eintretensschwelle genommen hatte und verurteilte die Ukraine letztlich für einen Sachverhalt, den selbst der Beschwerdeführer nicht behauptet hatte. ${ }^{303}$ Eine Minderheit des Spruchkörpers störte sich insbesondere am letzteren Umstand und deklarierte daher alle Misshandlungsvorwürfe als

\footnotetext{
${ }^{299}$ Vgl. dazu und zum Folgenden EGMR, Urteil vom 6. Juli 2017, Sadkov v. Ukraine, §§ 91-99.

${ }^{300} \mathrm{Vgl}$. zur Frage, ob jede prozedurale Verletzung Anlass gibt, eine de-novo-Prüfung des maßgeblichen Sachverhalts durchzuführen, soeben, IV. D. 1. b.

${ }^{301}$ Vgl. oben, IV. C. 2. b.

${ }^{302} \mathrm{Vgl}$. dazu und zum Folgenden EGMR, Urteil vom 6. Juli 2017, Sadkov v. Ukraine, §§ 91-99.

${ }^{303}$ Vgl. EGMR, Urteil vom 6. Juli 2017, Sadkov v. Ukraine, § 101.
} 
offensichtlich unbegründet, womit weder in prozeduraler noch in materieller Hinsicht Raum für die Feststellung einer Verletzung von Art. 3 EMRK bestanden hätte. ${ }^{304}$ Tatsächlich zeigt der Fall Sadkov v. Ukraine paradigmatisch auf, dass Urteile des EGMR zu Misshandlungsvorwürfen in Polizeigewahrsam fast nur „,schwarz“ oder „weiß“ ausfallen können: Entweder wird ein Fall mangels Beweisen als offensichtlich unbegründet zurückgewiesen oder auf den Fall wird eingetreten und aufgrund der oftmals angewandten Beweislastumkehr dann in den allermeisten Fällen auch eine materielle Verletzung von Art. 3 EMRK bejaht.

Dies macht deutlich, dass Grauzonenfälle mit dem bestehenden beweisrechtlichen Instrumentarium nur schwierig zu erfassen sind. Womöglich läge eine Lösung des Problems darin, die Beweislastumkehr vorsichtiger anzuwenden, wenn zwar nachgewiesen ist, dass eine Beschwerdeführerin in Polizeigewahrsam Verletzungen erlitten hat, ihre Schilderung des Vorfalls jedoch vernünftigerweise nicht den tatsächlichen Begebenheiten entsprechen kann. Damit wäre ausgeschlossen, dass der EGMR einen Mitgliedstaat für einen Sachverhalt verurteilt, der selbst von einer Beschwerdeführerin nicht vorgebracht worden ist. ${ }^{305}$

\section{Stimmiges Gesamtbild}

In der schweizerischen Doktrin ist kritisiert worden, dass der EGMR den Sachverhalt in Einzelfällen anders würdigt als die nationalen Gerichte; die Kritik basierte dabei oftmals auf einer Analyse schweizerischer Fälle und hatte teilweise sicher auch ihre Berechtigung. ${ }^{306}$ Gleichzeitig ist jedoch eine Erweiterung der Perspektive notwendig. Nach Art. 19 EMRK überwacht der EGMR die effektive Durchsetzung der Konventionsgarantien im Einflussbereich aller 47 Europaratsstaaten. Dabei muss er einheitliche Standards anwenden und kann auf besondere „Sensibilitäten“ nur sehr beschränkt Rücksicht nehmen; insofern nimmt er eine umfassendere Perspektive ein als die nationalen Beobachterinnen seiner Rechtsprechung. Eine ausgewogene Würdigung der Praxis des EGMR setzt deshalb voraus, dass die entwickelten Standards in einer Gesamtsicht auf ihre Praxistauglichkeit und konsistente Anwendung überprüft werden. ${ }^{307}$

Zwar mag zutreffen, dass prozedurale Verletzungen von Art. 3 und Art. 13 EMRK in schweizerischen Verfahren die Ausnahme bilden. ${ }^{308}$ Insoweit ist aus schweizerischer Perspektive auch nachvollziehbar, dass vom EGMR in Sachverhaltsfragen

\footnotetext{
${ }^{304}$ Vgl. EGMR, Urteil vom 6. Juli 2017, Sadkov v. Ukraine, Joint Partly Dissenting Opinion Nussberger, Møse und O'Leary.

${ }^{305}$ Vgl. die diesbezügliche Kritik in EGMR, Urteil vom 6. Juli 2017, Sadkov v. Ukraine, Joint Partly Dissenting Opinion Nussberger, Møse und O’Leary.

${ }^{306}$ Vgl. beispielsweise Schürer, S. 512 ff.; Seiler, S. 257 ff.

${ }^{307}$ Vgl. zur Auswahl der hier untersuchten Fälle oben, I. D.

${ }^{308}$ Im Zeitraum zwischen dem 1. November 2014 und dem 31. Oktober 2017 kam es zu keiner einzigen Verurteilung wegen einer prozeduralen Verletzung von Art. 3 EMRK.
} 
Zurückhaltung eingefordert wird. ${ }^{309}$ Gesamteuropäisch zeigt sich jedoch ein anderes Bild: Die zahlreichen durch den EGMR festgestellten prozeduralen Verletzungen von Art. 3 EMRK beziehungsweise Art. 13 EMRK dokumentieren, dass nicht überall der (politische) Wille und die (juristische) Expertise vorhanden sind, um Vorwürfe von Menschenrechtsverletzungen angemessen zu untersuchen. Notgedrungen führt dies in den Verfahren vor dem EGMR in vielen Fällen zu einer ausgedehnten Kontrolle der innerstaatlich bereits festgestellten Tatsachen und teilweise auch zu abweichenden Sachverhaltsannahmen des EGMR. Umgekehrt hat der EGMR seine Kontrolle der innerstaatlichen Tatsachenfeststellung aber auch verschiedentlich auf ein Minimum beschränkt, wenn das innerstaatliche Verfahren den Anforderungen von Art. 3 und Art. 13 EMRK genügt hatte. Der nicht immer ausdrücklich benannte, inhaltlich aber mittlerweile konsolidierte Willkürmaßstab führt in solchen Fällen in der Regel dazu, dass auf die Einschätzung der nationalen Gerichte abgestellt und eine materielle Verletzung von Art. 3 EMRK verneint wird. Die Praxis des EGMR konvergiert mit dem Subsidiaritätsgrundsatz, der abhängig von der Qualität des innerstaatlichen Verfahrens genauso für eine Zurückhaltung des EGMR sprechen kann, wie für eine Intervention.

So oder anders haben die vorliegenden Betrachtungen aber erneut die bedeutenden materiell-rechtlichen Implikationen des Beweisrechts des EGMR deutlich gemacht. ${ }^{310}$ Nachdem Tatsachenfragen in der Vergangenheit offenbar von untergeordneter Bedeutung waren, sieht sich der EGMR immer häufiger mit divergierenden Tatsachenschilderungen konfrontiert. Insofern bedarf das bisher wenig ausdifferenzierte Beweisrecht des EGMR auch im Interesse der Rechtssicherheit einer Konsolidierung. Oberstes Leitmotiv muss dabei die Suche nach der materiellen Wahrheit sein. Zu berücksichtigen ist aber auch, dass der EGMR die effektive Durchsetzung von Menschenrechten gewährleisten soll und sich in seinem Verfahren in der Regel zwei ungleiche Parteien gegenüberstehen; im Hinblick auf das Beweismaß und die objektive Beweislast kann sich für das Verfahren vor dem EGMR daher eine andere Ausgestaltung des Beweisrechts aufdrängen als in nationalen Straf-, Zivil- und Verwaltungsrechtsprozessordnungen. ${ }^{311}$

Die neuere Rechtsprechung des EGMR lässt klare Anzeichen einer solchen Ausdifferenzierung erkennen. Ein Beispiel dafür ist die in der neueren Rechtsprechung entwickelte Variabilität der Prüfungsdichte in Sachverhaltsfragen. Wie im vorliegenden Kapitel ausführlich aufgezeigt worden ist, oszilliert die Prüfungsdichte des EGMR diesbezüglich abhängig von der Qualität des innerstaatlichen Verfahrens zwischen einer reinen Willkürprüfung und einer umfassenden de-novo-Prüfung der innerstaatlich bereits festgestellten Tatsachen. Die Variabilität des Prüfungsmaßstabs ist vom EGMR in seinen Urteilen nicht immer ausdrücklich benannt worden. Inhaltlich liegt sie aber vielen Urteilen zugrunde. ${ }^{312}$ Ein weiteres Beispiel für die

\footnotetext{
${ }^{309}$ Pfiffner/Bollinger; Schürer, S. 519 f.

${ }^{310} \mathrm{Vgl}$. dazu schon oben, II. B.

${ }^{311}$ Vgl. auch EGMR (Große Kammer), Urteil vom 13. Dezember 2012, El-Masri v. Mazedonien, § 151.

${ }^{312}$ Für die Zukunft drängt sich in diesem Sinne allenfalls auf, den prozeduralen Gehalt von Art. 3 EMRK konsequent vor dem materiellen Gehalt von Art. 3 EMRK zu prüfen.
} 
Konsolidierung des Beweisrechts des EGMR bildet die Ausdifferenzierung der Beweislastumkehr in Fällen behaupteter Misshandlungen in Polizeigewahrsam. In mehreren Urteilen aus jüngerer Zeit hat der EGMR die Anwendbarkeit dieser Beweislastumkehr verneint, weil nicht ,,au-delà de tout doute raisonnable“ nachgewiesen war, dass bestimmte Verletzungen in jenem Zeitraum entstanden waren, in dem sich die Beschwerdeführenden in Polizeigewahrsam befunden hatten. ${ }^{313}$ Im Fall Hentschel und Stark v. Deutschland hat der EGMR die Beweislastumkehr nicht zugelassen, weil die Polizeikräfte trotz der Absperrung eines Fansektors in einem Fußballstadion keine ausschließliche Kontrolle über die Fans ausübten und insoweit die tragende Begründung der Beweislastumkehr - der ausschließliche Zugriff der Behörden auf eine Situation und das damit verbundene Informationsmonopol - keine Anwendung fand. ${ }^{314}$

Es ist zu erwarten, dass sich das Beweisrecht des EGMR mit der weiter wachsenden Bedeutung der Tatsachenfeststellung in seinen Verfahren weiter ausdifferenzieren wird. Diese Konsolidierung wird wesentlich dazu beitragen, dass die beweisrechtliche Herangehensweise des EGMR - auch und gerade im Verhältnis zur hier thematisierten Tatsachenfeststellung der nationalen Gerichte - zusätzlich an Vorhersehbarkeit gewinnt. Gleichzeitig wird der EGMR aber zu Recht darauf bedacht sein, sich bei der Etablierung von Standards genug Freiraum zu belassen, um den spezifischen Anforderungen des Einzelfalls gerecht zu werden. Die Balance zwischen Rechtssicherheit und Freiräumen zur adaptierten Handhabung spezifischer Einzelfälle gilt es dabei auch zu wahren, wenn im Verfahren vor dem EGMR neue Tatsachenvorbringen und Beweise eingebracht werden. Diese bis anhin ausgeklammerte Frage bildet Gegenstand des nächsten Kapitels.

\footnotetext{
${ }^{313}$ Vgl. EGMR, Urteil vom 10. Oktober 2017, Tarjani v. Ungarn, § 51; EGMR, Urteil vom 13. Juni 2017, Daşlik v. Türkei, §§ 45-50; EGMR, Urteil vom 4. April 2017, Thuo v. Zypern, § 148; EGMR, Urteil vom 28. Februar 2017, Müftüoğlu und andere v. Türkei, § 63.

${ }^{314}$ Vgl. EGMR, Urteil vom 9. November 2017, Hentschel und Stark v. Deutschland, § 72.
}

\begin{abstract}
Open Access Dieses Kapitel wird unter der Creative Commons Namensnennung 4.0 International Lizenz (http://creativecommons.org/licenses/by/4.0/deed.de) veröffentlicht, welche die Nutzung, Vervielfältigung, Bearbeitung, Verbreitung und Wiedergabe in jeglichem Medium und Format erlaubt, sofern Sie den/die ursprünglichen Autor(en) und die Quelle ordnungsgemäß nennen, einen Link zur Creative Commons Lizenz beifügen und angeben, ob Änderungen vorgenommen wurden.

Die in diesem Kapitel enthaltenen Bilder und sonstiges Drittmaterial unterliegen ebenfalls der genannten Creative Commons Lizenz, sofern sich aus der Abbildungslegende nichts anderes ergibt. Sofern das betreffende Material nicht unter der genannten Creative Commons Lizenz steht und die betreffende Handlung nicht nach gesetzlichen Vorschriften erlaubt ist, ist für die oben aufgeführten Weiterverwendungen des Materials die Einwilligung des jeweiligen Rechteinhabers einzuholen.
\end{abstract}

